OAK RIDGE

ORNL/TM-2002/33

NATIONAL LABORATORY

MANAGED BY UT-BAII-ELLE

FOR THE DEPARTMENT OF ENERGY

\title{
Correlation of Process Data and Electrochemical Noise to Assess Kraft Digester Corrosion: Kamloops Experiment
}

\section{April 2002}

\author{
S. J. Pawel \\ D. W. Townley \\ M. E. Gorog \\ D. F. Wilson
}




\section{DOCUMENT AVAILABILITY}

Reports produced after January 1,1996, are generally available free via the U.S. Department of Energy (DOE) Information Bridge.

\section{Web site http://www.osti.gov/bridge}

Reports produced before January 1, 1996, may be purchased by members of the public from the following source:

National Technical Information Service

5285 Port Royal Road

Springfield, VA 22161

Telephone 703-605-6000 (I-800-553-6847)

TDD 703-487-4639

Fax 703.605.6900

E-mail info@ntis.fedworld.gov

Web site http://www.ntis.gov/support/ordernowabout.htm

Reports are available to DOE employees, DOE contractors, Energy Technology Data Exchange (ETDE) representatives, and International Nuclear Information System (INIS) representatives from the following source:

Office of Scientific and Technical Information

P.O. Box 62

Oak Ridge, TN 37831

Telephone 865-576-8401

Fax 865-576-5728

E-mail reports@adonis.osti.gov

Web site http://www.osti.gov/contact.html

This report was prepared as an account of work sponsored by an agency of the United States Government. Neither the United States Government nor any agency thereof, nor any of their employees, makes any warranty, express or implied, or assumes any legal liability or responsibility for the accuracy, completeness, or usefulness of any information, apparatus, product, or process disclosed, or represents that its use would not infringe privately owned rights. Reference herein to any specific commercial product, process, or service by trade name, trademark, manufacturer, or otherwise, does not necessarily constitute or imply its endorsement, recommendation, or favoring by the United States Government or any agency thereof. The views and opinions of authors expressed herein do not necessarily state or reflect those of the United States Government or any agency thereof. 
ORNL/TM-2002/33

Metals and Ceramics Division

Correlation of Process Data and Electrochemical Noise to Assess Kraft Digester Corrosion: Kamloops Experiment

\author{
S. J. Pawe1* \\ D. W. Townley† \\ M. E. Gorog $\ddagger$ \\ D. F. Wilson* \\ *Metals and Ceramics Division, ORNL, Oak Ridge, TN \\ $\dagger$ M. J. Schiff and Associates, Upland, CA \\ $\ddagger$ Weyerhaeuser Technical Center, Federal Way, WA
}

Date Published: April 2002

Prepared for

U. S. Department of Energy

Office of Industrial Technologies

\author{
Prepared by the \\ OAK RIDGE NATIONAL LABORATORY \\ Oak Ridge, Tennessee 3783 1-6285 \\ Operated by \\ U T - B a t t e 11 e, L L C \\ for the \\ U. S. DEPARTMENT OF ENERGY \\ Under contract DE-AC05-00OR22725
}




\section{.}

, 


\section{CONTENTS}

\section{Page}

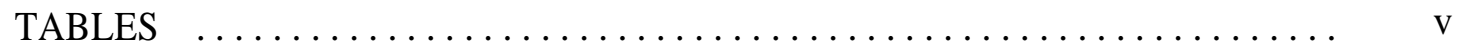

FIGURES $\ldots \ldots \ldots \ldots \ldots \ldots \ldots \ldots \ldots \ldots \ldots \ldots \ldots \ldots \ldots \ldots \ldots \ldots \ldots \ldots$

ACRONYMS AND SYMBOLS $\quad \ldots \ldots \ldots \ldots \ldots \ldots \ldots \ldots \ldots \ldots \ldots \ldots \ldots \ldots \ldots \ldots \ldots$

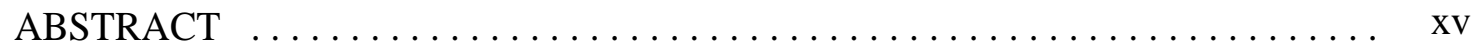

1. O INTRODUCTION $\ldots \ldots \ldots \ldots \ldots \ldots \ldots \ldots \ldots \ldots \ldots \ldots \ldots \ldots \ldots \ldots \ldots$

2.0 KAMLOOPS DIGESTER $\ldots \ldots \ldots \ldots \ldots \ldots \ldots \ldots \ldots \ldots \ldots \ldots \ldots \ldots$

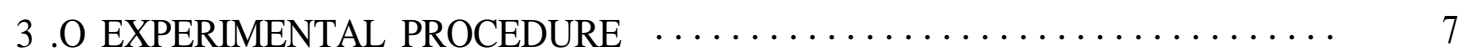

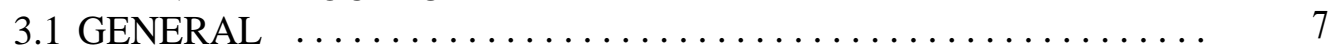

3.2 PROBE DESIGN $\ldots \ldots \ldots \ldots \ldots \ldots \ldots \ldots \ldots \ldots \ldots \ldots \ldots \ldots \ldots \ldots \ldots \ldots \ldots$

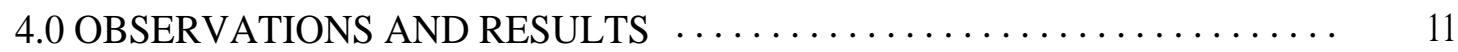

4.1 INITIAL VESSEL INSPECTION $\ldots \ldots \ldots \ldots \ldots \ldots \ldots \ldots \ldots \ldots \ldots . \ldots \ldots \ldots$

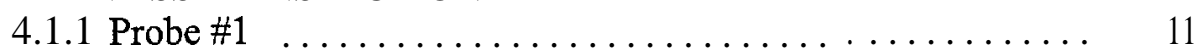

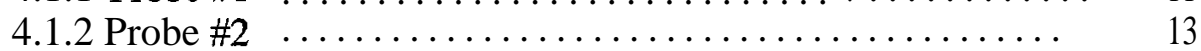

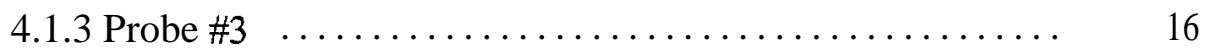

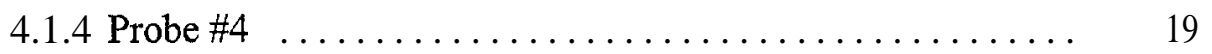

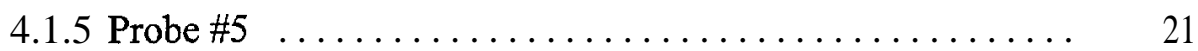

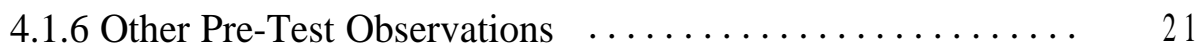

4.1.7 Comments on Localized Corrosion Pattern .......... 27

4.2 HISTORICAL INSPECTION DATA AVAILABLE FROM KAMLOOPS 29

4.2.1 Photographic Documentation .................. 29

4.2.2 Ultrasonic Wall Thickness Data ............... 34

4.2.3 Electrochemical Potential .................. 34

4.3 REPRESENTATIVE ECN AND OPERATIONAL DATA $\ldots \ldots \ldots \ldots \quad 35$

4.3.1 Data Analysis and Interpretation $\ldots \ldots \ldots \ldots \ldots \ldots . .35$

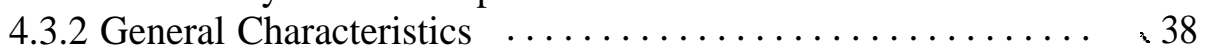

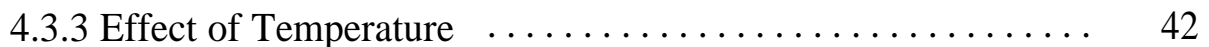

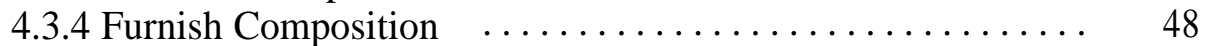

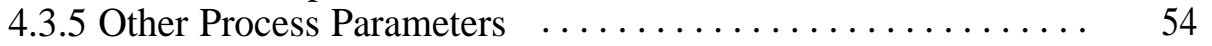

4.3.6 Shutdown and Start-up Transients $\ldots \ldots \ldots \ldots \ldots \ldots \ldots .56$

4.3.7 Assessment of ECN Calculated Parameters .......... 58

4.4 FINAL VESSEL INSPECTION $\ldots \ldots \ldots \ldots \ldots \ldots \ldots \ldots \ldots \ldots \ldots . \ldots \ldots$

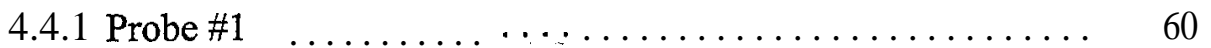

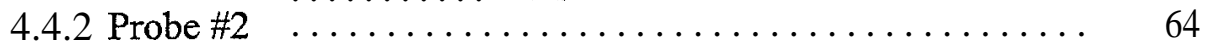

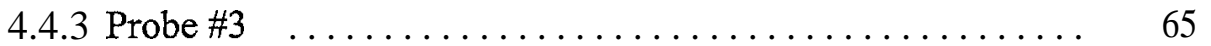

4.4 .4 Probe $\# 4$............................... 68

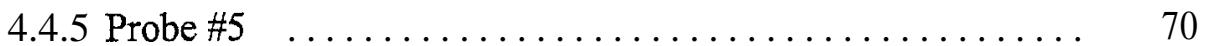

4.4.6 Summary of Follow-up Inspection $\ldots \ldots \ldots \ldots \ldots \ldots \ldots$

4.4.7 Examination of Electrodes from Each Probe $\ldots \ldots \ldots \ldots .72$ 


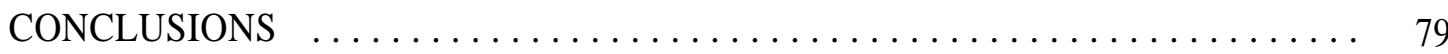

ACKNOWLEDGEMENTS . . ................................ 81

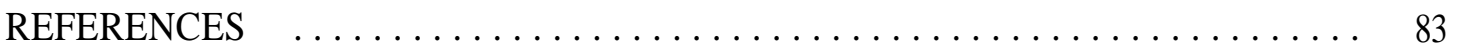

APPENDIX A - Corrosion Rate Calculation form Current Sums . . . . . . . . . 85

APPENDIX B - Process Data Collected at Kamloops . . . . . . . . . . . . . . 87 


\section{$\begin{array}{llllll}\mathbf{T} & \mathbf{A} & \mathbf{B} & \mathbf{L} & \mathbf{E} & \mathbf{S}\end{array}$}

Table

Page

1 Snapshot of potential data from the Karnloops digester during

February 2000. All potentials are given with respect to a

molybdenum $(\mathrm{Mo} / \mathrm{MoS})$ electrode $\ldots \ldots \ldots \ldots \ldots \ldots \ldots \ldots \ldots$

2 Comparison of ECN potential values for the ECN probes. All

potentials are given relative to $\mathrm{Ag} / \mathrm{Ag}_{2} \mathrm{~S}$. Potentials achieved

during shut-down and restart transients are not included here

3 Temperature statistics for the time interval depicted in Fig. $34 \ldots \ldots \ldots$.

4 Temperature statistics for the time interval depicted in Fig. $35 \quad \ldots \ldots \ldots \ldots 45$

5 Temperature statistics for the time interval depicted in Fig. $36 \quad \ldots \ldots \ldots .46$

6 Summary data representing the relative change in the ECN corrosion current associated with high concentrations of Douglas fir in the furnish. Over the experiment, there were six periods with furnish composition $>70 \%$ Douglas fir, and the current ratio given in Equation (1) was calculated for each probe in each period. Note the pulping period in which the highest (or lowest) current ratio occurs is not necessarily the same for each probe $\ldots \ldots \ldots \ldots \ldots$

7 Summary data representing the relative change in the ECN corrosion current associated with pulping whitewood (near 0\% Douglas fir). Over the experiment, there were three whitewood pulping periods, and the current ratio given in Equation (2) was calculated for each probe in each period. The pulping period in which the highest (or lowest) current ratio occurs is not necessarily the same for each probe .....

8 Summary data representing the relative change in the ECN corrosion current associated with shutdown transients. Over the experiment, there were three shutdowns, and the current ratio given in Equation (3) was calculated for each probe in each period $\ldots \ldots \ldots \ldots \ldots \ldots$

9 Post-testdimensions on electrodes from each probe. Dimensions are given in non-standard units (mils, rather than $\mathrm{mm}$ ) because the measurements were collected in this fashion, which facilitates ready comparison and mitigates round-off errors. [To convert to $\mathrm{mm}$, multiply the numbers in the table by 0.025.] Designation "top" means the exposed end of the electrode 
10 Average corrosion rates calculated for the digester shell compared with corrosion rate information available from the ECN probes.

Corrosion rates are given in the non-standard units of mils/y (rather than $\mathrm{mm} / \mathrm{y}$ ) because mill personnel routinely use the mils/y

designation. To convert to $\mathrm{mm} / \mathrm{y}$, multiply the numbers in the table

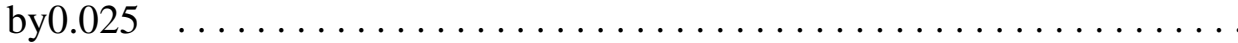




\section{FIGURES}

$\begin{array}{lll}\text { Figure } & \text { Page }\end{array}$

1 Schematic diagram of the Kamloops digester $\ldots \ldots \ldots \ldots \ldots \ldots \ldots$

2 ECN probe configuration used for the Kamloops experiment. The piece of silver functions as the reference electrode and the thermocouple is sheathed in. a closed tube of alloy 600 . For scale, note that the teflon shroud (white) has a diameter of $3.6 \mathrm{~cm}$ and each electrode has a diameter of $0.9 \mathrm{~cm} \quad \ldots \ldots \ldots \ldots . \ldots . \ldots$

3 Sketch of probe assembly. The drawing is not to scale, and is intended to show only the spatial relationship between various components. For clarity, the second layer of heat shrink was

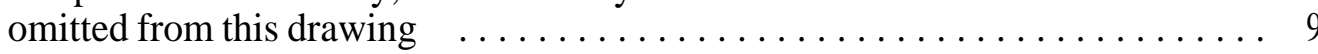

4 General view of the digester shell in the area of Probe \#1. At the time of this photograph, the probe port was occupied by a potential monitor. Only small amounts of residual carbonate scale (relatively light colored areas) remain on the shell, and some residual black liquor is draining from the annular area of the port. The white "scale indicator" just below the port is $3.5 \mathrm{~cm}$ long. A piece of scaffold rigging appears in the foreground $\ldots \ldots \ldots \ldots \ldots \ldots \ldots$,

$5 \quad$ Closer view of the shell surface surrounding the port for Probe \#1. The boss area encircling the port is very slightly raised above the shell contour and is stainless steel overlay. Note that the shell in this location is smooth - no pitting or surface roughening. Small areas of light brown carbonate scale remain on the shell,

6 General view of the digester shell surrounding the port for Probe \#2.

At the time of this photograph, the port was occupied by a potential monitor and residual black liquor was draining from the port annulus. Most of the area is covered by a thin, tan-colored carbonate scale. At right, a scaffolding support and a partially obscured trim screen are visible. For scale, the port diameter is about $3.5 \mathrm{~cm} \ldots \ldots \ldots \ldots \ldots$

$7 \quad$ Closer view of the shell surface surrounding the port for Probe $\# 2$. In general, some minor surface relief and scattered light pitting are evident on the shell surfaces in this area, but the largest pits - approximately $0.5 \mathrm{~mm}$ (20 mils) deep - are immediately adjacent to the stainless steel port boss. Many of the pits exhibit red-orange flash rusting 
8 General view of the trim screen and a portion of RS 18 located near the port for Probe \#2. Pitting in this area (red-orange flash rust coloration) is concentrated adjacent to the trim screen boss and in/on the weld seam. The white "scale indicator" is $3.5 \mathrm{~cm}$ long. The bright orange paint marks locations for additional inspection

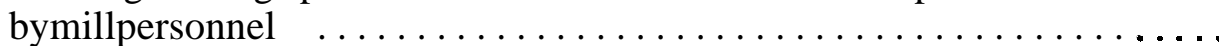

9 Closer view of corrosion adjacent to the trim screen boss. Pits in this location, and in/on the nearby round seam weld, tend to be larger in diameter and deeper - up to 1.6-1.7 mm (60-70 mils) deep - than pits closer to the port for Probe \#2

10 General view of the digester shell surrounding the port for Probe \#3. All the pits in this area are approximately the same depth, but the pit density associated with the weld (RS 12) and the area immediately adjacent to the port is much greater. . . . . . . . . . . . . . . . . .

11 Closer view of the shell surface surrounding the port for Probe \#3. The pits in this area - on the shell, adjacent to the boss, and those in/near the round seam weld are approximately 1.6-1.7 mm (60-70

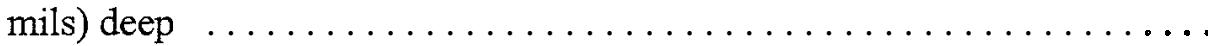

12 General view of digester shell between extraction screens and modified cooking screens. The white "scale indicator" is $3.5 \mathrm{~mm}$ long and rests on a smooth, unattacked surface while much of the surrounding area is significantly pitted $\ldots \ldots \ldots \ldots \ldots \ldots \ldots$

13 Magnified view of the area depicted in Fig. 12. The pits in this region tend to overlap to form sizeable areas exhibiting a wall thickness decrease of $1.6-1.7 \mathrm{~mm}$ (60-70 mils) compared to the smooth surfaces nearby

14 General view of the digester shell in the vicinity of the port for Probe \#4. The internal header box ("shelf") associated with the modified cooking screens is just visible at the top of the photograph. The shell surfaces exhibit very little pitting in the immediate vicinityofthisport

15 Closer view of the area imrnediately surrounding the port for Probe \#4. The pits observed here - generally adjacent to the port boss and associated with the former position of an L-shaped bracket just to the right of the port - are uniformly $1.6-1.7 \mathrm{~mm}$

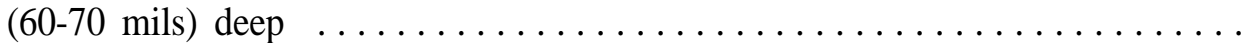


16 Region of the digester shell below the modified cooking screens showing extensive pitting. This specific region, near RS5, shows the tendency for pits (red-orange rust colored) to grow together laterally leaving only relatively small areas (gray) of smooth digester shell. The regions without rust stains stand uniformly about $1.7 \mathrm{~mm}$ (70 mils) above the bottom of the pitted/recessed area $\ldots \ldots$.

17 General view of the digester shell in the vicinity of the port for Probe \#5. Just below the port for Probe \#5, RS 1 is visible, as

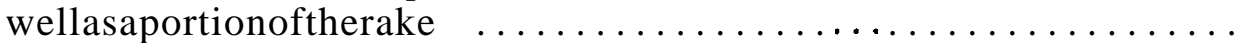

18 Closer view of the area immediately surrounding the port for Probe \#5. The pits observed here are scattered but uniformly 0.5-0.7 mm (20-30 mils) deep . . . . . . . . . . . . . . . . . .

19 Digester shell near RS6. RS6 is parallel to and partly included in the horizontal portion of the orange inspection "T" and the white scale marker ( $3.5 \mathrm{~cm}$ long) is on the uppermost of the "tracks" parallel to RS6 on top and bottom. There is significant indication of pitting in the entire area - individual pits tend to be approximately 1.0-1.2 mm (40-50 mils) deep, but the surface of the tracks and the weld at RS6 have receded further. The black material in the vertical portion of the " $\mathrm{T}$ " is residual black liquor. Also note the "V" shaped indication of significant corrosion just above the scale marker $\ldots \ldots$.

20 View looking down across a dummy plate surface located among the MC screens. Most of the pits are aligned in vertical rows; the rows shown here do not align with the vertical rows of pits on the plate in the lower group of MC screens

21 Section of dummy plate removed from the digester in 1996

22 Representative horizontal (circumferential) cross-section of the dummy plate shown in Fig. 21. Note that all the pits in this view have smooth bottoms and are the same depth

23 Dummy plate from the top row of EX screens. This plate, installed in 1996, is almost perfectly smooth, except for some pitting in areas associated with grinding. In this view, indications include the stitch weld near the hinge at left, the two weld attachment areas at right, and the seam along the top $\ldots, \ldots \ldots \ldots \ldots \ldots$

24 Close-up view of isolated pitting on the digester shell. The magnetic clip at top left is $4 \mathrm{~cm}$ long at the widest point. Note that the flash rust locations are not always at the bottom (low point, as determined by gravity flow for moisture) of each pit $\ldots, \ldots \ldots \ldots \ldots$ 
25 Intersection of RS7 and LS10 in 1996 (top) and 1999 (bottom).

Example locations with features to compare are circled $\ldots \ldots \ldots \ldots \ldots$

26 Intersection of RS6 and LS7 in 1996 (top) and 1999 (bottom).

Note in particular the smooth weld bead surface and the circled

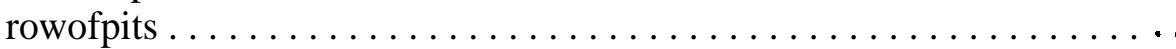

27 Intersection of RS2 and LS4 in 1996 (top) and 1997 (bottom).

Examples of locations to compare features are circled .......... 32

281999 inspection photograph of the RS6/LS10 intersection. Note the "island" of smooth shell surface in the upper right of the photograph, which stands about $1 \mathrm{~mm}$ (40 mils) above the surrounding corroded area $\ldots \ldots \ldots \ldots \ldots \ldots \ldots \ldots \ldots \ldots \ldots \ldots \ldots \ldots$

29 Representative ECN data for Probe $\# 5 \ldots \ldots \ldots \ldots \ldots \ldots \ldots \ldots \ldots \ldots$

30 Polarization curve for mild steel in wash zone liquor removed from the Kamloops digester

31 Representative ECN data for Probe \#3

32 Polarization curve for mild steel in lower extraction liquor removed from the Kamloops digester.

33 Temperature and potential data for Probe \#5

34 Nominal variation in temperature for Probes $\# 4$ and $\# 5 \quad \ldots \ldots \ldots \ldots \ldots$

35 Temperature profile for Probes \#4 and \#5 during a period of

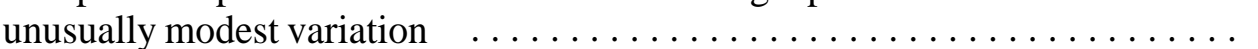

36 Temperature profile for Probes \#4 and \#5 during a period with an extended temperature perturbation

37 Representative ECN potential data for Probe \#2 showing variation as a function of furnish composition

38 Representative ECN current data for Probe \#2 as a function of furnish composition 
39 Residual alkali measured on the bottom circulation loop decreases coincident with a Douglas fir pulping campaign $\ldots \ldots \ldots \ldots 6$

40 Post-test view of Probe \#1. The area $10-12 \mathrm{~cm}$ around the probe position has been cleaned of carbonate. scale. Red/orange regions are rust stains associated with low spots in the surface relief and

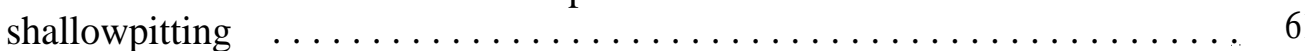

41 Post-test view of Probe \#1 following removal of accumulated

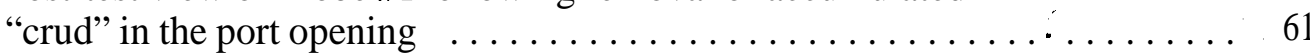

42 View of the external flange associated with Probe \#1. None of the other flanges showed any sign of leakage $\ldots \ldots \ldots \ldots \ldots \ldots$

43 Intersection of RS21 with LS33 or LS34. Gray material - particularly evident at the bottom of the photo - is carbonate scale $\ldots \ldots \ldots \ldots \ldots$

44 Post-test view of Probe \#2. Significant corrosion and surface relief is confined to the area adjacent to the port boss. Residual carbonate scale covers most of the shell at this position, but it is sufficiently thin to reveal surface relief contours $\ldots \ldots \ldots \ldots \ldots \ldots \ldots$

45 Shell and trim screen near the position of Probe \#2. The most significant corrosion is adjacent to the port boss

46 Post-test view of Probe \#3 and the surrounding digester shell $\ldots \ldots \ldots \ldots 66$

47 Closer view of Probe \#3. The teflon has recessed from its original position flush with the process at the mouth of the port by about $1 \mathrm{~cm}$

49 A recessed area associated with grinding the shell surface to remove anattachment

51 Closer view of Probe \#4. The teflon is displaced completely from the electrodes. Note the ID of the port appears relatively uncorroded. Also note that the end of the piece of steel formerly attached to the silver is rusted - the silver has been broken off at

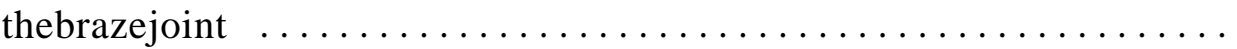


52 Post-test view of Probe \#5

$53 \quad$ Closer view of Probe $\# 5 \quad \ldots \ldots \ldots \ldots \ldots \ldots \ldots \ldots \ldots \ldots \ldots \ldots \ldots$

$54 \quad$ Post-test appearance of an electrode from each probe in the digester. Probes \#1-5 are represented left-to-right, respectively,

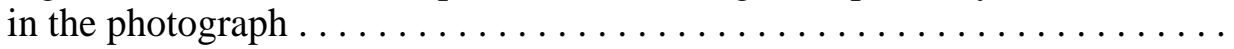

55 Post-cleaning appearance of an electrode from each probe in the digester. Probes \#1-5 are represented left-to-right, respectively, in the photograph 


\section{ACRONYMS AND SYMBOLS}

$\begin{array}{ll}\text { ECN } & \text { Electrochemical Noise } \\ \text { EX } & \text { extraction (screens) } \\ \text { LI } & \text { localization index } \\ \text { LS } & \text { longitudinal seam (weld) } \\ \mathrm{MC} & \text { modified cooking (screens) } \\ \mathrm{RS} & \text { round seam (weld) } \\ \mathrm{SCE} & \text { saturated calomel electrode } \\ \mathrm{ZRA} & \text { zero resistance ammeter } \\ \mathrm{e}^{+} & \text {unit charge of electricity }\left(1.6 \times 10^{-19} \text { coul) }\right. \\ \mathrm{I} & \text { current } \\ \mathrm{I}_{\mathrm{RMS}} & \text { root mean square value of current } \\ \mathrm{m} & \text { charge on metallic ion produced by corrosion process } \\ \mathrm{M} & \text { atomic weight of corroding material } \\ \mathrm{N}_{\circ} & \text { Avagadro's number }\left(6.023 \times 10^{23} / \text { mol) }\right. \\ \mathrm{P} & \text { penetration } \\ \mathrm{Q} & \text { integrated current sum over time } \mathrm{t} \\ \mathrm{t} & \text { exposure time } \\ \mathrm{W} & \text { mass dissolving as a result of corrosion in time } \mathrm{t} \\ \sigma_{\phi} & \text { standard deviation of potential } \\ \sigma_{\mathrm{I}} & \text { standard deviation of current }\end{array}$





\begin{abstract}
Electrochemical noise $(\mathrm{ECN})$ probes were deployed in a carbon steel continuous kraft digester at five locations roughly equi-spaced from top to bottom of the vessel. Current and potential noise, the temperature at each probe location, and the value of about 60 process parameters (flow rates, liquor chemistry, etc.) were monitored continuously for a period of one year. Historical vessel inspection data, including inspections accomplished immediately prior to and immediately following probe deployment, and post-test evaluation of the probe components were used to assess/compare corrosion indications from the probes with physical changes in wall thickness and corrosion patterns on the digester shell.
\end{abstract}

The results indicate that furnish composition is a significant variable influencing digester corrosion, with increasing amounts of Douglas fir in the nominal furnish correlating directly with increased corrosion activity on the ECN probes. All five probes detected changes in furnish composition approximately simultaneously, indicating rapid chemical communication through the liquor, but the effect was strongest and persisted longest relatively high in the digester. The ECN probes also indicate significant corrosion activity occurred at each probe position during shutdown/restart transients. Little or no correlation between ECN probe corrosion activity and other operational variables was observed.

Post-test evaluation of the probes confirmed general corrosion of a magnitude that closely agreed with corrosion current sums calculated for each probe over the exposure period and with historical average corrosion rates for the respective locations. Further, no pitting was observed on any of the electrodes, which is consistent with the ECN data, relevant polarization curves developed for steel in liquor removed from the digester, and the post-test inspection of the digester. 


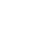




\subsection{INTRODUCTION}

In the pulp and paper industry, digesters are typically large, cylindrical pressure vessels in which pulp for paper-making is extracted from wood chips. There are a variety of specific chemical processes that are used, but each of them has as a goal the removal of as much lignin from the wood as practical while retaining the maximum amount of cellulose with particular fiber properties. The most common pulping process in North America is termed the kraft process, in which hot alkaline sulfide solutions (specific formulations are referred to as "liquors") are used to dissolve lignin and separate wood fibers. In North America, most continuous digesters are carbon steel construction, while most batch digesters are fabricated with stainless steel or utilize stainless steel overlay (types 309 and 312 are typical) on carbon steel. While kraft pulping is a relatively mature technology in terms of process chemistry, the multiplicity of process factors influencing corrosion - and potential synergisms among them - that degrade the process containment are poorly understood and periodically lead to significant maintenance issues.

The location and severity of corrosion in kraft digesters can differ markedly with the construction material and type of operation (batch or continuous) as well as many largely unknown details of flow, temperature, and liquor chemistry unique to each specific facility. Recently, modifications in pulping/cooking parameters - mandated by environmental concerns, production goals, or energy requirements -have generated changes in process flow and chemistry that have introduced further changes and uncertainties in the localized. environment and vessel corrosion. As a result of these changes, and perhaps combined with improved inspections, reports of digester corrosion problems (general thinning and pitting) appear to be on the increase.

Historically, investigations of digester corrosion have utilized synthetic liquors prepared for use in laboratory coupon exposures. These tests have been instrumental in the identification of the influence(s) of some individual chemical constituents on, the corrosion of digester construction materials. However, they suffer from the limitation that use of synthetic liquors does not allow for an assessment of the potential synergy among all the elements of the digester environment-the full suite of chemical constituents including organics as well as flow (liquor and chips), temperature variations, and other process factors. Even tests utilizing process liquor taken from operating digesters cannot fully simulate process factors, in part because liquors degrade rapidly upon contact with air and also because prior exposure at temperature may influence subsequent corrosivity in the laboratory. 
An alternate approach to evaluate digester corrosion has been the use of coupons of various types placed in operating digesters. These tests, too, have generated useful information but suffer from the limitation that the coupons can only be evaluated - for weight change, corrosion patterns, film formation, etc. - at extended intervals (typically one year) defined by the vessel maintenance-outage schedule. As a result, the coupons generate information about cumulative damage over the inspection interval but no information about specific conditions/times in which the corrosion process is active. Further, the coupons often cannot be placed such that they do not disturb the local flow patterns (e.g., are not flush-mounted with the digester wall).

Largely due to its ability to monitor corrosion processes in real time, the electrochemical noise $(\mathrm{ECN})$ technique for monitoring corrosion is gaining acceptance in industrial applications. [For instance, Refs. 1-5 are representative examples of many different field applications of ECN presented at a recent symposium on the topic.] All corrosion processes (general and localized) cause spontaneous fluctuations of the free corrosion potential and current associated with corroding surfaces. These fluctuations, collectively termed ECN, and the analysis thereof, can be used to assess corrosion processes. ECN generally exhibits low frequency $(<1 \mathrm{~Hz})$ and small amplitude (potential range $\mu \mathrm{V}-\mathrm{mV}$ and current range $\mathrm{nA}$ to $\mathrm{mA}$ ) signals. In a general sense, the magnitude, duration, and chronology of the ECN transients, along with the potential at which these occur, can be used to determine whether the transients indicate general or localized (pitting or cracking) corrosion [6-7].

In the ECN technique, potential and current (and oftentimes temperature, too) are simultaneously measured. The current flow between two nominally identical coupled electrodes is monitored through a zero resistance ammeter. The corrosion potential of the couple is monitored with respect to a third electrode (reference) via a high impedance voltmeter. [Although the probe configuration could be used to generate polarization data, the standard ECN technique does not impose an external potential that could disturb/disrupt passive film formation and the local chemistry.] This data, along with appropriate statistical manipulations and polarization information, can be used to assess the corrosion process form (general, pitting, cracking) and relative intensity during operations. Because instantaneous changes in corrosion activity can be determined, the ECN technique can be used to identify changing process conditions giving rise to corrosion as it occurs. 
The purpose of this document is to report data gathered from a group of ECN probes deployed in an operating continuous digester and to correlate the data with operating parameters and historic inspection data to assess corrosion in the vessel. 


\subsection{KAMLOOPS DIGESTER}

The digester fitted with ECN probes for this study is located in Kamloops, British Columbia, at the Weyerhaeuser pulp mill named for the city. The mill is located adjacent to the Thompson River due south of the Kamloops airport.

The digester under study is a carbon steel Kamyr vessel commissioned in 1994 and operated in the continuous pulping mode. The digester is approximately $52 \mathrm{~m}$ tall and the internal diameter varies from about $7 \mathrm{~m}$ at the top to $8 \mathrm{~m}$ at the bottom. With only minor variation in the process details, various modes of the Lo-Solids ${ }^{\mathrm{TM}}$ process to pulp primarily pine and spruce species have been consistently in use since 2 months after start-up.

A schematic of the digester vessel appears in Fig. 1, along with the location of the five identical probes installed for this investigation. The probes were placed in ports originally constructed for the purpose of potential monitoring, which were roughly equi-spaced over the vertical dimension of the digester. The specific probe locations - along with approximate corresponding elevation from the bottom of the digester - and design shell thickness at that location included:

Probe \#1-about $0.5 \mathrm{~m}$ below the top dome seam (46 m); $38 \mathrm{~mm}$ wall thickess, Probe $\# 2$ - near the centerline of the trim screen locations $(37 \mathrm{~m}) ; 39 \mathrm{~mm}$ wall thickness, Probe \#3-about $0.5 \mathrm{~m}$ below the lower extraction screens (25. $\mathrm{m}) ; 46 \mathrm{~mm}$ wall thickness, Probe \#4-about $0.5 \mathrm{~m}$ below the lower modified cooking screens (16 m); $53 \mathrm{~mm}$ wall thickness, and

Probe \#5-about $2 \mathrm{~m}$ below the wash screen (2 m); $58 \mathrm{~mm}$ wall thickness. 


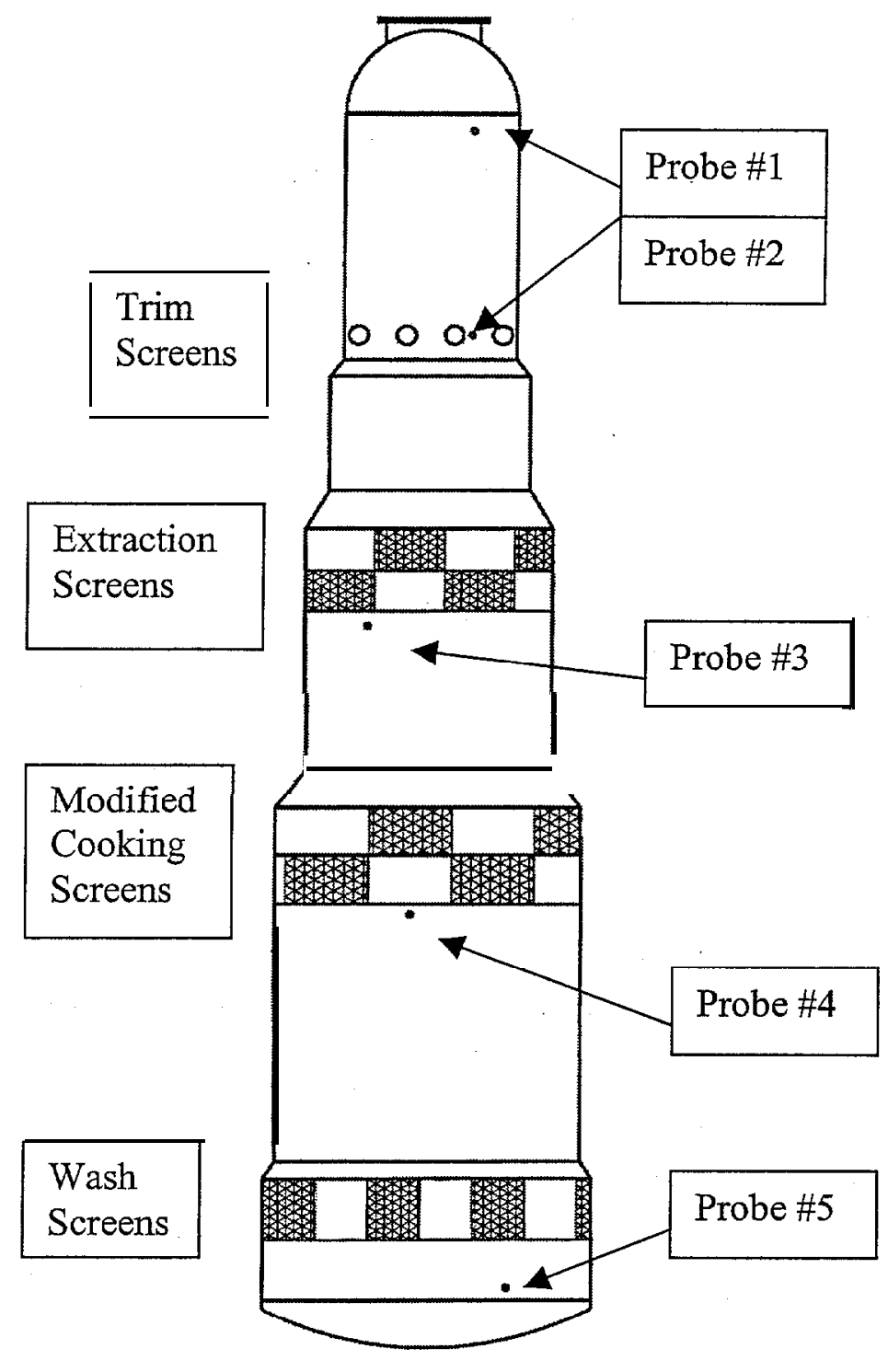

Fig. 1. Schematic diagram of the Kamloops digester. 


\subsection{EXPERIMENTAL PROCEDURE}

\subsection{GENERAL}

At the annual major maintenance outage (June 2000), the digester vessel was drained and pressure-washed with water to facilitate internal inspection. Following visual inspection and photographic documentation of the condition of the digester shell, the mill maintenance crews accomplished their work in and around the digester (which included a wall thickness survey). At the end of the maintenance outage, the ECN probes were positioned (along with placement of electrical leads, establishment of data collection routine, etc.) and data collection commenced during restart of the vessel. At the subsequent maintenance outage (June 2001), the vessel was again inspected and photographed, and the probes were retrieved for detailed evaluation. This report documents the inspection activities at the outset of probe exposure as well as the termination of the experiment and summarizes the data collection and interpretation.

\subsection{PROBE DESIGN}

Because the ports for probe installation were built into the vessel at the time of original construction, the ECN probes were designed to fit the available port diameter of $3.8 \mathrm{~cm}$ (1.5 in.). The probe configuration used for this investigation is shown in Fig. 2. The two working electrodes were fabricated from rod stock of mild steel with a diameter of $0.95 \mathrm{~cm}$. The reference electrode was a small rod of silver, which upon exposure to the liquor/pulp environment establishes a reference potential based on the $\mathrm{Ag} / \mathrm{Ag}_{2} \mathrm{~S}$ equilibrium. The thermocouple was a type-K variety in an alloy 600 sheath. All of the probe materials were mounted in a teflon shroud such that the working end of each was flush with the end of the teflon. Although the probe materials had a tight "force-fit" in the teflon shroud, two set-screws (not shown in Fig. 2) were also used to fix the position of the shroud relative to the thermocouple sheath inside the shroud. The probe assembly was then mounted through a flanged port in the digester shell such that the working end of the probe was flush with the internal surface of the digester so as not to disturb localized flow and to represent the shell surface as well as possible. 


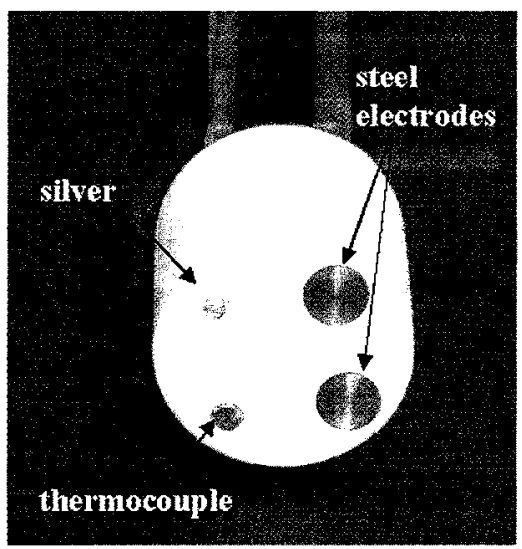

Fig. 2. ECN probe configuration used for the Kamloops experiment. The piece of silver functions as the reference electrode, and the thermocouple is sheathed in a closed tube of alloy 600. For scale, note that the teflon shroud (white) has a diameter of $3.6 \mathrm{~cm}$ and each electrode has a diameter of $0.9 \mathrm{~cm}$.

Inside the teflon shroud, connections to the steel rods serving as leads were made as follows (see Fig. 3). A threaded hole in the rear of the cylindrical carbon steel electrode facilitated attachment to the threaded tip of the steel rod. A small "nose-cone" shaped piece of teflon acted as a compression fitting covering the threaded connection to retain a tight fit and prohibit process fluid from leaking into this connection. Two layers of heat-shrink plastic were used to cover the entire length of the steel leads from the pressure fitting on the flange to the rear portion of the teflon fitting. Similarly, heat-shrink plastic was used to cover the stainless steel rod to which the piece of silver was brazed as well as the thermocouple sheath. In this fashion, all of the metallic surfaces of the probe were isolated from the process solution except for the welldefined electrode areas exposed at the working end of the teflon shroud.

Data collection from the probes commenced in mid-June 2000 following the major maintenance outage. With two exceptions, the digester was operated continuously from start-up until late May 200 1. The exceptions were a pair of two-week shut-downs, one in mid-November 2000 and the other in mid-March 200 1. The digester was cooled and drained (but not washed) during each of these interruptions. Data was collected successfully for the entire year of operation with the exception of portions of the outage periods. 


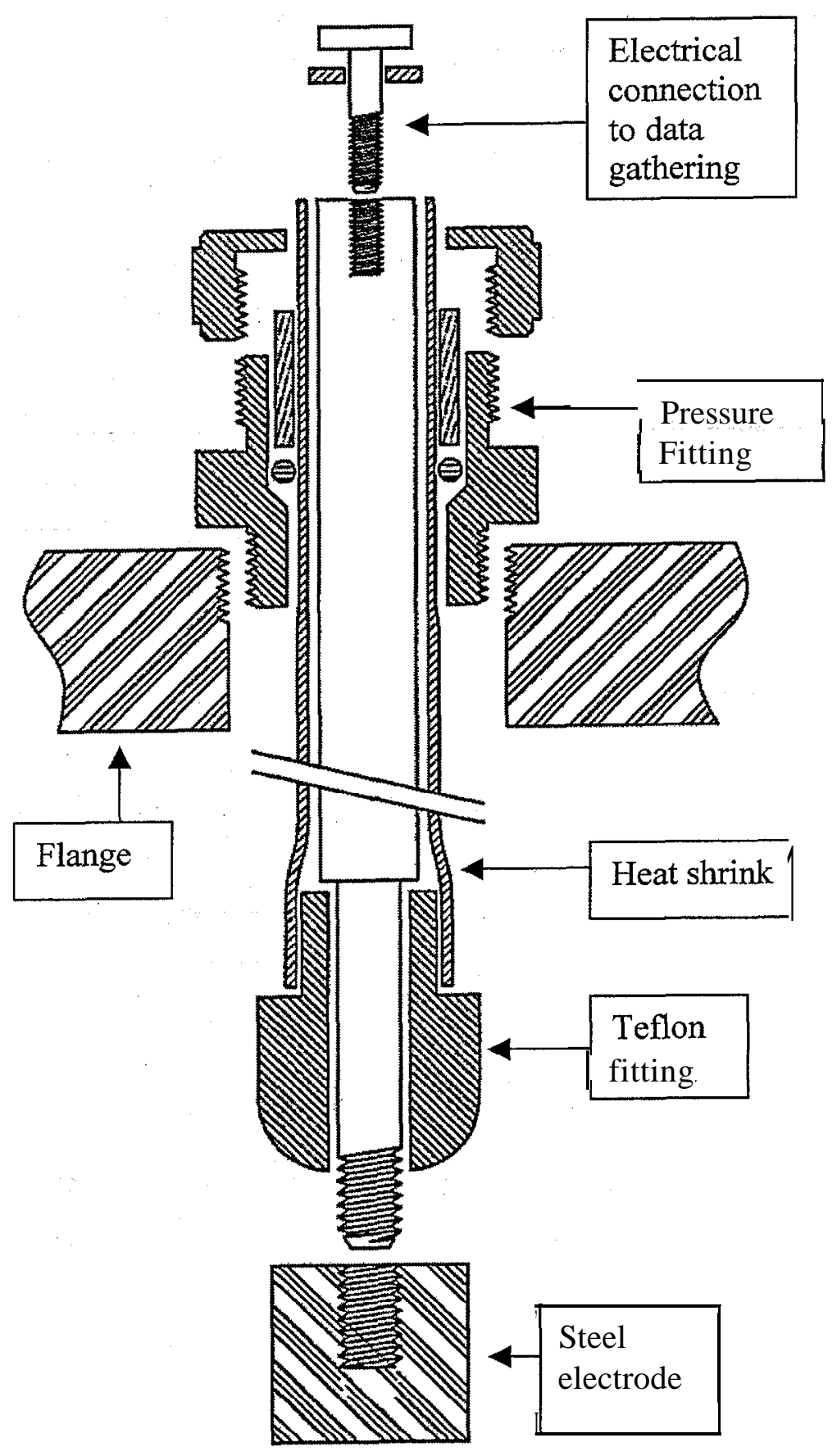

Fig. 3. Sketch of probe assembly. The drawing is not to scale, and is intended to show only the spatial relationship between various components. For clarity, the second layer of heat shrink was omitted from this drawing. 
Current and potential values were collected at intervals of one second for each probe. The system hardware was an 8-channel monitoring $\operatorname{rack}(*)$ with a standard laptop computer using corrosion software $^{(\dagger)}$ designed for this type of data collection. Statistical parameters (averages, standard deviations, root-mean-square values) were calculated at five-minute intervals. For the first several weeks all the raw data was saved, but eventually new raw data was discarded and only the calculated parameters were saved. The analysis discussed here uses only five-minute averages calculated from current and potential noise for each time interval. The probe thermocouples (not activated until September 2000) originally gathered data on 30-second intervals, but this was soon increased to one-minute periods. In addition, bulk process data (for example, flow rates, temperatures, pump speeds, and liquor composition) from about 60 sensors was collected on approximately 15 -minute intervals over the duration of the experiment.

In addition to the suite of process temperature information, two rings of 16 external magnetic-mount thermocouples - roughly equi-spaced around the circumference - were attached to the digester under the insulation. One ring was placed just below the extraction screens (about $22 \mathrm{~m}$ from the bottom of the vessel) and the other ring was placed just below the modified cooking screens (about $13 \mathrm{~m}$ from the bottom of the vessel). While these external thermocouples could not measure the precise temperature inside the digester, they were used to assess relative temperature differences around the vessel at these specific elevations. The external rings operated properly for only about 2-3 months of the year-long experiment.

For the purpose of this evaluation, the largest excursions of current noise and potential noise were identified and a common feature (or group of features) among the available process parameters was sought for correlation with the ECN excursions.

(*) CIS400 control unit with CIS502 current-potential logging' and zero-resistance ammeter modules from Petroleum Research and Production, Ltd., in England, and ADAM 4018 8-channel temperature loggers, from Advantech, USA.

$(\dagger)$ Amulet software system, from Corrosion and Condition Control, Ltd. in England. 


\subsection{OBSERVATIONS AND RESULTS}

\subsection{INITIAL VESSEL INSPECTION}

Since the beginning of operation, the digester at Kamloops has been inspected on an approximately annual basis (12-15 month intervals). A scaffold is erected inside the vessel and the shell surfaces are power-washed with water - not acid cleaned - prior to inspection. The inspection includes a suite of ultrasonic thickness measurements in specific areas (but not necessarily the same precise spots from year-to-year), dye-penetrant examination of stainless steel welds (nozzles and top dome seam), magnetic particle examination for cracking in carbon steel seams, and a general visual assessment. No detailed photographic record representing the visual inspections and corresponding ultrasonic thickness data exists, but during at least three inspections, a series of photographs of many of the intersections of the round seam (RS) and longitudinal seam (LS) welds was collected. In addition, limited photographic information representing general shell conditions is available.

To document the condition of the digester shell in and around the ports prior to installation of the ECN probes, a thorough visual inspection was conducted (June 2000). At the time of this inspection, the original potential monitoring probes had not been removed from the ports.

\subsubsection{Probe \#1}

The digester shell near the topmost probe location (for Probe \#1) is shown in Figs. 4-5. The port is located about $0.5 \mathrm{~m}$ below the dome-to-shell transition weld - which is also termed RS22, or the $22^{\text {nd }}$ round seam from the bottom of the vessel - and about $46 \mathrm{~m}$ above the bottom of the vessel (RS 1). Much of the surface in this area retained a loosely adherent carbonate scale that was relatively thick $(-1.5 \mathrm{~mm})$. In places where the carbonate scale had become dislodged, the substrate carbon steel was smooth and exhibited a uniform dark coloration (deep blue to black). The smooth area - apparently free of anything except very modest general corrosion - extends several meters down the digester wall from this location. Based on visual assessment of the area represented by Probe \#1, cumulative corrosion in this location has been very minor or even nil. 


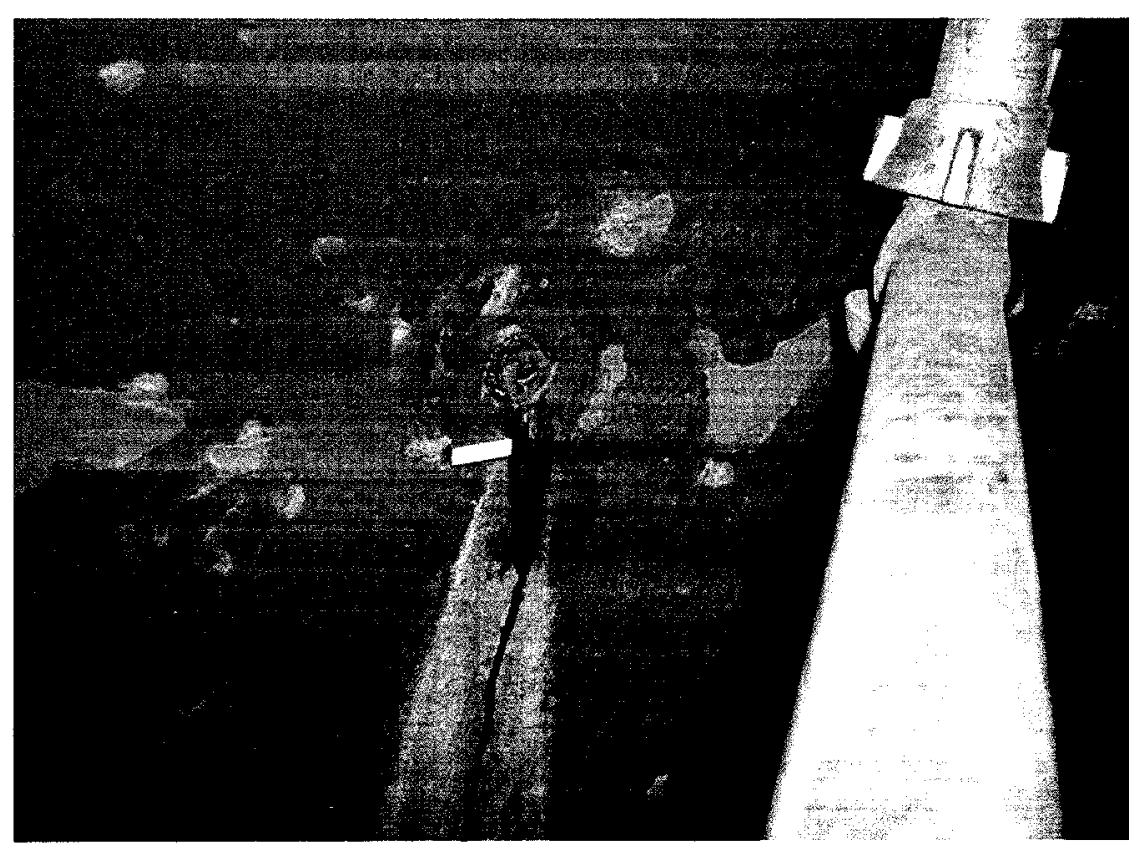

Fig. 4. General view of the digester shell in the area of Probe \#1. At the time of this photograph, the probe port was occupied by a potential monitor. Only small amounts of residual carbonate scale (relatively light colored areas) remain on the shell, and some residual black liquor is draining from the annular area of the port. The white "scale indicator" just below the port is $3.5 \mathrm{~cm}$ long. A piece of scaffold rigging appears in the foreground.

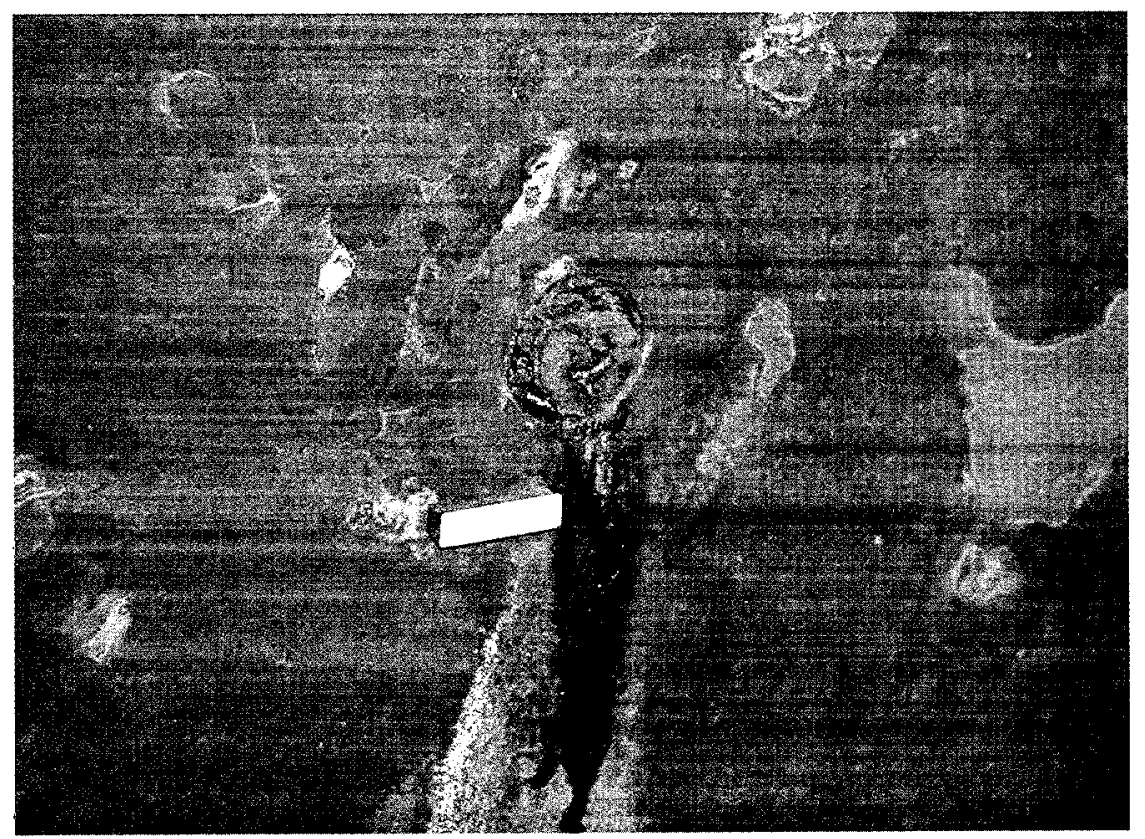

Fig. 5. Closer view of the shell surface surrounding the port for Probe \#1. The boss area encircling the port is very slightly raised above the shell contour and is stainless steel overlay. Note that the shell in this location is smooth - no pitting or surface roughening. Small areas of light brown carbonate scale remain on the shell. 
The initial signs of localized corrosion (for the present termed pitting, but it will be discussed further below) were observed just below RS21, about $3 \mathrm{~m}$ below the port for Probe \#1. The "pit" indications at this level, about $43 \mathrm{~m}$ from the bottom of the vessel, were relatively scattered with none larger than a fingertip and none deeper than about $0.25 \mathrm{~mm}$ (10 mils). Some carbonate scale remained at this location, potentially obscuring some of the shallow pitting. Generally speaking, the diameter, depth, and density (indications per unit area) of the pits increases slowly at progressively lower positions in the digester.

\subsubsection{Probe \#2}

The port for Probe \#2 is located in line with the trim screens (between RS18 and 19). The digester shell near this port is shown in Figs. 6 and 7. In the general area around the port, a light, adherent carbonate scale makes the surface appear relatively smooth. However, closer inspection reveals that there is actually shallow surface relief associated with clusters of light pitting in this area. While the carbonate scale somewhat obscures the pit dimensions, the shell pitting is generally less than $1 \mathrm{~cm}$ in diameter and less than $0.5 \mathrm{~mm}$ (20 mils) deep.

Figures 8 and 9 show a nearby trim screen. Immediately adjacent to the screen boss, and in the areas on/adjacent to RS 18 (just below the trim screens), indications of localized corrosion are numerous. The pits in these regions are approximately $1.6 \mathrm{~mm}(60-70 \mathrm{mils})$ deep and somewhat larger in diameter than previously noted indications. 


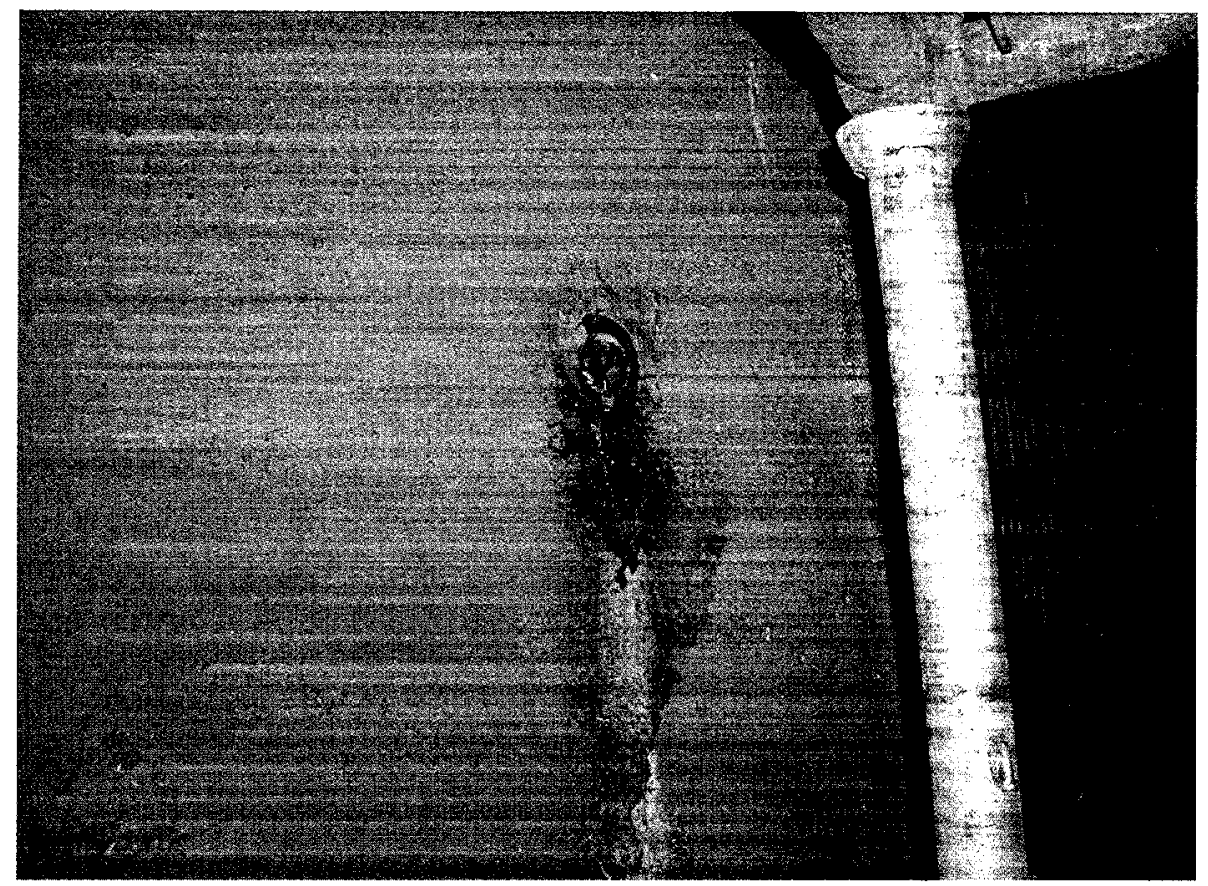

Fig. 6. General view of the digester shell surrounding the port for Probe \#2. At the time of this photograph, the port was occupied by a potential monitor and residual black liquor was draining from the port annulus. Most of the area is covered by a thin, tan-colored carbonate scale. At right, a scaffolding support and a partially obscured trim screen are visible. For scale, the port diameter is about $3.5 \mathrm{~cm}$.

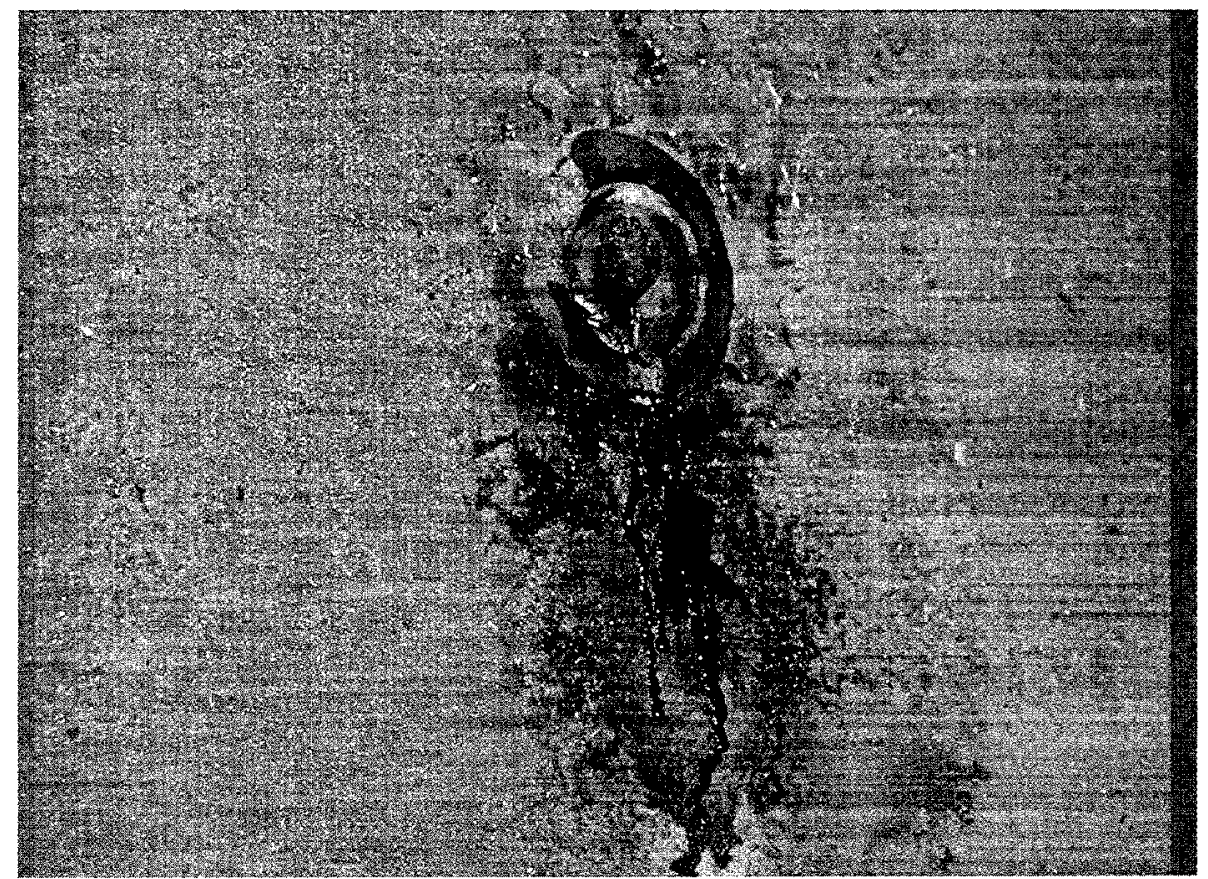

Fig. 7. Close-up view of view of the shell surface surrounding the port for Probe \#2. In general, some minor surface relief and scattered light pitting are evident on the shell surfaces in this area, but the largest pits - approximately $0.5 \mathrm{~mm}$ (20 mils) deep - are immediately adjacent to the stainless steel port boss. Many of the pits exhibit red-orange flash rusting. 


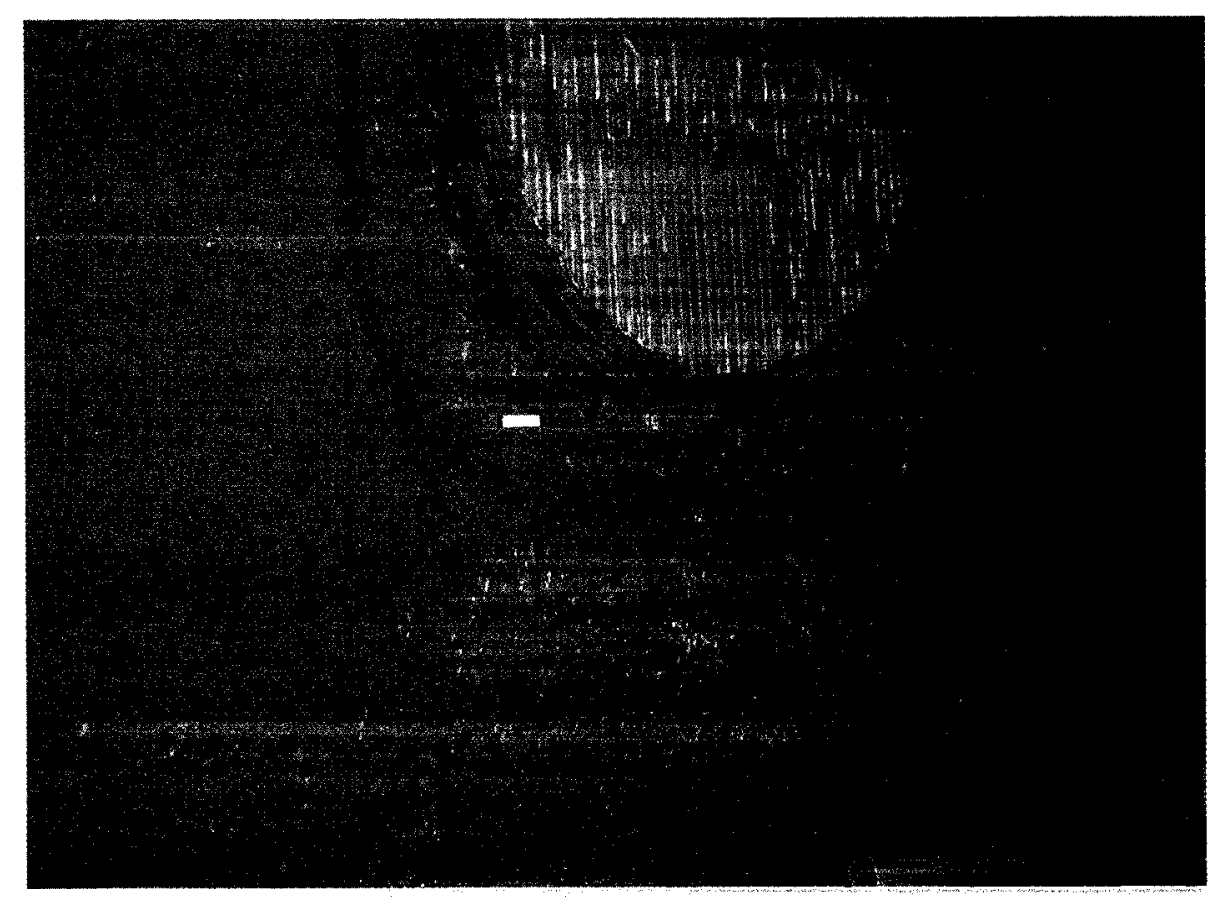

Fig. 8. General view of the trim screen and a portion of RS18 located near the port for Probe \#2. Pitting in this area (red-orange flash rust coloration) is concentrated adjacent to the trim screen boss and in/on the weld seam. The white "scale indicator" is $3.5 \mathrm{~cm}$ long. The bright orange paint marks locations for additional inspection by mill personnel.

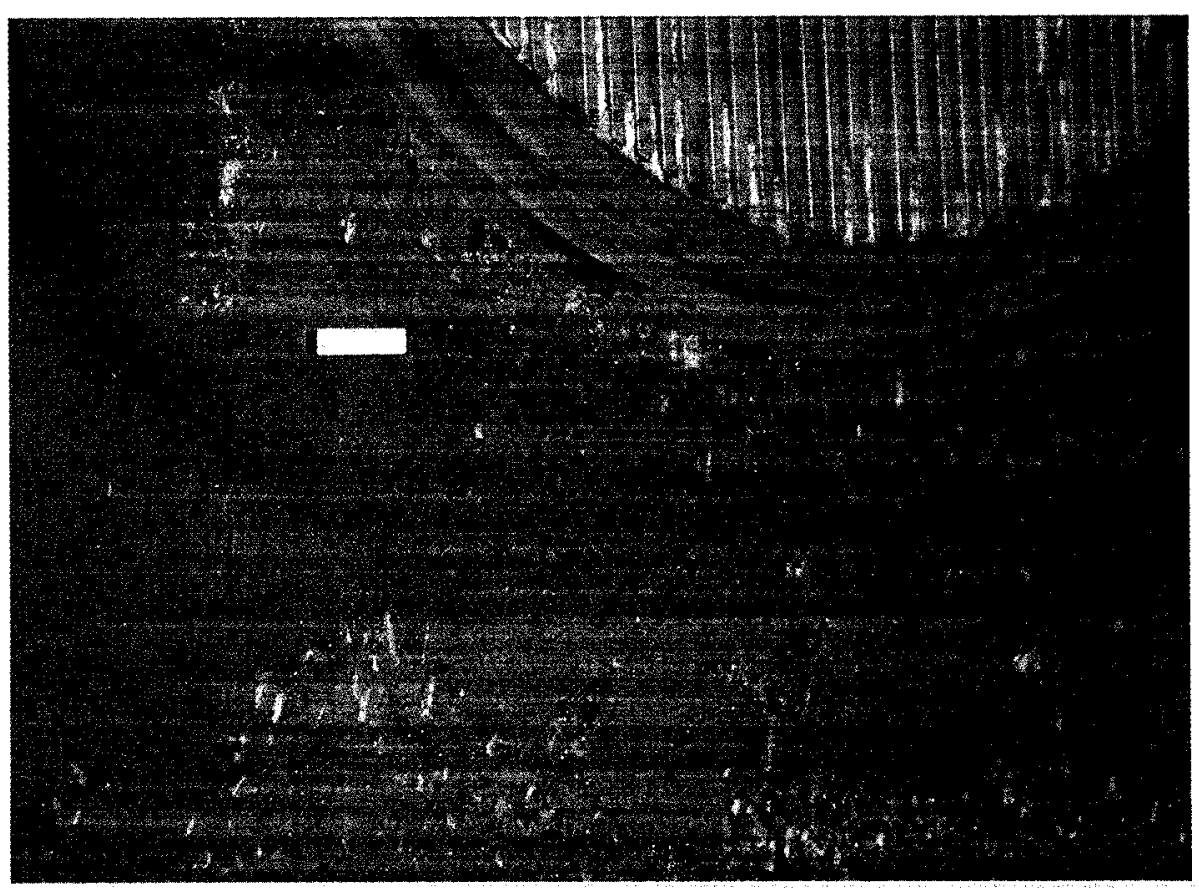

Fig. 9. Closer view of corrosion adjacent to the trim screen boss. Pits in this location, and in/on the nearby round seam weld, tend to be larger in diameter and deeper - up to 1.6-1.7 mm (60-70 mils) deep -than pits closer to the port for Probe \#2. 


\subsubsection{Probe \#3}

The bottom of the internal extraction (EX) screen header is located about $1 \mathrm{~m}$ above RS12 and about $0.5 \mathrm{~m}$ above the position for Probe \#3. The internal diameter of the digester increases in step-function fashion by about $0.5 \mathrm{~m}$ from the extraction screen header to the shell just below the header and, as such, the internal header forms a "shelf" that potentially influences the pulp/liquor flow in and around the Probe \#3 position. Figures 10 and 11 show the digester shell in the immediate vicinity of the port for Probe \#3. The pits here are irregularly distributed but are uniformly 1.5-1.7 mm deep (60-70 mils). At this location, many of the pits still have individual character, but the pits tend to cluster and overlap adjacent to the port boss and along the RS12 weld. Without exception, the pits have a smooth bottom and sides, and a right-angle intersection between the shell surface and the pit body. The unpitted area of the shell surface appears absolutely smooth at this location.

Slightly lower in the digester, the pitting indications tend to change from mostly individual pits with only minor areas of overlap to areas sometimes described in the industry as "oceans-and-islands." In the latter case, the pitted areas seem to have spread laterally and coalesced to the point that relatively large areas (from a few $\mathrm{cm}^{2}$ to most of a square meter) represent the bottom of the pitted area (the "oceans" part of the descriptive term, uniformly 1.5-1.7 mm deep) leaving only small areas ("islands") protruding above the position of the ocean floor. Representative photographs of this observation appear in Figs. 12 and 13. There is no probe port in the area of pitting easily distinguished as the "oceans and islands" pattern. 


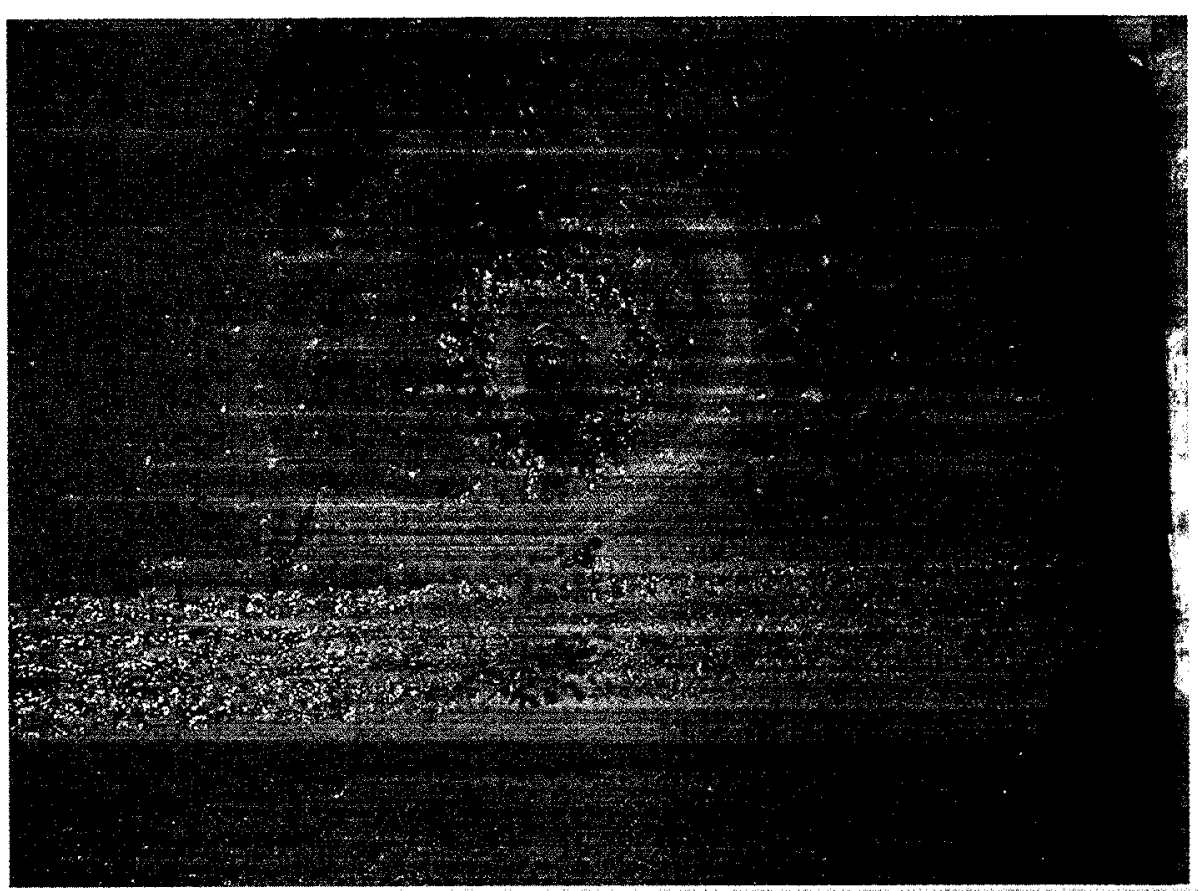

Fig. 10. General view of the digester shell surrounding the port for Probe \#3. A.ll the: pits in this area are approximately the same depth, but the pit density associated with the weld (R.S12) and the area immediately adjacent to the port is much greater.

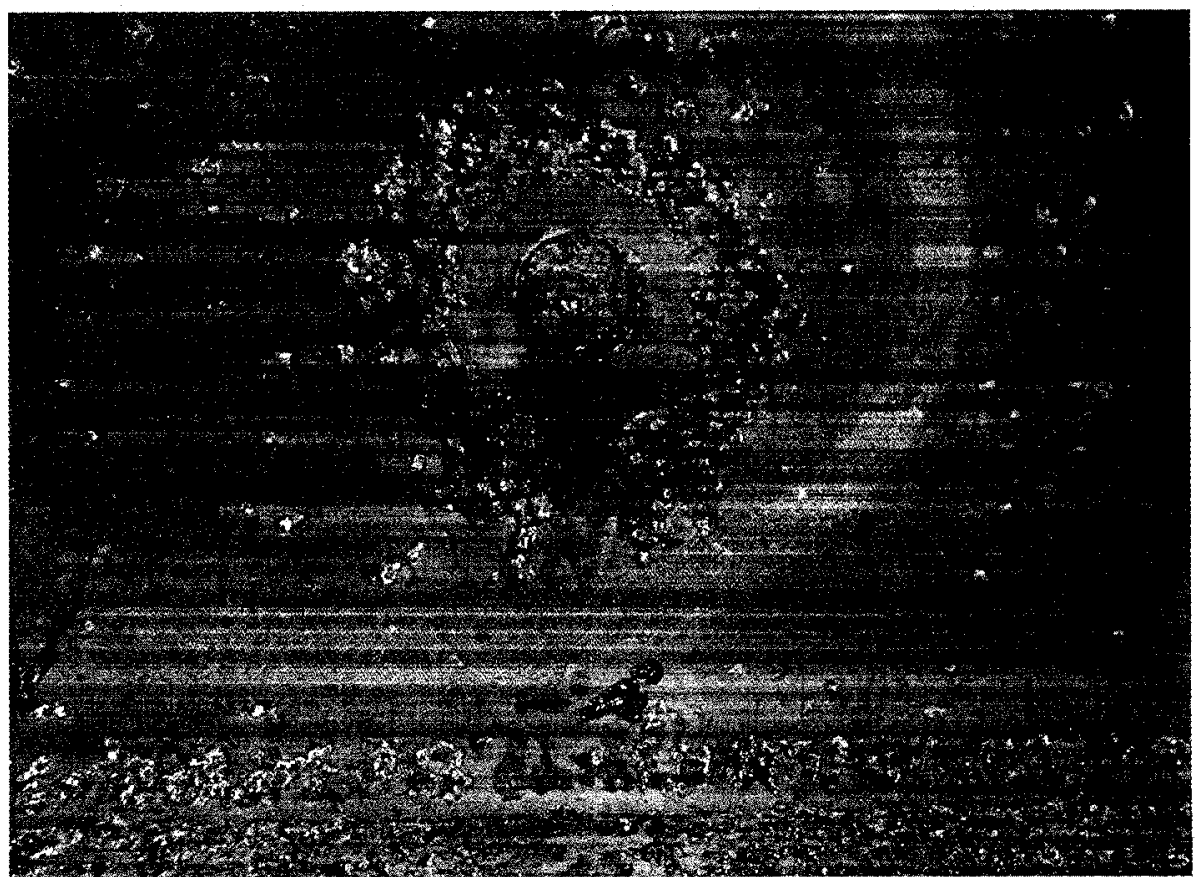

Fig., 11. Closer view of the shell surface surrounding the port for Probe \#3. The pitsi in this area - on the shell, adjacent to the boss, and those in/near the round seam weld are approximately 1.6- $1.7 \mathrm{~mm}$ (60-70 mils) deep. 


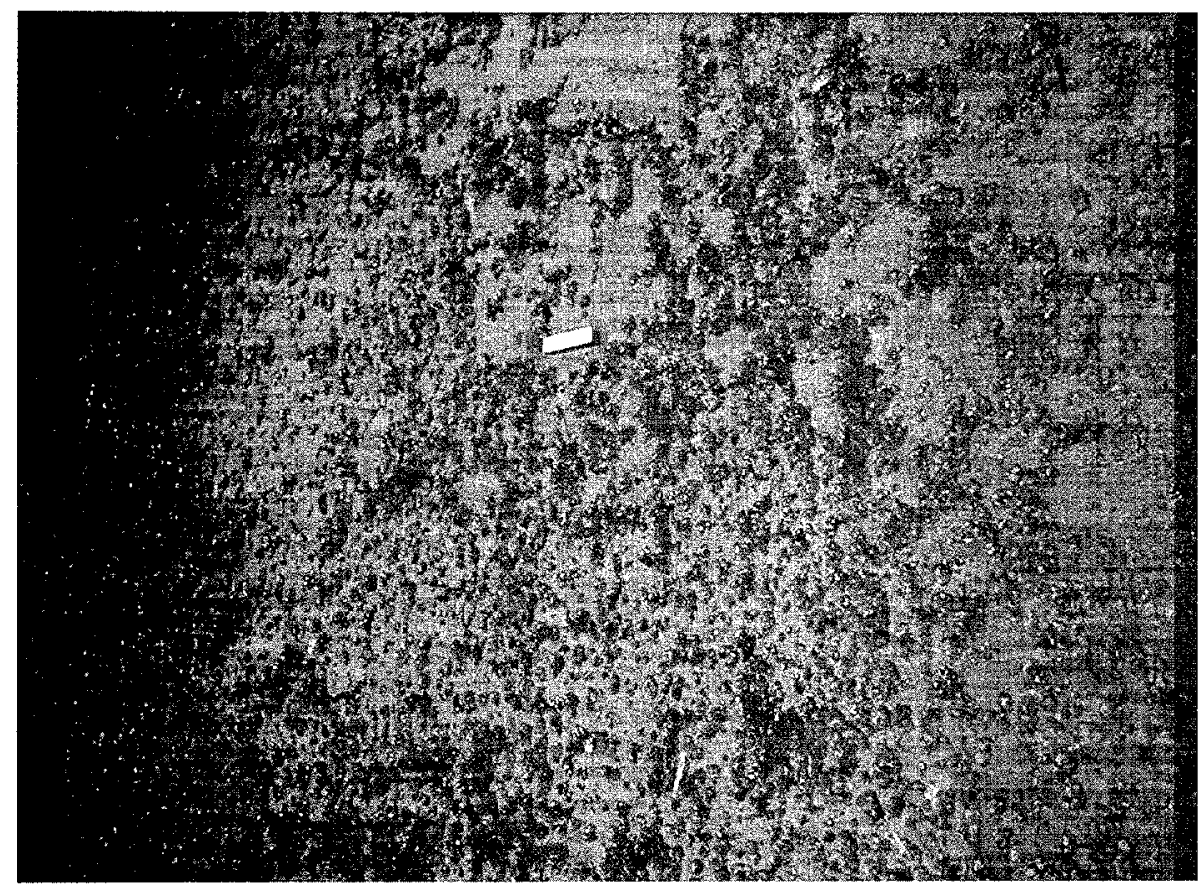

Fig. 12. General view of digester shell between extraction screens and modified cooking screens. The white "scale indicator" is $3.5 \mathrm{~mm}$ long and rests on a smooth, unattacked surface while much of the surrounding area is significantly pitted.

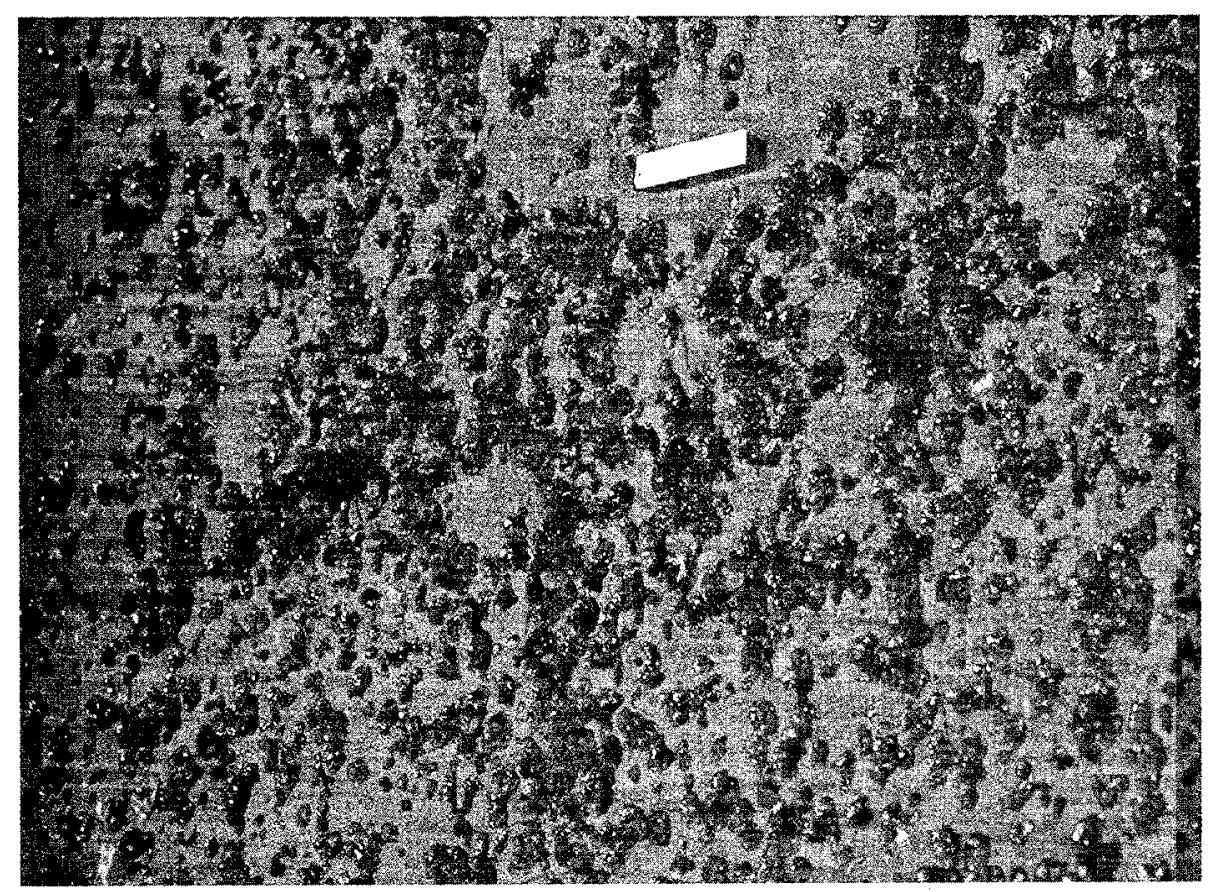

Fig. 13. Magnified view of the area depicted in Fig. 12. The pits in this region tend to overlap to form sizeable areas exhibiting a wall thickness decrease of 1.6-1.7 mm (60-70 mils) compared to the smooth surfaces nearby. 


\subsubsection{Probe \#4}

The fourth probe from the top of the vessel is located just below the modified cooking (MC) screens. Similar to the situation for Probe \#3, the probe location is about $0.5 \mathrm{~m}$ below a shelf associated with the MC screens. Shell corrosion in this area at the time of probe installation was somewhat scattered, and no large clusters of pits were observed except those immediately adjacent to the probe port. Figures 14 and 15 are representative of these observations; the pit depth at this location is uniformly $1.5-1.7 \mathrm{~mm}$ (60-70 mils).

Between the MC screens and the wash screens, the relative fraction of corroded shell surface increases significantly - and fairly abruptly - compared to higher in the vessel. Figure 16 is representative of this observation. Compared to the somewhat isolated areas in which corrosion appears to be minimal (the "islands" portion of the oceans-and-islands pattern), the depth of "ocean" region of corrosion is about $1.7 \mathrm{~mm}$ (about 70 mils), which is consistent with the depth of more isolated corrosion spots observed higher in the vessel.

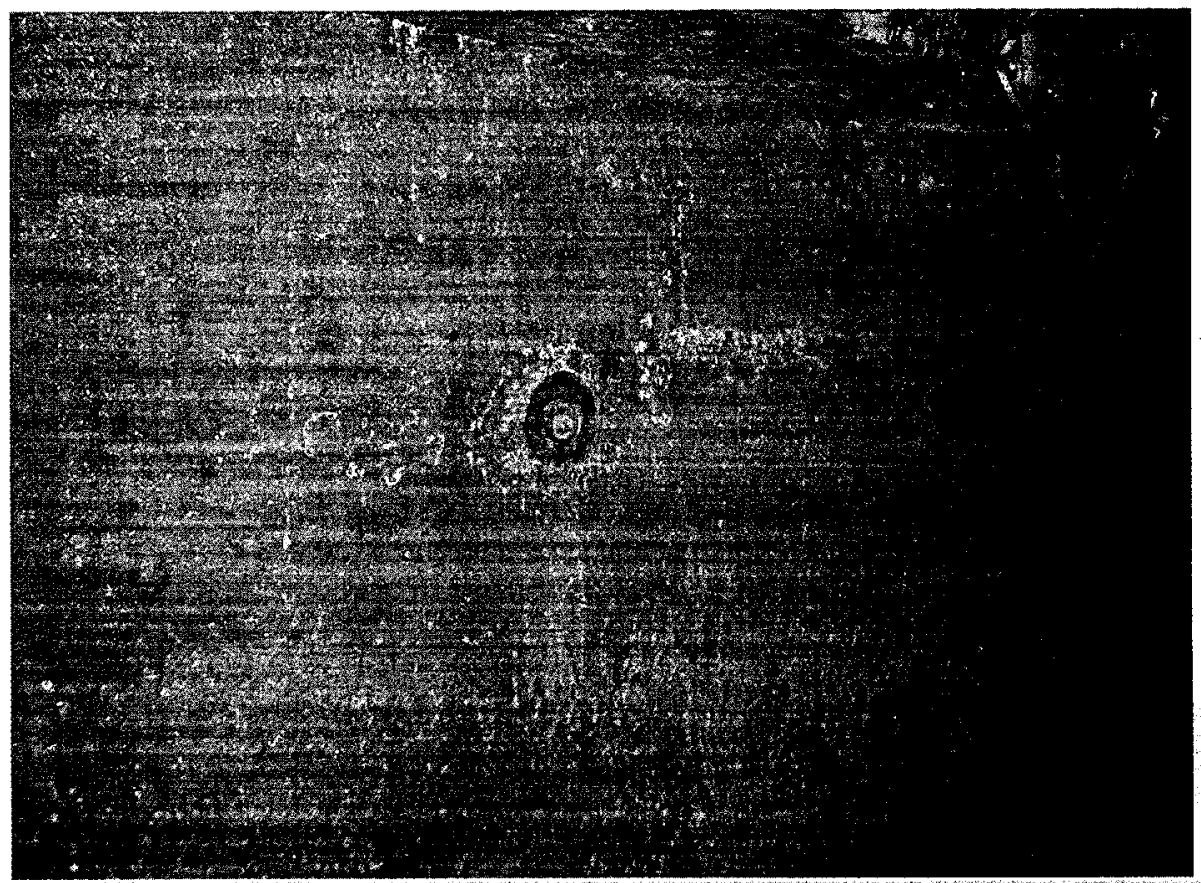

Fig. 14. General view of the digester shell in the vicinity of the port for Probe \#4. The internal header box ("shelf") associated with the modified cooking screens is just visible at the top of the photograph. The shell surfaces exhibit very little pitting in the immediate vicinity of this port. 


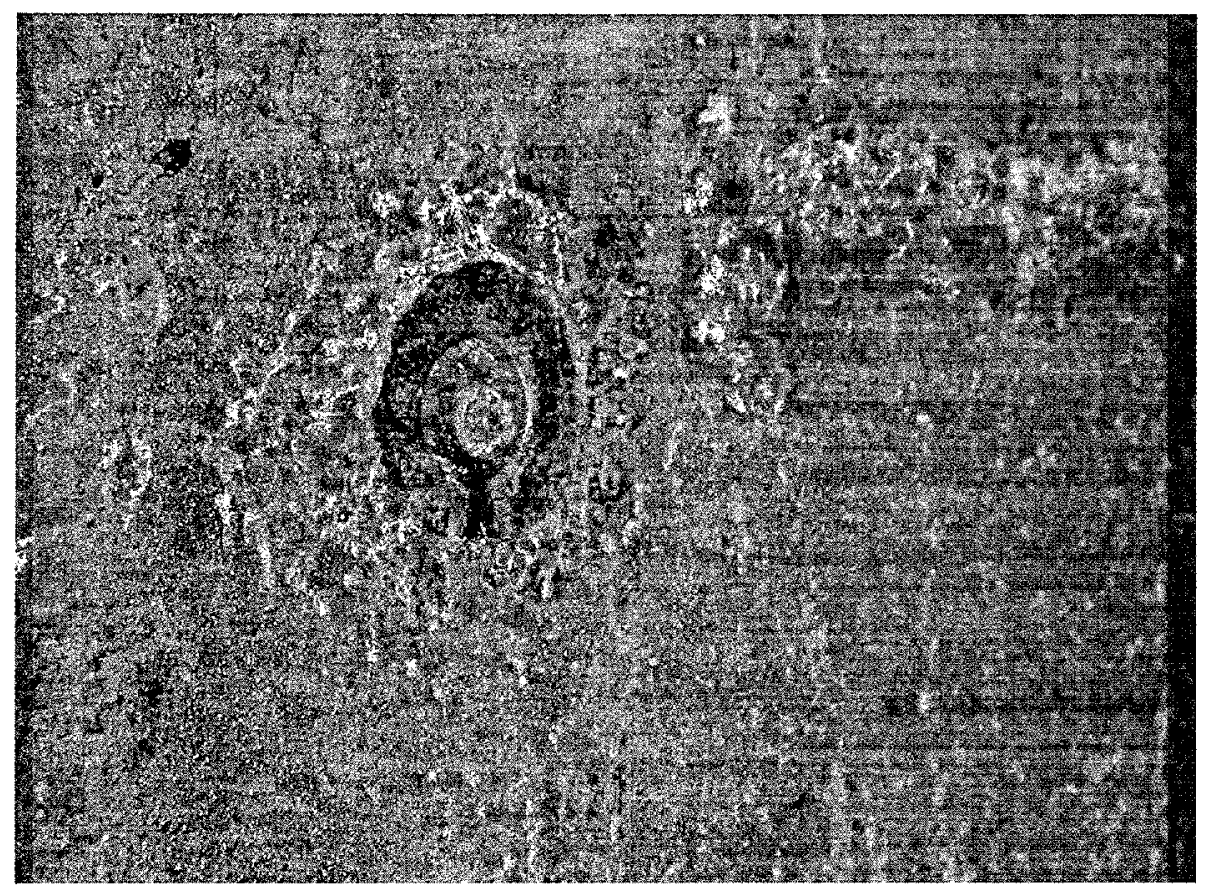

Fig. 15. Closer view of the area immediately surrounding the port for Probe \#4. The pits observed here - generally adjacent to the port boss and associated with the former position of an L-shaped bracket just to the right of the port - are uniformly 1.6-1.7 $\mathrm{mm}$ (60-70 mils) deep.

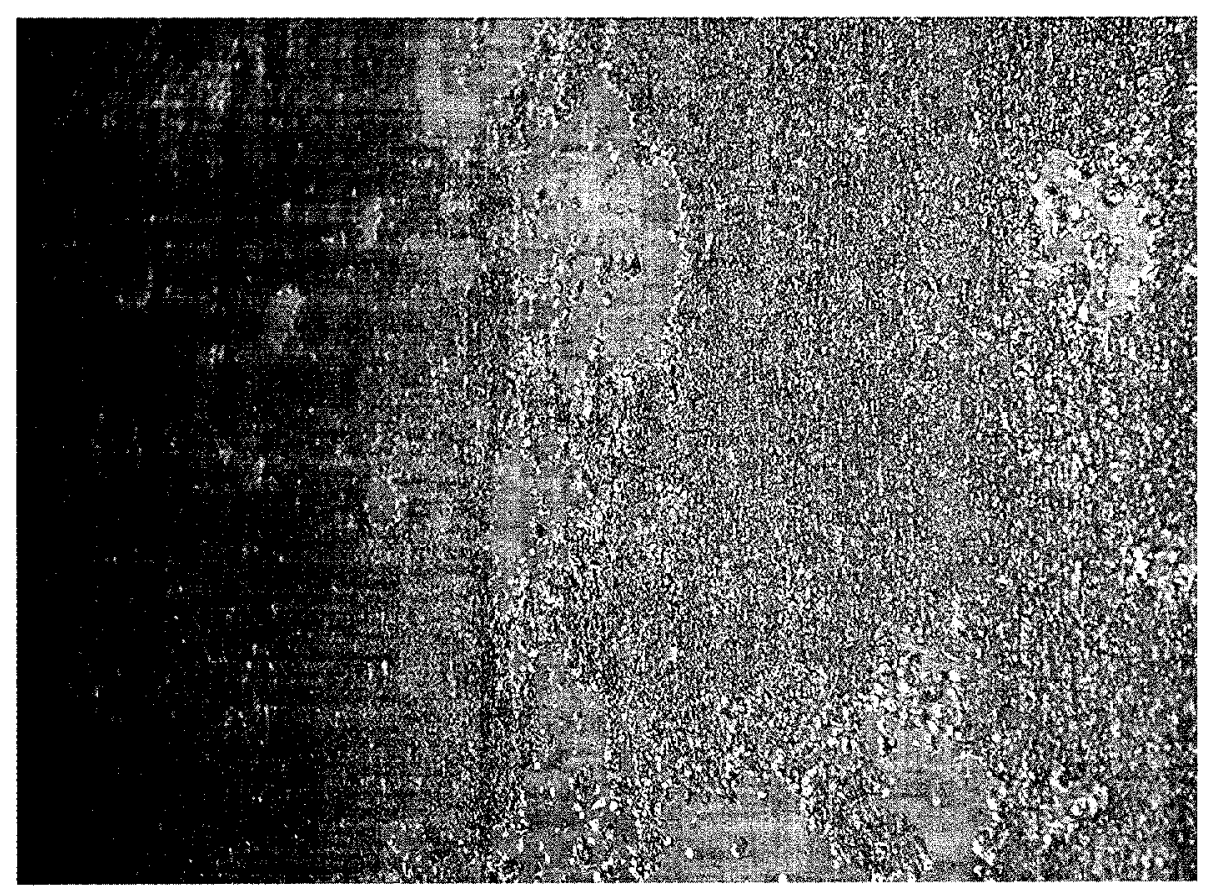

Fig. 16. Region of the digester shell below the modified cooking screens showing extensive pitting. This specific region, near RS5, shows the tendency for pits (red-orange rust colored) to grow together laterally leaving only relatively small areas (gray) of smooth digester shell. The regions without rust stains stand uniformly about $1.7 \mathrm{~mm}$ (70 mils) above the bottom of the pitted/recessed area. 


\subsubsection{Probe \#5}

The lowest probe port is below the wash screens and just above RS1 (the lowest circumferentialweld). Scattered pitting across much of the shell surface was present at the time of the inspection, but the pitting (OS-0.7 mm deep) was much more shallow than slightly higher in the vessel. Figures 17 and 18 document the pre-test condition of the digester shell near Probe \#5.

\subsubsection{Other Pre-Test Observations}

In addition to accelerated corrosion observed adjacent to welds and port bosses, a number of observations were gathered suggesting digester shell corrosion is somewhat sensitive - at least in the initiation stage - to surface condition. One example is shown in Fig. 19, which is the area surrounding RS6. The round seam weld and the immediately adjacent area are heavily pitted such that the weld surface is now below that of the shell surface at many points. Based on the position of the relatively uncorroded shell surface, the depth of pits in the weld is on the order of $2.5 \mathrm{~mm}$ (100 mils), but the total extent of metal loss in the weld is likely to be greater considering the weld crown that has also been removed by corrosion. Most of the digester surface in this area exhibits scattered pitting and clusters of pits (small "ocean" areas) on the order of 1-1.2 mm (40-50 mils) deep. However, parallel to the RS on either side are some "tracks" in which the entire area (about 3-4 cm wide) has receded somewhat further. The tracks correspond with the location of the paths taken by the wheels/fixturing of the automatic welders that were utilized to field-fabricate some of the round seam welds. The somewhat accelerated corrosion pattern along the track locations as well as on/adjacent to the weld itself suggests that disruption of the mill scale by rubbing/grinding on the surface may have contributed to the observed corrosion pattern. 


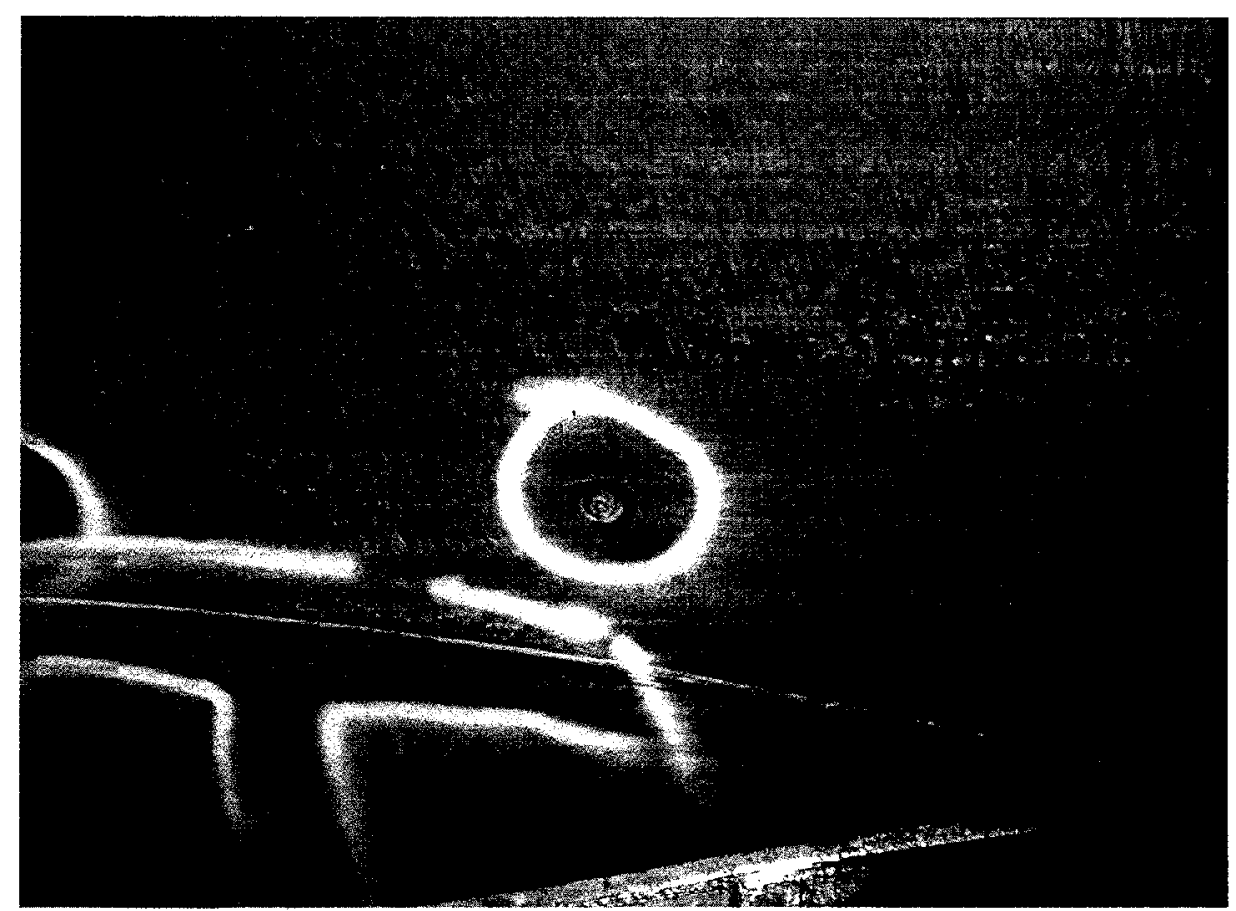

Fig. 17. General view of the digester shell in the vicinity of the port for Probe \#5. Just below the port for Probe \#5, RS 1 is visible, as well as a portion of the rake.

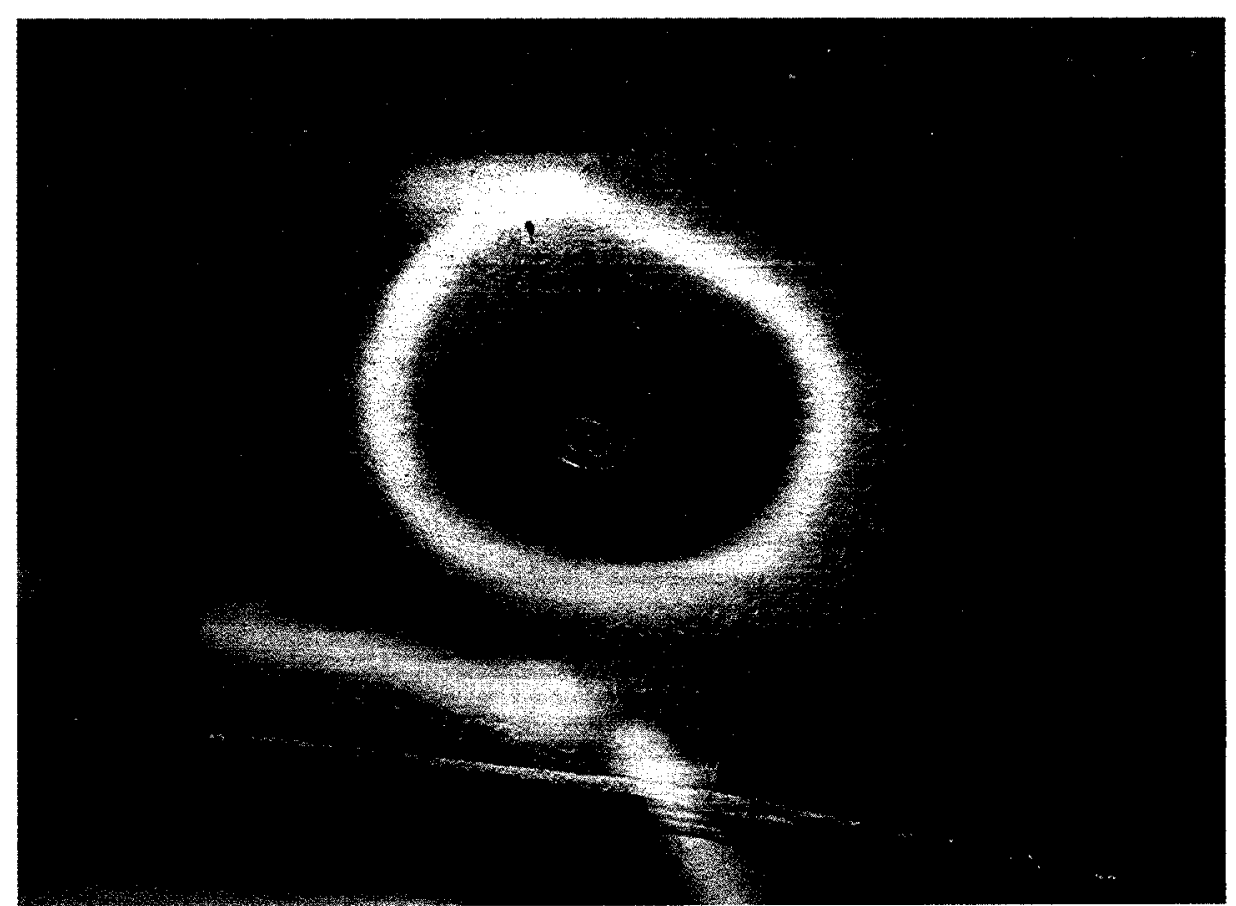

Fig. 18. Close-up view of the area immediately surrounding the port for Probe \#5. The pits observed here are scattered but uniformly 0.5-0.7 mm (20-30 mils) deep. 
Also in Fig. 19, there is a small "V" shape just above the topmost track indicating similar accelerated corrosion to that observed in the welder tracks. These "V" shapes (sometimes "L" shapes - see, for example, Figs. 14 and 15) are located in a number of places inside the vessel and apparently represent locations where a fixture was welded to the digester wall to support construction activities. Areas that were ground in order to remove the fixture (as well as areas ground to prepare the area for welding) apparently became susceptible to accelerated corrosion or at least accelerated initiation of the process. In a few cases, patterns consistent with individual grinding marks were also observed to exhibit accelerated corrosion.

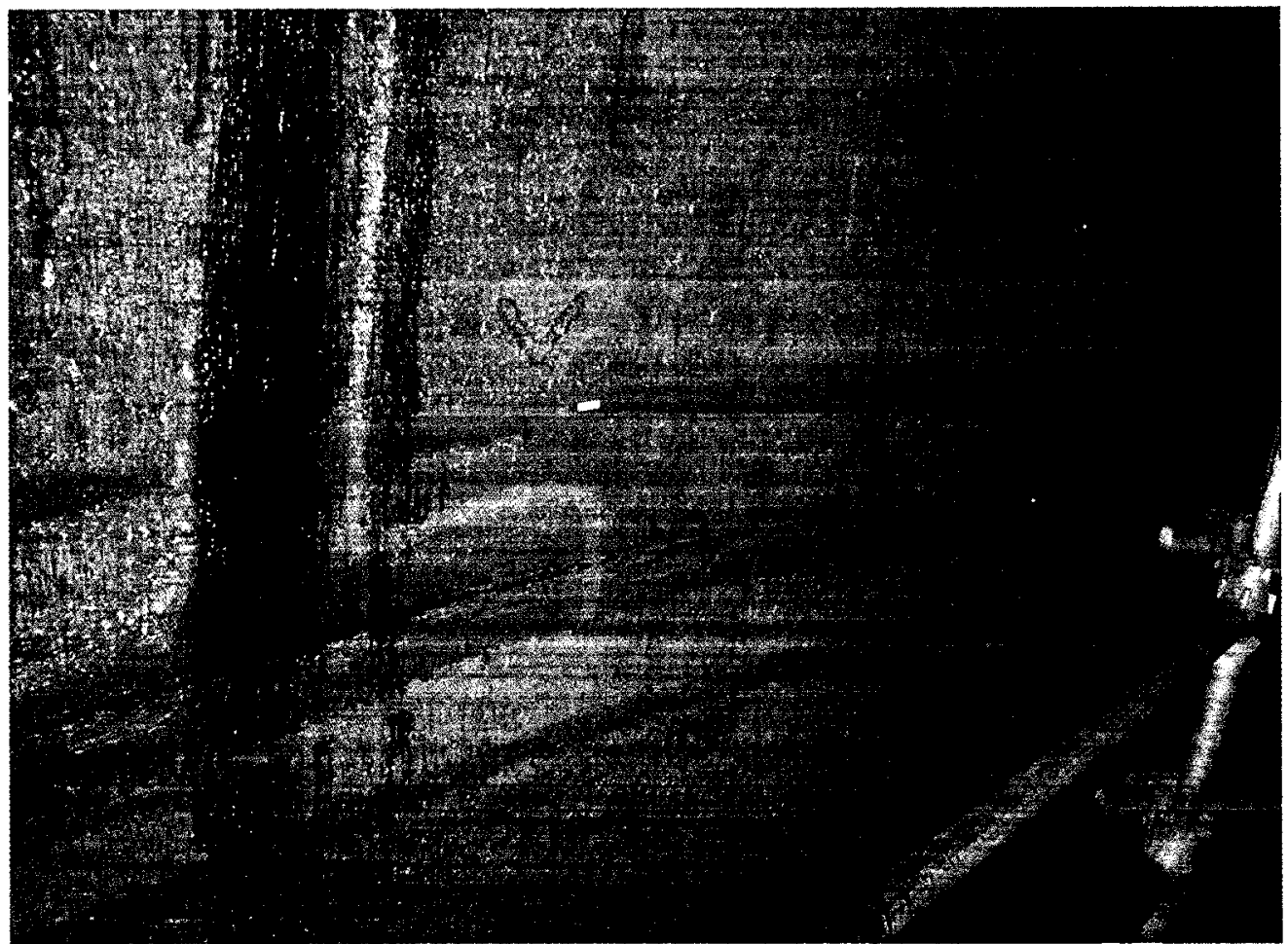

Fig. 19. Digester shell near RS6. RS6 is parallel to and partly included in the horizontal portion of the orange inspection "T" and the white scale marker $(3.5 \mathrm{~cm}$ long) is on the uppermost of the "tracks" parallel to RS6 on top and bottom. There is significant indication of pitting in the entire area - individual pits tend to be approximately 1.0-1.2 mm (40-50 mils) deep, but the surface of the tracks and the weld at RS6 have receded further. The black material in the vertical portion of the " $\mathrm{T}$ " is residual black liquor. Also note the "V" shaped indication of significant corrosion just above the scale marker. 
Further evidence of sensitivity to surface condition was observed fairly high in the digester (near RS18). The locations of former ultrasonic thickness measurements (extending many meters up the shell at about $30 \mathrm{~cm}$ intervals at 0 and $180^{\circ}$ positions) seemed to stand out in that no carbonate scale was observed to adhere to the small circular indications. Since the annual wall thickness survey had not yet occurred at the time of this inspection, this observation suggests that something about the surface preparation and/or the residual coupling liquid renders these spots different from the nominal shell surface in some aspect. The spots themselves did not appear particularly corroded, but that may be a result of regular surface preparation (grinding to a uniform thickness) for the measurement at each location.

The dummy plates (steel that covers the diameter transition at the screens on the internal surfaces) adjacent to the EX and MC screens are not constructed of precisely the same grade of steel (A36 for plates and A5 16 for shell; no practical compositional difference) but the corrosion pattern on the shell and dummy plates exhibits many similarities, In particular, the dummy plate surfaces have clusters/rows of pits all of the same depth, while large areas appear to be perfectly smooth. In all cases, the pits have smooth, rounded bottoms with an abrupt change in thickness (near a right angle) at the intersection of the shell and pit contour. At the maximum penetration, the pits are uniformly $1 \mathrm{~S}-1.7 \mathrm{~mm}$ (60-70 mils) deep, precisely the same as the nearby shell surfaces. In addition to apparently random clusters of pits, however, the dummy plates also exhibit perfectly aligned vertical rows of pits (see Fig. 20). 


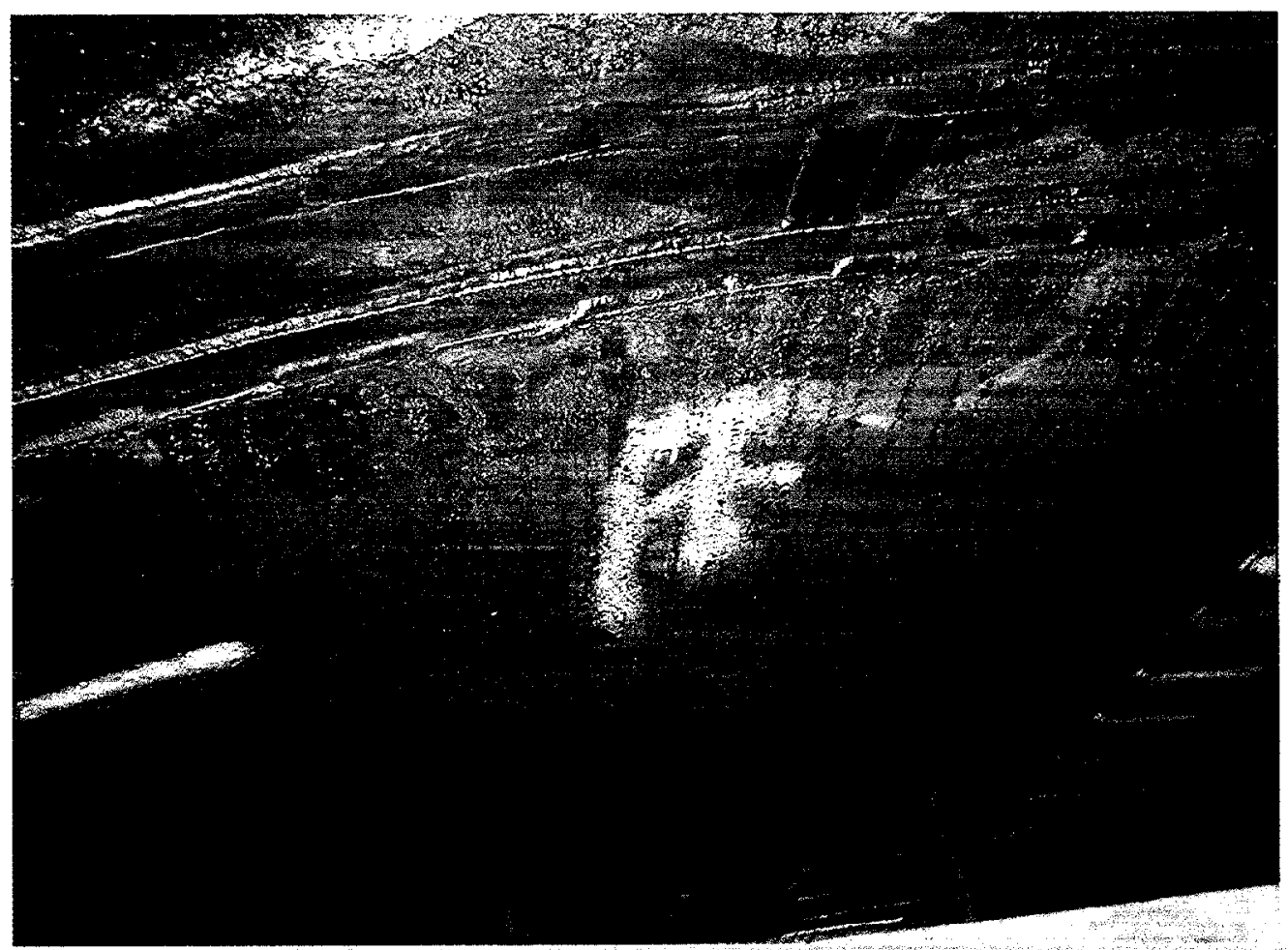

Fig. 20. View looking down across a dummy plate surface located among the MC screens. Most of the pits are aligned in vertical rows; the rows shown here do not align with the vertical rows of pits on the plate in the lower group of MC screens.

One section of dummy plate, which was removed in 1996, was made available for metallographic analysis. The analysis confirmed that the pits had smooth, rounded sides with an abrupt transition to apparently uncorroded material (Fig. 21). In addition, all the pits on the plate were very close to precisely the same depth (Fig. 22). No microstructural patterns - such as gradients in hardness, grain size, composition, or inclusion density - could account for the precise depth of pitting or for the vertically oriented rows of pits. One possibility is that rolling of the flat plate to form the slightly curved shell contour cracked/crumpled the mill scale along longs of accumulated stress. The surface film was indeed different at the pit locations than in/on the pit surfaces, but none of the film(s) seemed to retain typical mill scale composition, so it was not possible to confrm the hypothesis regarding the vertical rows of pits. 


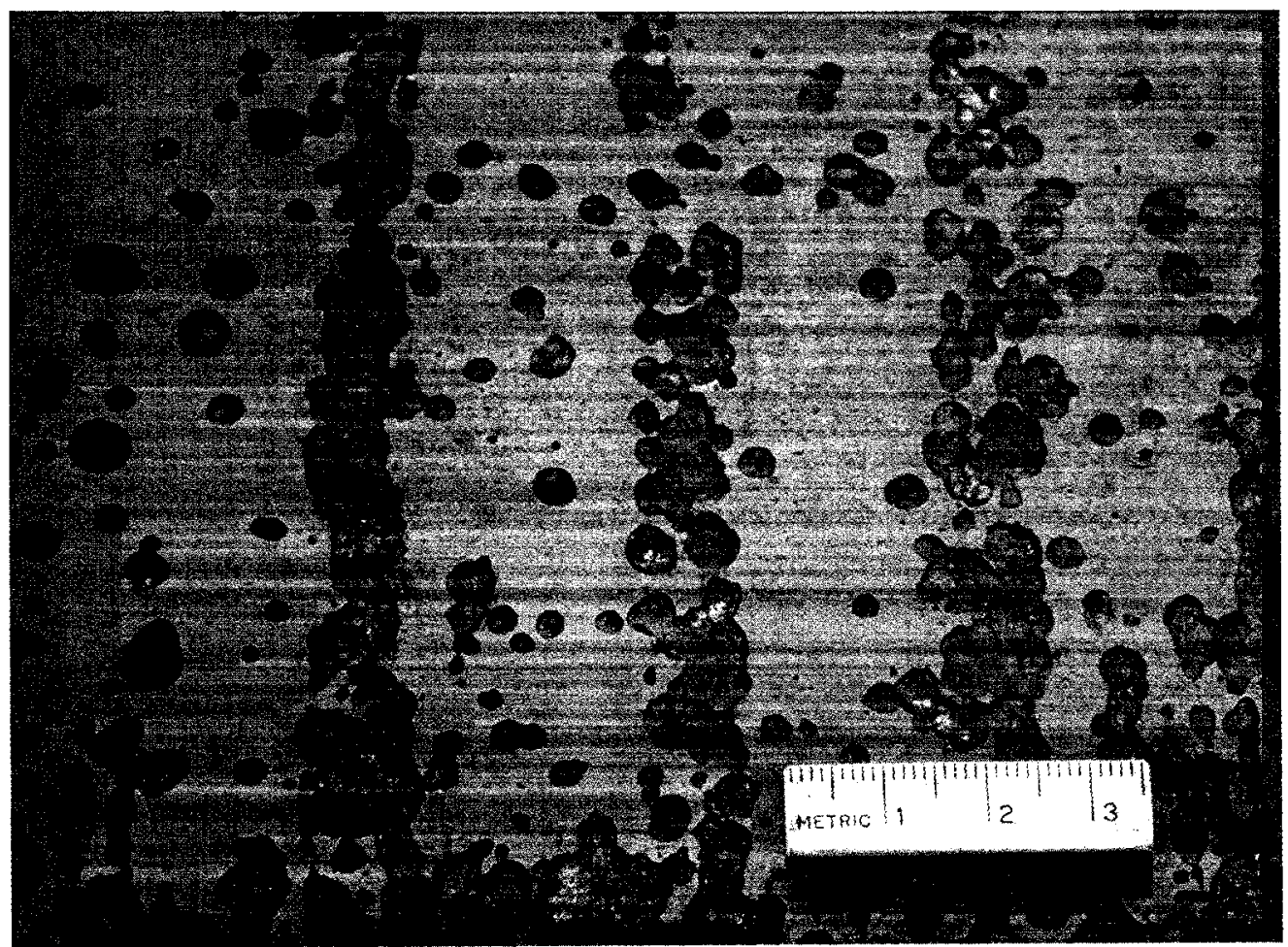

Fig. 21. Section of dummy plate removed from the digester in 1996.

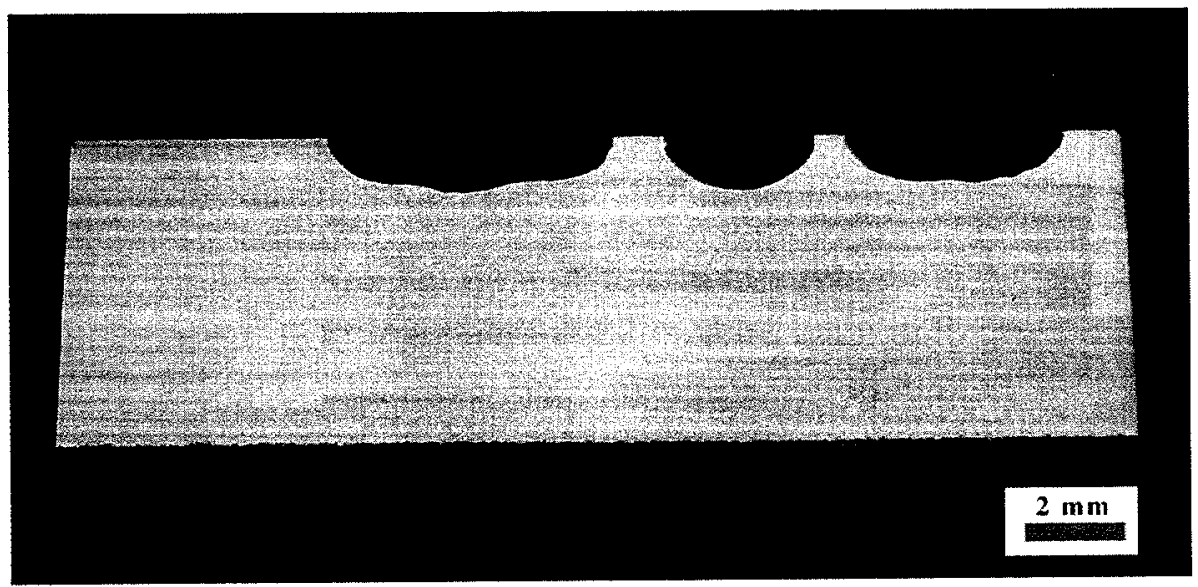

Fig. 22. Representative horizontal (circumferential) cross-section of the dummy plate shown in Fig. 21. Note that all the pits in this view have smooth bottoms and are the same depth. 
It is interesting that the replacement plate (installed in 1996) was observed to be in near pristine condition at the time of the June 2000 inspection (and the follow-up inspection in June 2001). As Fig. 23 shows, the only corrosion damage appears to be associated with areas subjected to grinding for stitch welds and attachments. The depth of attack in these areas was estimated to be $1 \mathrm{~mm}$ (about 40 mils).

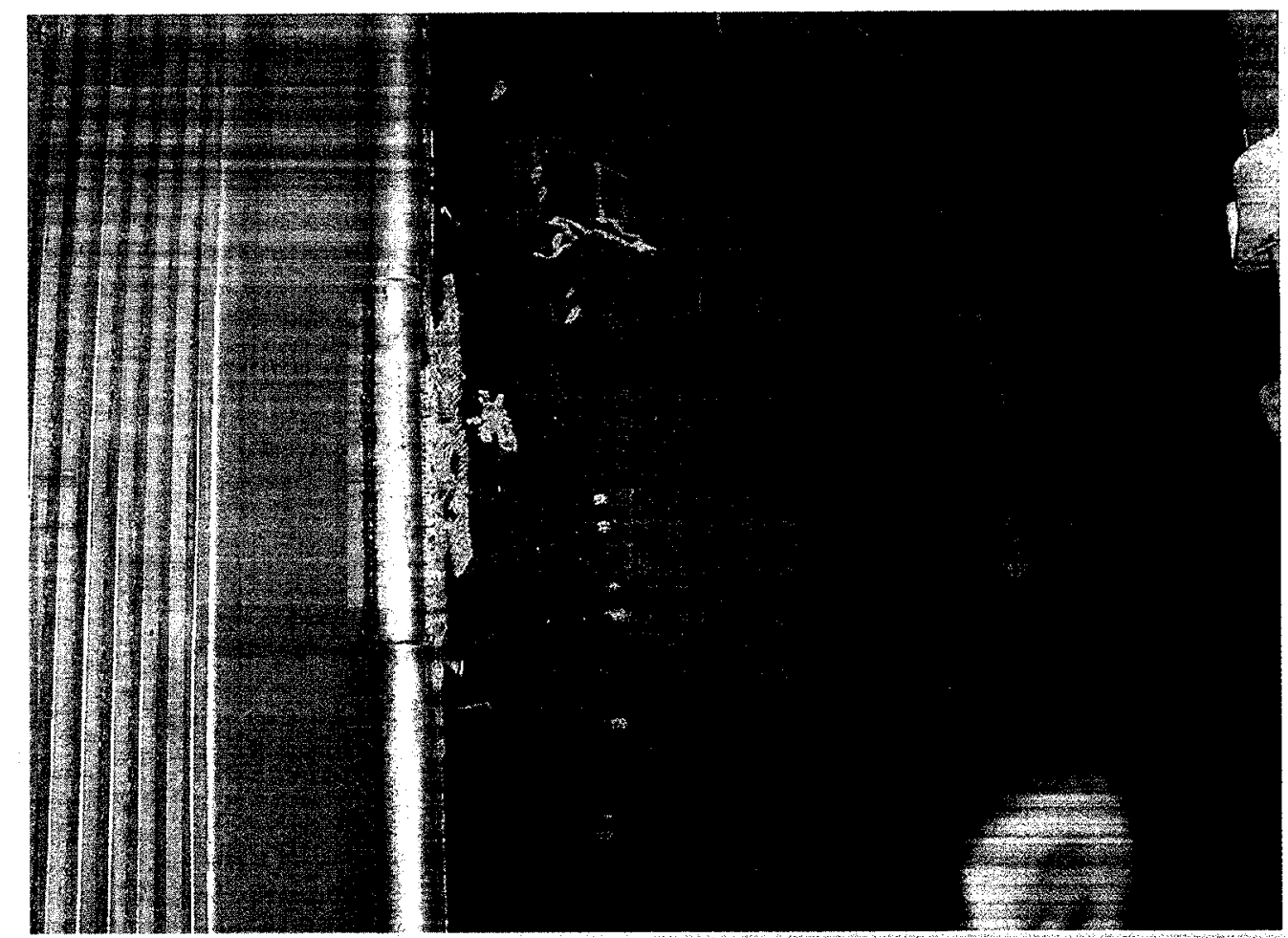

Fig. 23. Dummy plate from the top row of EX screens. This plate, installed in 1996, is almost perfectly smooth, except for some pitting in areas associated with grinding. In this view, indications include the stitch weld near the hinge at left, the two weld attachment areas at right, and the seam along the top.

\subsubsection{Comments on Localized Corrosion Pattern}

The pattern of localized wall thinning observed on the digester shell and dummy plates has some physical similarities to typical pitting, such as roughly hemispherical shapes that occur in (apparently) random locations. Figure 24 is among the best close-up photographs collected of the pitting observed on the shell on the Kamloops digester. However, the indications have several features that distinguish them from pits in the most classical sense of the word. Including observations made inside other carbon steel continuous digester vessels, these factors are described below. 


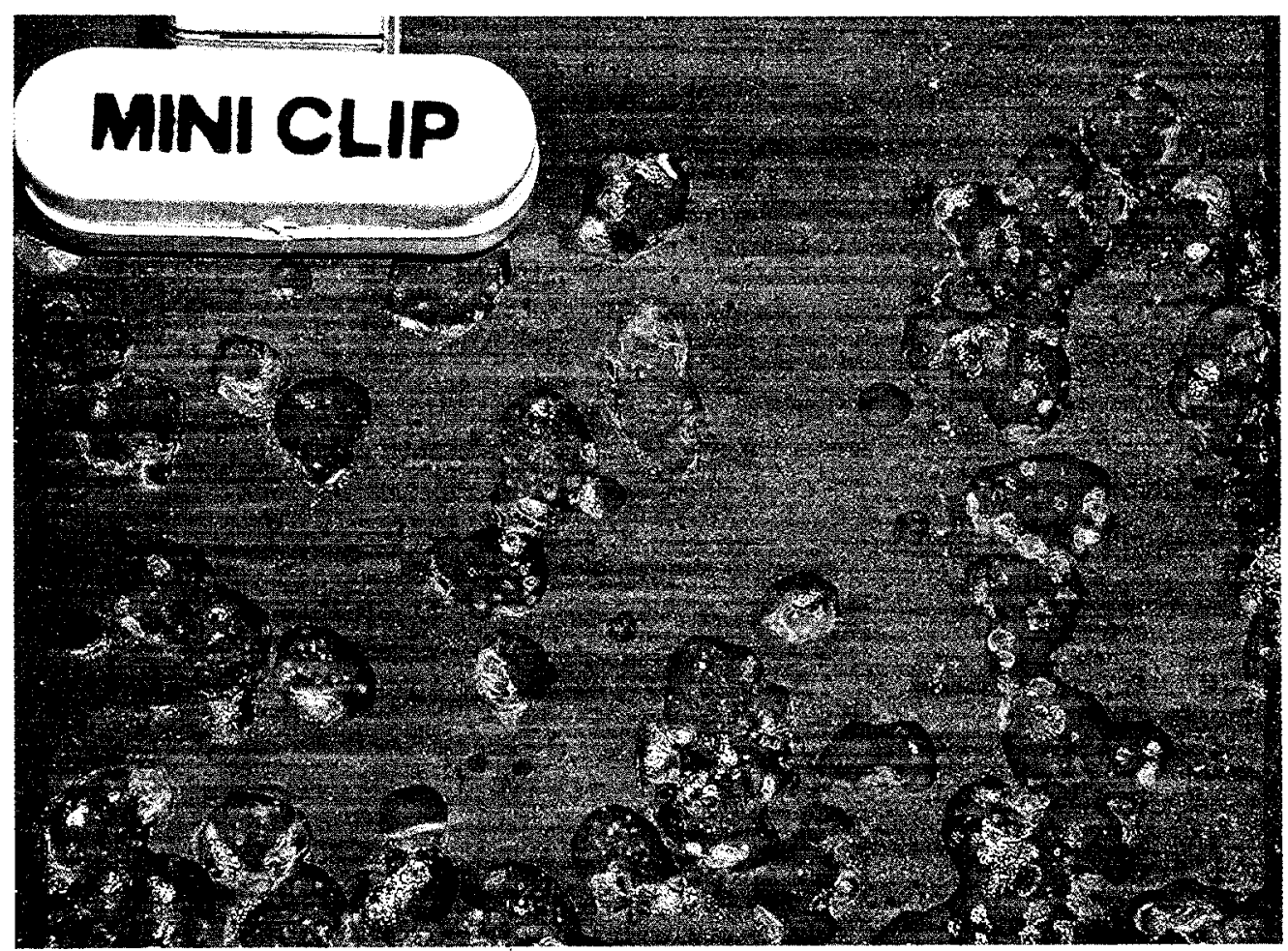

Fig. 24. Close-up view of isolated pitting on the digester shell. The magnetic clip at top left is $4 \mathrm{~cm}$ long at the widest point. Note that the flash rust locations are not always at the bottom (low point, as determined by gravity flow for moisture) of each pit.

All the indications in a given area are the same depth within the ability of non-destructive measurements to detect pit depth, classical pitting often has a wide range of pit depths and shapes. In fact, the characteristic depth of pits at various locations in the Kamloops digester is the same as that observed in similarly constructed digesters observed by the authors at different paper mills.

The walls and bottoms of the pits are uniformly smooth rather than rough and irregular.

With rare exception, there is little or no tendency to undercut the relatively passive areas adjacent to the pit; in classical pitting, occluded areas beneath the pit opening are common.

- Rather than get deeper as a function of increased exposure time, the pits observed here seem to spread laterally after reaching a certain characteristic depth; in electrochemical pitting, repassivation (if it occurs at all) would typically occur at the sides of the cell rather than at the bottom. 
- Electrochemical pits frequently have a "gravity" component to their shape due to the downward flow of the relatively thick and viscous fluid typically formed in a pit; the pits observed on the vertical shell walls of the digester have been uniformly round.

- Electrochemical pitting sometimes occurs in clusters, but there is some amount of cathodic protection provided by an active pit to the surrounding area. As a result, pits rarely would be expected to form the "oceans and islands" pattern observed here unless entire groups of pits can repassivate before others are initiated. If the pits are initiated at different times, however, it seems unusual that all would achieve the same characteristic depth prior to expanding laterally.

\subsection{HISTORICAL INSPECTION DATA AVAILABLE FROM KAMLOOPS}

\subsubsection{Photographic Documentation}

During inspections that occurred in 1996, 1997, and 1999, photographs were collected from intersections of the RS and LS welds inside the vessel. Comparison of the photographs at specific locations as a function of time suggests that much of the corrosion damage observed during the June 2000 inspection occurred prior to the 1996 inspection. For example, Fig. 25 shows two photographs of the "T" intersection of LS 10 and RS7. The photograph taken in 1996 is remarkably identical to the one taken in 1999, and many individual pits can be identified in the 1996 photograph that are unchanged in the 1999 photograph. The depth of the pits is, of course, not obvious from the photographs but there are a few clues that the diameter of many pits may have increased slightly over the three-year span indicated here. Note in particular the relative spacing between pits in some clusters - potential deception of camera angle and distance aside, it seems likely that the pit diameter has increased slightly over the three-year span between photographs. Two additional examples are shown in Fig. 26 (RS6/LS7) and Fig. 27 (RS2/LS4). In general, pictures of the RS/LS intersections in years after 1999 are not as informative because many of the weld seams were ground and weld repaired between 1997 and 1999. As a result, details previously visible are no longer available to track as a comparison through time. 


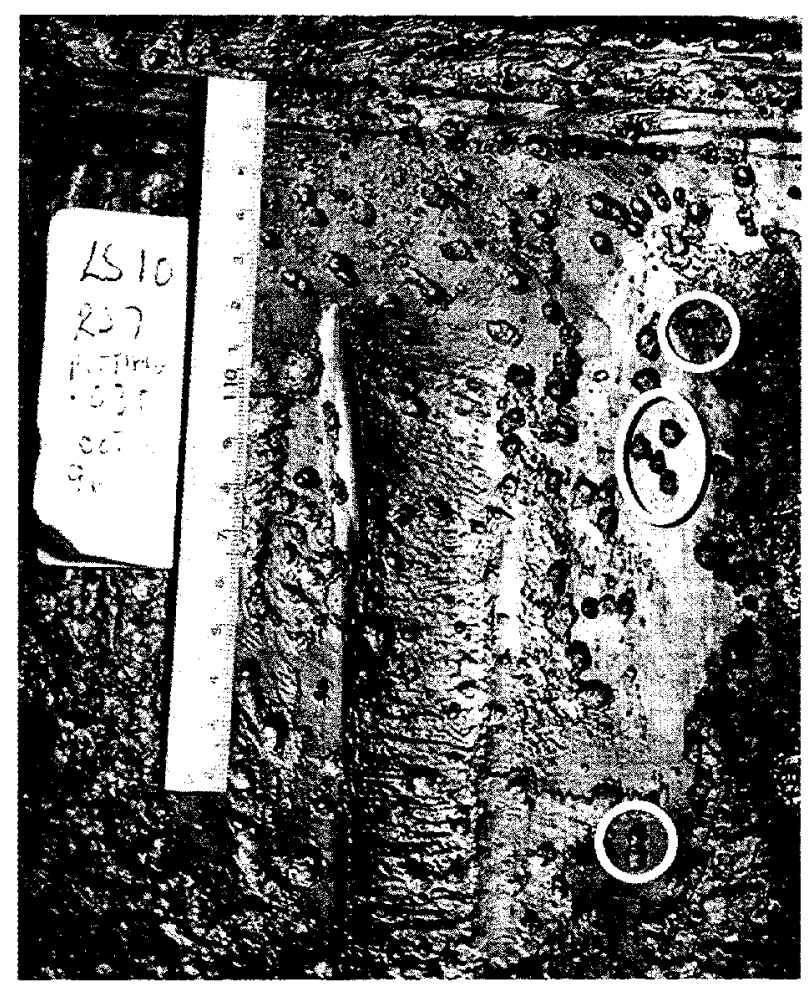

$$
\begin{aligned}
& \text { RS7/LS10 } \\
& 1996 \text { photo }
\end{aligned}
$$

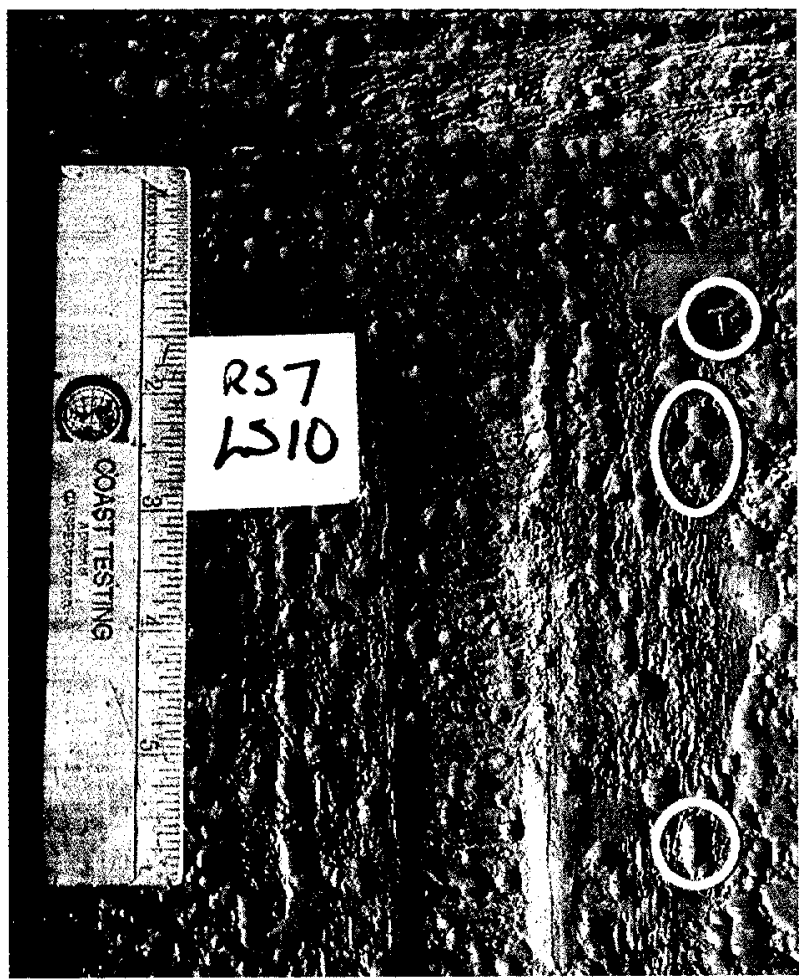

$$
\begin{aligned}
& \text { RS7/LS10 } \\
& 1999 \text { photo }
\end{aligned}
$$

Fig. 25. Intersection of RS7 and LS10 in 1996 (top) and 1999 (bottom). Example locations with features to compare are circled. 


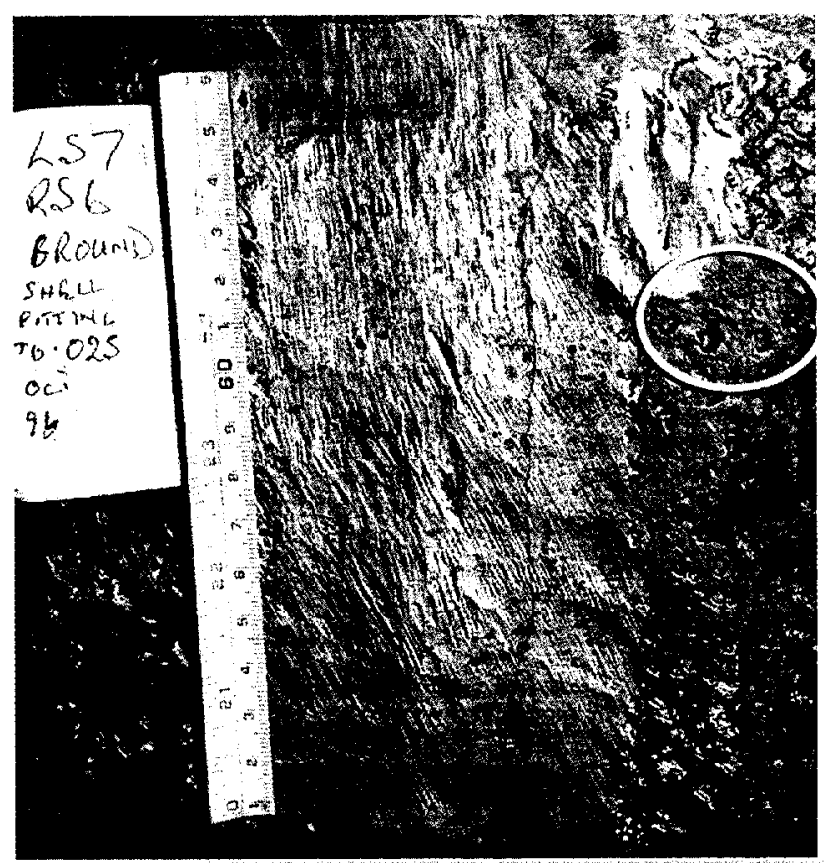

RS6/LS7

1996 photo

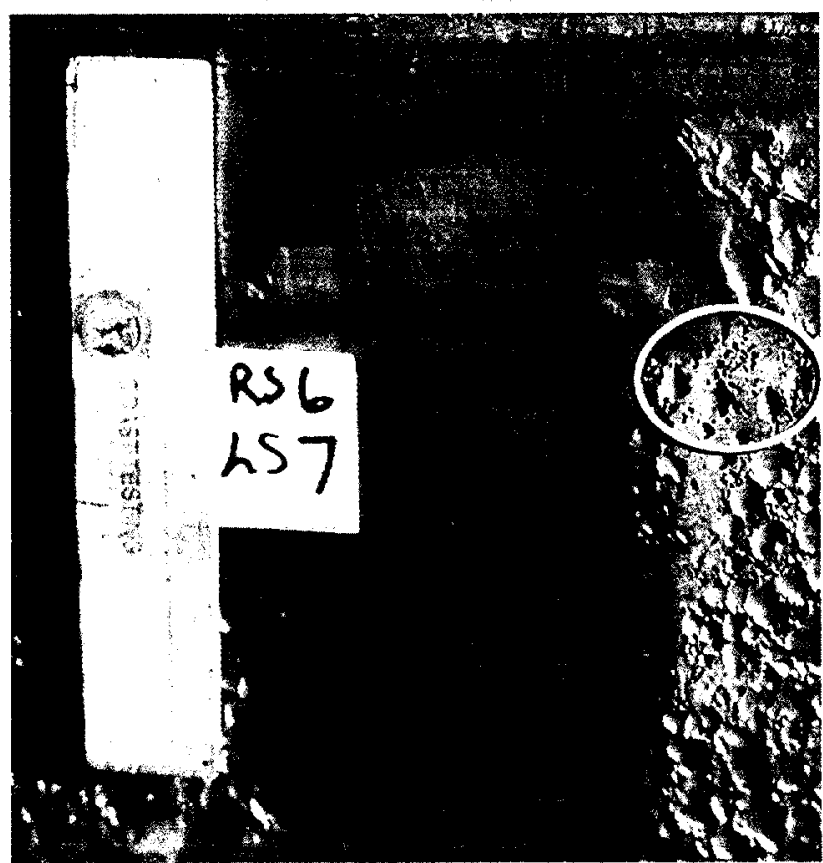

RS6/LS7

1999 photo

Fig. 26. Intersection of RS6 and LS7 in 1996 (top) and 1999 (bottom). Note in particular the smooth weld bead surface and the circled row of pits. 


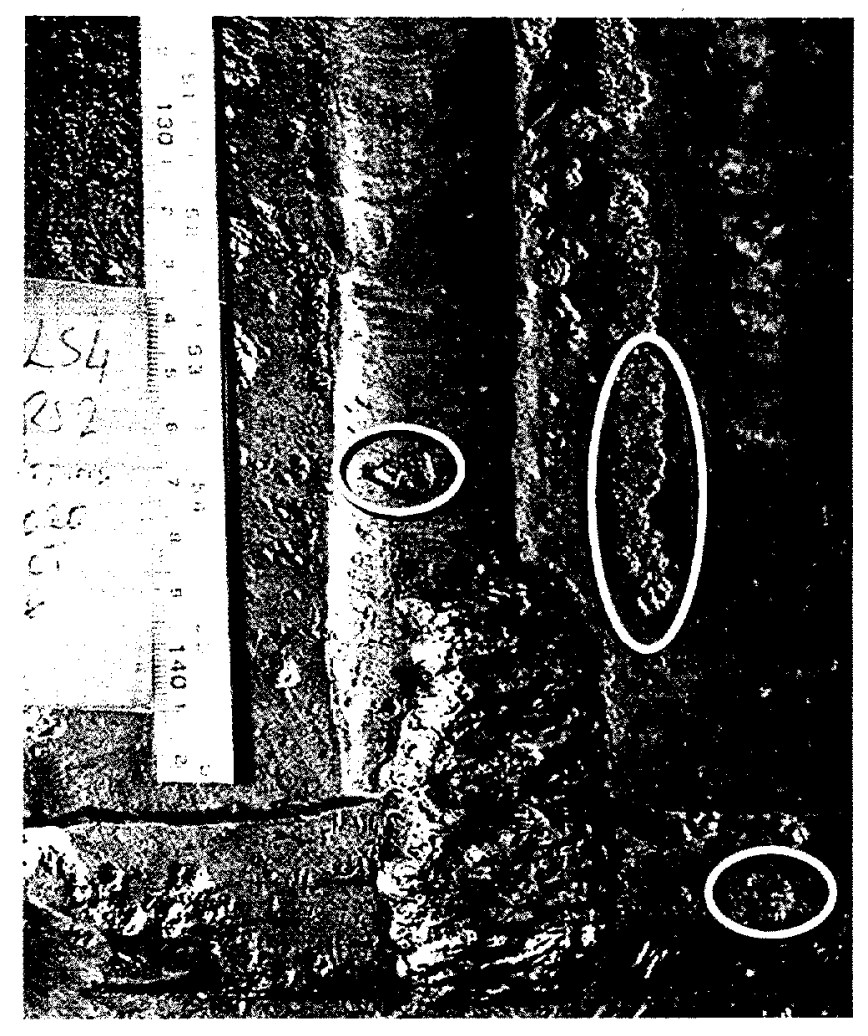

\begin{tabular}{|l|}
\hline RS2/LS4 \\
1996 photo
\end{tabular}

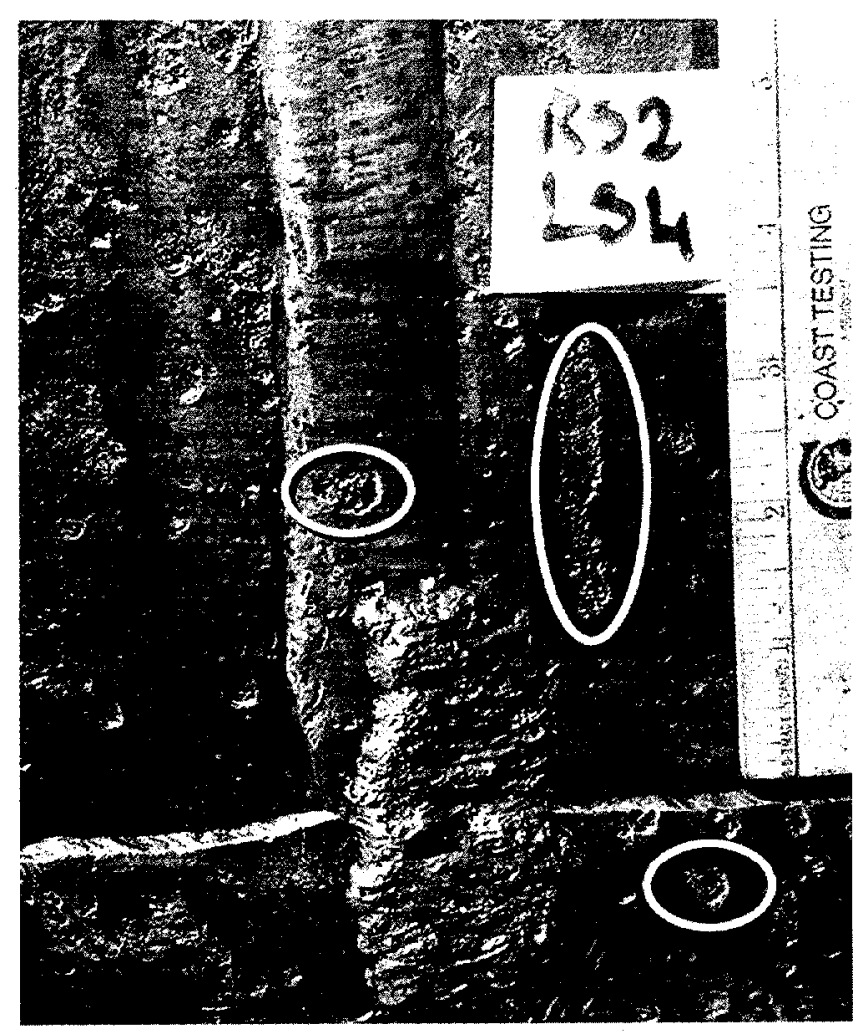

RS2/LS4

1997 photo

Fig. 27. Intersection of RS2 and LS4 in 1996 (top) and 1997 (bottom). Examples of locations to compare features are circled. 
Among the other historically available photographs is an interesting one from 1999 (Fig. 28). It shows an "island)) of unattacked material in a large "ocean" of corroded material in the upper right comer, and is a particularly good view of the step-function nature of the transition from uncorroded material (perfectly flat/smooth) to material recessed by $1 \mathrm{~mm}$ or more. This region was also photographed in several other inspections, and has remained unchanged since 1996.

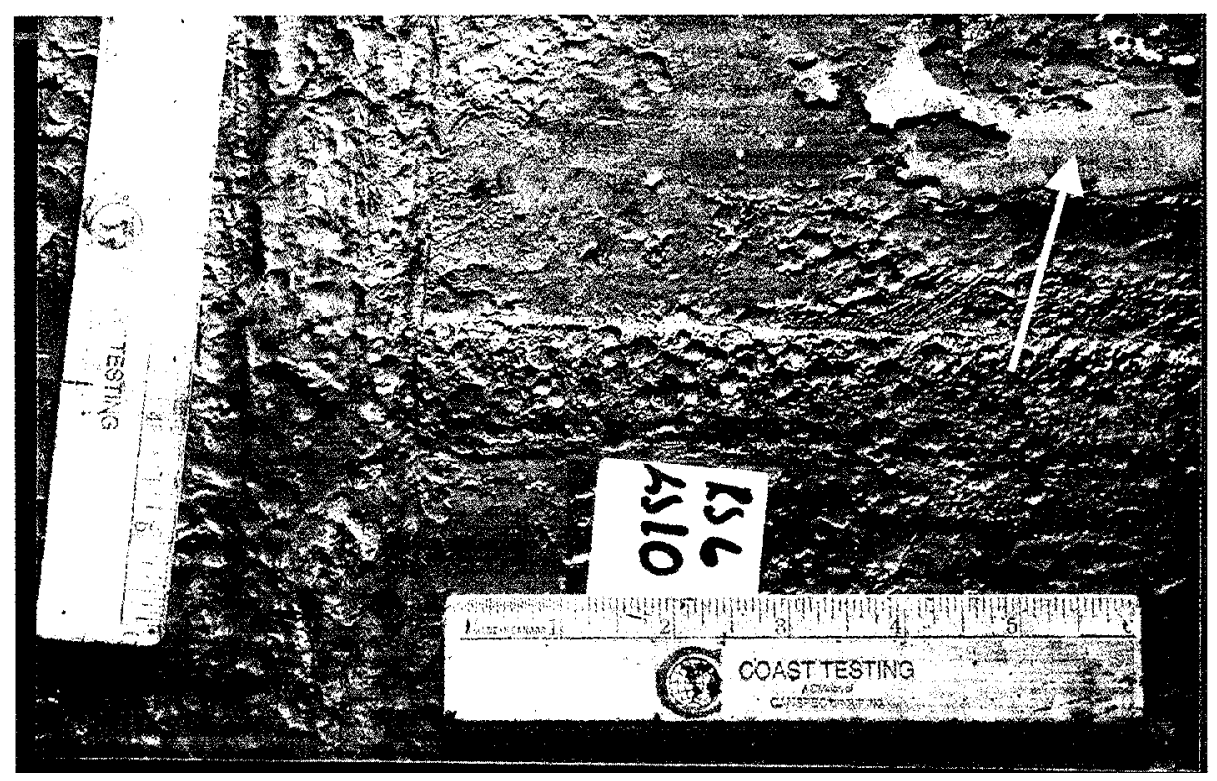

Fig. 28. 1999 inspection photograph of the RS6/LS10 intersection. Note the "island" of smooth shell surface in the upper right of the photograph, which stands about $1 \mathrm{~mm}$ (40 mils) above the surrounding corroded area.

In 1997, a photo survey was generated to record the general condition of the shell as a function of position. While none of the photographs have wall thickness data associated directly with them, they depict relative pitting patterns as a function of position within the digester and they demonstrate that the extent of corrosion observed at the June 2000 inspection is largely unchanged from 1997. 


\subsubsection{Ultrasonic Wall Thickness Data}

Digester shell thickness data has been collected at each maintenance outage since start-up of the vessel. Unfortunately, the original (as-fabricated) steel thickness was not documented, so it is not possible to use the historical records to determine the absolute extent of thinning or even general corrosion rates without some estimation involved. Further, Weyerhaeuser personnel have indicated there are other factors that complicate interpretation of wall thickness data, such as variable surface preparation and inconsistent measurement strategy - that is, uncertainty whether data was collected routinely from "ocean" or "island" positions when pitting is in the measurement area. Nevertheless, wall thickness data collected at annual inspections can be used to assess corrosion trends at various locations in the vessel.

With these caveats, the data collected by Weyerhaeuser indicates that the highest corrosion rates in the digester - on the order of 0.4-0.5 mm/y (15-20 mils/y) - are expected in a band just above the extraction screens. Note that no probes were located in that area for this experiment. Probes \#1 and \#5 were located in regions associated with $<0.25 \mathrm{~mm} / \mathrm{y}$ ( $<10 \mathrm{mils} / \mathrm{y}$ ) of wall thinning, while Probes \#2, \#3, and \#4 were all in regions experiencing about 0.25-0.4 mm/y (10-15 mils/y) thinning. Some specific data will be cited in the "post-experiment" analysis.

\subsubsection{Electrochemical Potential}

Representative potential data collected from the first several years of digester operation was provided to ORNL by the Weyerhaeuser Kamloops staff. The reference electrode was molybdenum (establishes Mo/MoS equilibrium) and the working electrode was a piece of mild steel similar to the digester construction material. A summary of the trends depicted in the data is given in Table 1. As will become apparent in subsequent discussion, the ECN potential data collected in this experiment indicates somewhat different trends than the data shown in Table 1. Obviously, the present ECN experiment and the former potential survey collected data at different operating times, which means that the digester may have been exposed to different conditions during the respective periods of data collection. In addition, the reference electrodes used in each experiment (Mo/MoS and $\mathrm{Ag} / \mathrm{Ag}_{2} \mathrm{~S}$ ) exhibit sufficiently different responses to the environment such that certain trends may be obscured as a consequence of reference electrode selection. 
Table 1. Snapshot of potential data from the Kamloops digester during February 2000. All potentials are given with respect to a molybdenum (Mo/MoS) electrode.

\begin{tabular}{|l|l|l|l|l|}
\hline Position & $\begin{array}{l}\text { Nominal } \\
\text { potential, } \mathrm{mV}\end{array}$ & $\begin{array}{l}\text { Range of } \\
\text { potential, } \mathrm{mV}\end{array}$ & $\begin{array}{l}\text { Trend in } \\
\text { potential }^{a}\end{array}$ & Anticipated corrosion $^{b}$ \\
\hline Probe \#1 & +32 & $+20 /+45$ & Steady & $\begin{array}{l}\text { Mild/moderate thinning; } \\
\text { pitting }\end{array}$ \\
\hline Probe \#2 & +20 & $-5 /+30$ & Steady & $\begin{array}{l}\text { Mild/moderate thinning; } \\
\text { pitting }\end{array}$ \\
\hline Probe \#3 & +18 & $-30 /+30$ & $\begin{array}{l}\text { Moderately } \\
\text { noisy }\end{array}$ & $\begin{array}{l}\text { Mild/moderate thinning; } \\
\text { pitting }\end{array}$ \\
\hline Probe \#4 & +10 & $-45 /+45$ & Very noisy & $\begin{array}{l}\text { Mild/moderate thinning; } \\
\text { pitting; tends to passivate }\end{array}$ \\
\hline Probe \#5 & -82 & $-85 / 0$ & Very noisy & $\begin{array}{l}\text { Moderate to heavy } \\
\text { thinning; pitting }\end{array}$ \\
\hline
\end{tabular}

"In this description, "noisy" implies many rapid changes and significant fluctuations within the indicated range of potentials.

${ }^{b}$ The "anticipated corrosion" is the assessment offered by the consulting firm interpreting the potential data and is based on analysis of polarization curves performed using the working electrode compared to the typical free potential at that location.

\subsection{REPRESENTATIVE ECN AND OPERATIONAL DATA}

\subsubsection{Data Analysis and Interpretation}

The ECN data collected over the entire year-long experiment was examined in an attempt to find specific events or periods of time in which probe corrosion - and therefore digester shell corrosion - changes from the nominal level of activity. Ultimately, the goal of the effort is to correlate changes in corrosion activity with specific operational characteristics of the digester and eliminate/minimize conditions contributing significantly to corrosion.

For the present experiment, the data was evaluated for such changes/events in two ways. Primarily, the electrode potential and current activity was examined graphically as a function of time (4-6 week segments) to look for significant/sustained changes in electrode potential or current activity. Time periods in which these changes were detected were compared to graphical representations of each of the operational variables (temperatures, flow rates, liquor composition, 
etc.) that are tracked and recorded by the mill. In this fashion, an attempt was made to correlate periods of relatively high corrosion rate with specific operational variables. In addition to using graphical trends to identify periods of corrosion activity corresponding to changes in operational parameters, the data was also evaluated via correlation coefficient analysis for all pairs of process variables with several delay times considered. [This analysis is described more fully in a subsequent section.]

A discussion about how current activity was interpreted for the purposes of this evaluation is appropriate. The value of current generated by the probes is a complex - and not necessarily straightforward - number. The current value at any sampling interval is the net current detected flowing through the zero-resistance ammeter (ZRA) connecting the nominally identical working electrodes. Depending on which electrode is momentarily active compared to the other electrode, current can flow from electrode A toward electrode B as well as in the opposite direction. As a result, ECN current can be either "positive" or "negative" with - for the present discussion - no particular significance attached to the sign of the current flow.

Several factors influence the magnitude of the current detected by the ZRA. For example, in any corrosion reaction, there are necessarily areas of both anodic and cathodic activity. If an individual working electrode is sufficiently large, at least some of the corrosion current will be consumed on the surface of the electrode (discreet anodes and cathodes on the same surface) and thus a portion of the corrosion current does not pass through the ZRA and is not detected by the system electronics. In principle, electrode size is an important design feature of an ECN system, with some balance required between the advantages of relatively large electrodes and very small ones, Larger electrodes come closer to representing real surfaces (inclusions, surface roughness, surface deposits/films, composition gradients, etc.) than do small electrodes, but as the surface area of the electrodes increases, the likelihood that the current selfterminates (anodes and cathodes on the same surface) also increases. Further, the expected signal-to-noise ratio may influence electrode size requirements; for example, a strongly passive system might require a very large electrode surface to cultivate the required signal. Finally, for pulping liquor corrosion, another electrode size/condition factor might be how readily various reactions take place which do not directly contribute to the corrosion reaction. For example, reduction/oxidation reactions involving sulfur species may contribute some electrons detected by the ZRA without directly participating in corrosion of the steel vessel. As long as the electrodes are reasonably similar to the structure they are to simulate (similar roughness, composition, film 
catalytic effects), it is assumed - for this discussion - the amount of indirect contribution is essentially constant and in the "white noise" of current activity (meaning equal probability of happening on either electrode and thus a factor that largely "cancels" from the current measurement). Further, as will be shown later, the potential experienced by each probe is not appropriate for large current contributions from side reactions involving sulfur species.

Ultimately, there is no known "formula" to determine a precise electrode size that is most appropriate for a given system. The literature is replete with examples of successful ECN applications with electrode sizes between 0.5 and $5 \mathrm{~cm}^{2}$ and there is no reason to expect that such a size is inappropriate for the present experiments. The electrode size chosen for the digester probes basically represents the largest working surface that could be tit onto a probe (two working electrodes, a reference electrode, and temperature measurement capability on the same surface) that mated into a $38-\mathrm{mm}$ diameter port.

In some of the graphs that follow, the ECN current is plotted as the absolute value of the current detected by the ZRA. Nominally, the ECN current signal oscillates in a largely random fashion about the value of zero (net current flows back and forth between nominally identical electrode surfaces). However, as the magnitude (not the sign) of current activity is of prime importance to identify operational parameters causing increases in general corrosion activity, the absolute value of current is often plotted for ease of presentation. [In particular, when the ECN signals suggest a general corrosion mechanism, the relative sign of the current has no significance at all. In the case of pitting or stress-corrosion cracking, the sign of the current (indicating a particular electrode) can be part of the interpretation. The corrosion activity in the Kamloops digester, at least during the period of this test, was exclusively general corrosion. More on that topic appears in discussion to follow.]

The sums of absolute current over a specific period of time can be related - albeit in a somewhat crude fashion - to the corrosion rate experienced by the probes (and, in principle, the nearby digester wall). In order to develop such a relationship, certain simplifying assumptions are required. First, the total current must be consumed uniformly over the entire exposed surface area of each pair of electrodes $\left(1.42 \mathrm{~cm}^{2}\right.$ for each probe). Essentially, this means that no localized corrosion - such as pitting or stress-corrosion cracking - is occurring (confirmed with polarization curves and post-test analysis of probes) and therefore current is related directly to thinning via general corrosion. In order to relate the current to mass loss and uniform thinning, it 
was assumed that the iron oxidizes from $\mathrm{Fe}$ to the $\mathrm{Fe}^{+2}$ state in all cases. Using these assumptions, the total current flow (summed in absolute value) over any period can be related to corrosion rate via Faraday's Law (see Appendix A). Since not all the current for any reaction passes through the ZRA, and some amount of the current that does pass through the ZRA is related to redox reactions, the value so calculated essentially represents only a relative estimate of corrosion rate. It will be shown, however, that for the conditions experienced in the Kamloops digester, that this corrosion rate estimate is very consistent with post-test analysis of the probes and with historical values of corrosion in the vessel.

\subsubsection{General Characteristics}

Because Probe \#5 was the least active among all the probes in terms of corrosion noise, examination of data from this probe is instructive for understanding general characteristics. For example, Fig. 29 shows that the nominal potential of the steel at the position of Probe $\# 5-$ for the month of December - was approximately $-140 \mathrm{mV}$ vs. $\mathrm{Ag} / \mathrm{Ag}_{2} \mathrm{~S}$, which corresponds roughly to a value of $-1020 \mathrm{mV}$ vs. SCE [8]. During the final few days of November shown on Fig. 29, there is a large transient associated with shutdown and start-up activity - this transient is included here for contrast with the more nominal behavior but will be discussed in a separate paragraph. The potential was relatively stable at about $-140 \mathrm{mV}$ vs. $\mathrm{Ag} / \mathrm{Ag}_{2} \mathrm{~S}$ over the duration of the experiment, and exhibited only about ten brief (minutes to a few hours in duration) potential spikes to more positive potential over the entire month of December. For the specific interval shown in Fig. 29, the potential typically spiked to the range of -50 to $-100 \mathrm{mV}$ vs. $\mathrm{Ag} / \mathrm{Ag}_{2} \mathrm{~S}$, although very occasionally a potential spike to almost $0 \mathrm{mV}$ vs. $\mathrm{Ag} / \mathrm{Ag}_{2} \mathrm{~S}$ was observed during other time periods.

Figure 29 also shows that there was a corresponding current response (shown here in absolute value; see discussion in section above) associated with each potential excursion. Generally speaking, the current noise associated with probe \#5 for the month of December was very modest at approximately a milliamp or less. The largest current spikes for Probe $\# 5$ in December were to approximately 10 milliamps. 


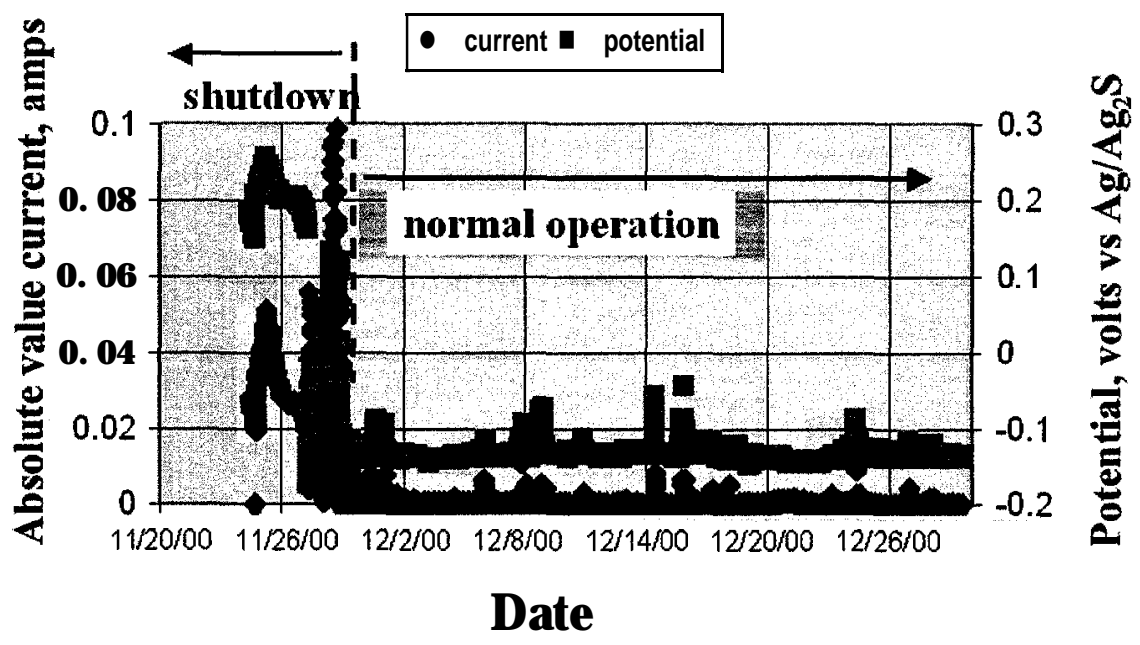

Fig. 29. Representative ECN data for Probe \#5.

The December corrosion activity indicated for Probe \#5 is exclusively general corrosion. Figure 30 is a polarization curve for mild steel in liquor removed from the wash zone (near the position of Probe \#5) in the Kamloops digester. It indicates that at the observed nominal potential for Probe \#5, the system is expected to be corroding modestly and in a general fashion at the open circuit potential. All of the potential spikes observed for Probe \#5 fall in/around the active "nose" of the polarization curve, and none achieve a sufficient potential to fall in the traditional passive range as indicated by the polarization behavior. Similarly, since pitting is associated with potentials even more positive than the passive range, the ECN data in Fig. 29 also predicts no pitting activity. As will be discussed in a subsequent section, the post-test analysis of the surfaces of Probe \#5 confirmed only extremely modest general corrosion and no pits. Further, the upper portion of the anodic polarization curve shown in Fig. 30 -the portion above about $-800 \mathrm{mV}$ vs. SCE - has a shape that is controlled largely by the scan rate and the liquor composition and is usually associated with redox reactions involving sulfur species in pulp-making liquors. In the range of potentials experienced by Probe \#5, the polarization curve indicates the current contribution from these redox reactions should be very small. 


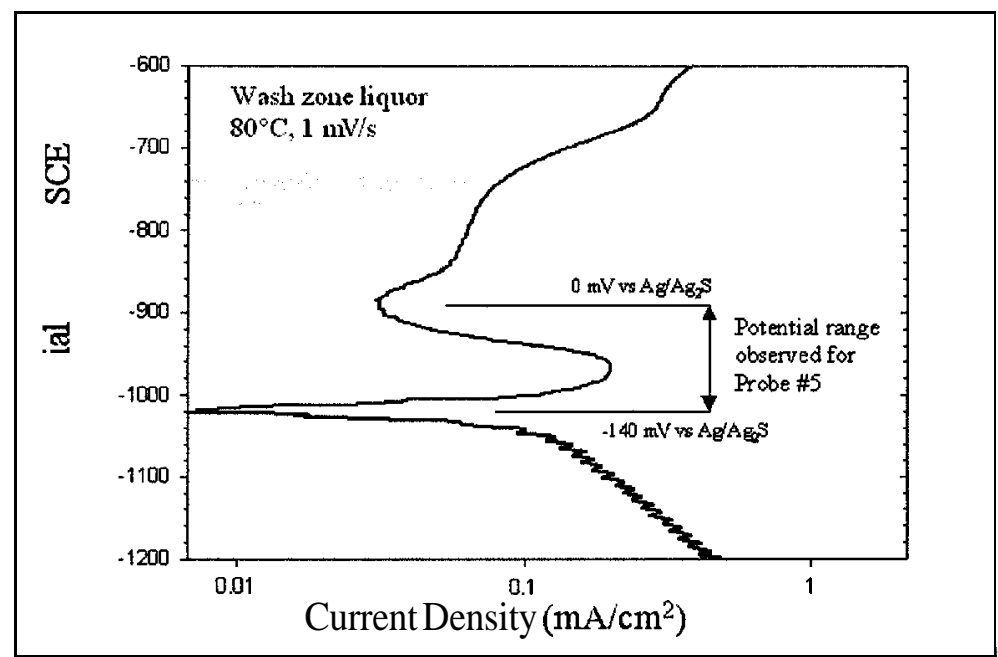

Fig. 30. Polarization curve for mild steel in wash zone liquor removed from the Kamloops digester.

In contrast to Probe \#5, the current and potential activity of Probe \#3 were much more variable over the period of investigation. Figure 31 shows a representative snapshot of ECN data for Probe \#3. [Like the data in Fig. 29, a large current/potential excursion is included for contrast with more nominal behavior. This will be discussed in relation to shutdown and start-up transients in a subsequent paragraph.] In the case of Probe \#3, the potential shifts rapidly and almost constantly between about $0 \mathrm{mV}$ and $80 \mathrm{mV}$ vs. $\mathrm{Ag} / \mathrm{Ag}_{2} \mathrm{~S}$ over the period of the experiment, with periodic spikes to about $180 \mathrm{mV}$ vs. $\mathrm{Ag} / \mathrm{Ag}_{2} \mathrm{~S}$. The current activity shows largely white noise around very low -but not precisely zero - current, and large bursts of current activity associated with the potential spikes.

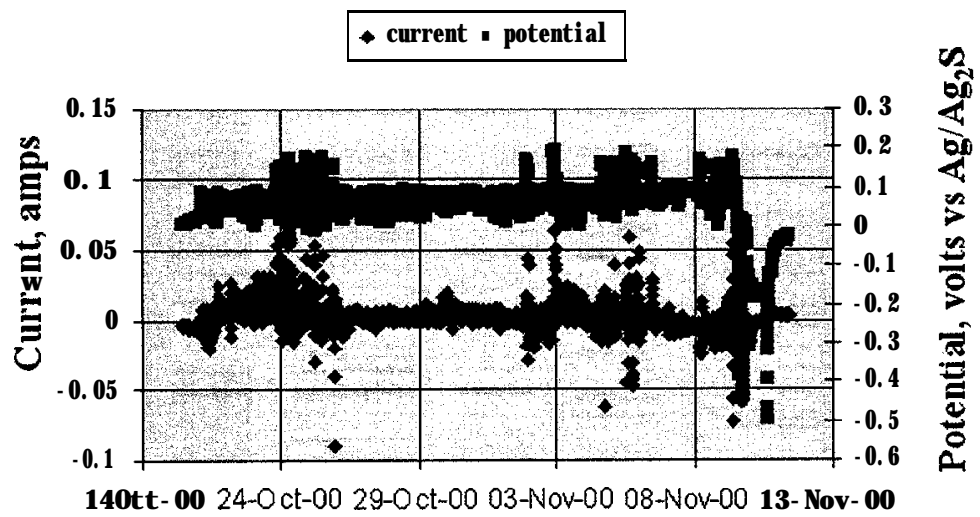

Date

Fig. 31. Representative ECN data for Probe \#3. 
A polarization curve for mild steel in lower extraction zone liquor (removed from the digester at a location near Probe \#3) is shown in Fig. 32. It shows that the nominal potential range of Probe \#3 (O-80 mV vs. $\mathrm{Ag} / \mathrm{Ag}_{2} \mathrm{~S}$ ) falls within the passive range of behavior for steel. The potential spikes to about $180 \mathrm{mV}$ vs. $\mathrm{Ag} / \mathrm{Ag}_{2} \mathrm{~S}$ (shown in Fig. 3 1) routinely generate large current responses, but current at this potential has a large component resulting from redox reactions involving sulfur in addition to perhaps some mildly transpassive behavior.

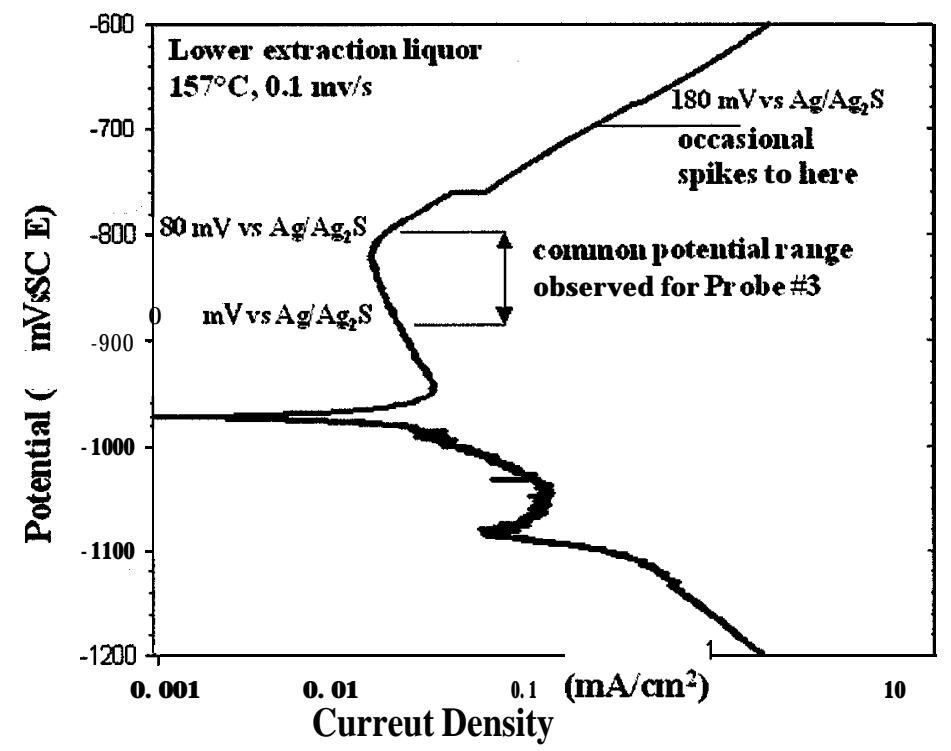

Fig. 32. Polarization curve for mild steel in lower extraction liquor removed from the Kamloops digester.

Data for other probes (\#1,\#2, and \#4) tend to fall between the extremes exhibited by Probes \#5 and \#3, except that the potential noise associated with Probe \#1 is typically very modest. Table 2 summarizes the potential trends observed in the ECN data. Although direct comparison with data from Table 1 is complicated by a difference in reference electrode and time period of operation, it is nevertheless clear that the results indicate significantly different trends. For example, conversion of potentials to a common base aside, the former data (Table 1) indicates a total range of nominal potentials for probe positions \#1-4 of about $20 \mathrm{mv}$, with position \#1 yielding the highest potential. The ECN data in Table 2 indicate a much larger nominal potential range among these positions (about $140 \mathrm{mv}$ ), with position \#3 at the highest value by a significant amount. Further, because of the similarity of potentials and small total 
range of potential at each position, the shell corrosion behavior at positions \#1-4 generated by Table 1 is very similar, which is clearly not the historical trend. As will be shown throughout this document, the ECN probes generated results consistent with the present and historical corrosion patterns.

Table 2. Comparison of ECN potential values for the ECN probes. All potentials are given relative to $\mathrm{Ag} / \mathrm{Ag}_{2} \mathrm{~S}$. Potentials achieved during shut-down and restart transients are not included here.

\begin{tabular}{|l|l|l|l|l|l|}
\hline & Probe \#1 & Probe \#2 & Probe \#3 & Probe \#4 & Probe \#5 \\
\hline $\begin{array}{l}\text { Nominal } \\
\text { potential" }\end{array}$ & $\begin{array}{l}\mathbf{- 6 0} \mathrm{mv} \\
\text { steady }\end{array}$ & $\begin{array}{l}-10 \mathrm{mv} \\
\text { steady }\end{array}$ & $\begin{array}{l}\mathbf{+ 5 0 - 8 0} \mathrm{mv} \\
\text { noisy }\end{array}$ & $\begin{array}{l}\mathbf{0 - 3 0} \mathrm{mv} \\
\text { noisy }\end{array}$ & $\begin{array}{l}-140 \mathrm{mv} \\
\sim \text { steady }\end{array}$ \\
\hline $\begin{array}{l}\text { Maximum } \\
\text { potential }^{b}\end{array}$ & $\mathbf{- 4 5} \mathrm{mv}$ & $+100 \mathrm{mv}$ & $+180 \mathrm{mv}$ & $+90 \mathrm{mv}$ & $-50 \mathrm{mv}$ \\
\hline $\begin{array}{l}\text { Minimum } \\
\text { potential }^{b}\end{array}$ & $\mathbf{- 7 0} \mathrm{mv}$ & $\mathbf{- 3 5} \mathrm{mv}$ & $-30 \mathrm{mv}$ & $-60 \mathrm{mv}$ & $-160 \mathrm{mv}$ \\
\hline
\end{tabular}

"Nominal potential is the value - determined by graphical estimation - at which the potential is most likely to be found during digester operation. An indication of "steady" indicates that there are not rapid/frequent potential changes during normal operation, while a designation of "noisy" indicates there are routine large potential fluctuations.

'Maximum and minimum potentials are not absolute values but rather the values consistently achieved on a periodic basis for more than instantaneous duration.

\subsubsection{Effect of Temperature}

In this section, information about the temperature data recorded over the duration of the experiment is presented. The purpose of the information is to document representative temperature measurements made during the experiment and to permit consideration of the possible role of temperature and temperature changes as they influence the ECN data, particularly when compared with other competing or "coincident" changes occurring in the digester.

The temperature at Probe $\# 5$ was nominally $60^{\circ} \mathrm{C}$ over the entire experiment. However, the temperature periodically spiked upward to a value of $90^{\circ} \mathrm{C}$ or greater for periods of minutes to a few hours. The reasons for the large and sudden swings in the temperature at the position of 
Probe \#5 are complex. Basically, Probe \#5 is located close to a thermocline that is determined by the hydraulic balance in the digester. Periodically, as many as several times a day, the position of this "boundary" between hot liquor and cooler wash solutions shifts a meter or two in response to the various in/out flows of the process, and the thermocouple in Probe \#5 readily detects each change. As will be shown in a subsequent paragraph, the temperatures at the respective positions of the other probes do not exhibit this type of variability, either in frequency or magnitude.

A representative temperature profile for Probe \#5 is shown in Fig. 33 - along with the corresponding potential data - and is plotted such that only the largest temperature spikes appear on the graph (temperatures over $100^{\circ} \mathrm{C}$ ). Again, focusing on the December data for the present (and omitting the transient at the end of November), plotting in this fashion makes it obvious that the potential/current noise activity is associated directly with the swings in temperature at this position in the digester. The trend for Probe $\# 5$ is that a AT of at least $40-50^{\circ} \mathrm{C}$ is required to generate a potential spike of $10 \mathrm{mV}$, with larger AT associated with larger potential spikes.

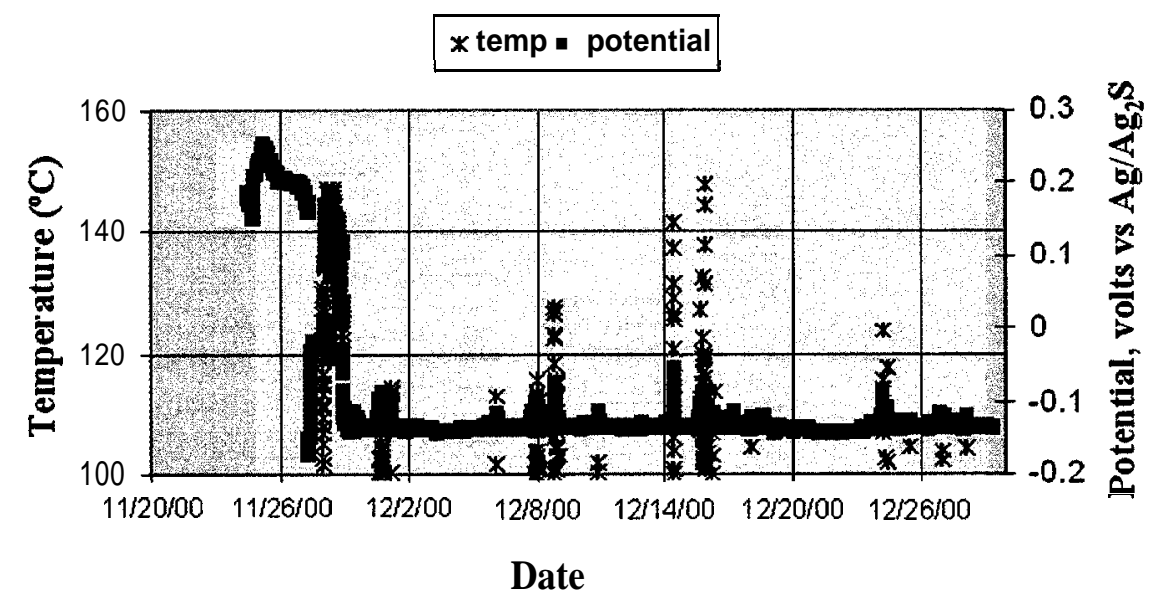

Fig. 33. Temperature and potential data for Probe \#5.

The nominal variation in temperature at the probe positions during operation is represented by the data in Fig. 34. The curves in Fig. 34 present data for Probe \#4 and Probe \#5 for a week early in February. Data for Probe $\# 1\left( \pm 5^{\circ} \mathrm{C}\right.$ around average), Probe $\# 2\left( \pm 5^{\circ} \mathrm{C}\right)$, and Probe $\# 3\left( \pm 8^{\circ} \mathrm{C}\right)$ were much less variable than Probe $\# 4$, but the temperatures were so generally similar that plotting on the same axis yields only clutter and largely indistinguishable curves. 


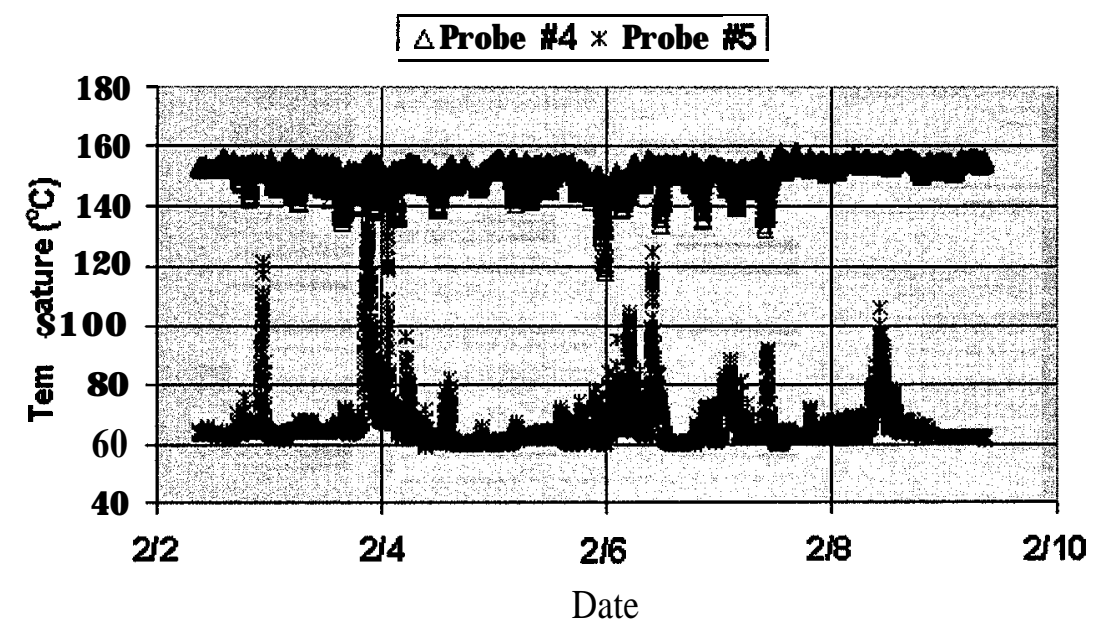

Fig. 34. Nominal variation in temperature for Probes \#4 and \#5.

These data indicate that the temperature at Probes \#1-\#4 had some modest variation with time that was largely independent of the large temperature swings associated with Probe \#5. In Table 3, some statistics for the data in Fig. 34 are presented which provide insight into the temperature variability at each probe position for the same week.

Table 3. Temperature statistics for the time interval depicted in Fig. 34.

\begin{tabular}{|c|c|c|c|c|}
\hline Probe \# & $\begin{array}{l}\text { Maximum } \\
\text { temperature }\left({ }^{\circ} \mathrm{C}\right)\end{array}$ & $\begin{array}{l}\text { Minimum } \\
\text { temperature }\left({ }^{\circ} \mathrm{C}\right)\end{array}$ & $\begin{array}{l}\text { Average } \\
\text { temperature }\left({ }^{\circ} \mathrm{C}\right)\end{array}$ & $\begin{array}{l}\text { Standard } \\
\text { deviation }\left({ }^{\circ} \mathrm{C}\right)\end{array}$ \\
\hline 1 & 154 & 143 & 148 & 1.3 \\
\hline 2 & 154 & 146 & 151 & 1.4 \\
\hline 3 & 159 & 140 & 153 & 3.3 \\
\hline 4 & 159 & 118 & 152 & 3.9 \\
\hline 5 & 136 & 59 & 66 & 8.7 \\
\hline
\end{tabular}


Figure 35 shows temperature data for a period in which the variation among Probes \#1\#4 (represented by Probe \#4) was unusually modest. Again, note that periodic significant variations in temperature at Probe \#5 had no influence on the temperature of Probe \#4 (nearest neighbor) or any of the other probes. In particular, the temperature spike for Probe \#5 on February 13 is the largest noted over the duration of the experiment for this probe, yet there is no coincident response for any of the other probes. Table 4 has relevant temperature statistics for the period shown in Fig. 35.

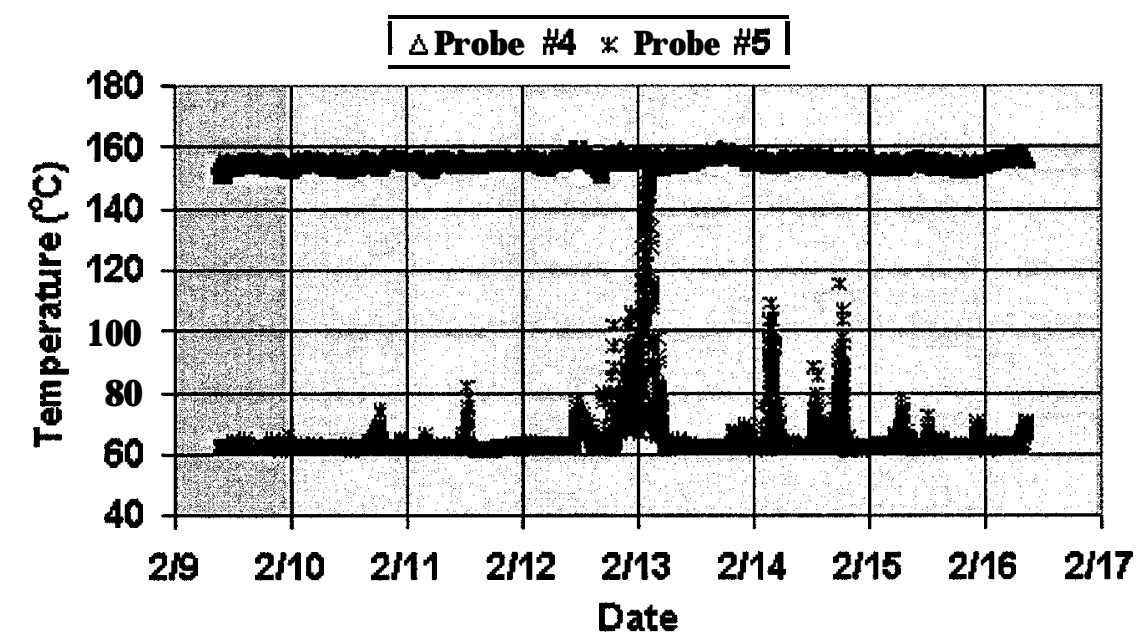

Fig. 35. Temperature profile for Probes \#4 and \#5 during a period of unusually modest variation.

Table 4. Temperature statistics for the time interval depicted in Fig. 35.

\begin{tabular}{|c|l|c|c|c|}
\hline Probe \# & $\begin{array}{l}\text { Maximum } \\
\text { temperature }\left({ }^{\circ} \mathrm{C}\right)\end{array}$ & $\begin{array}{l}\text { Minimum } \\
\text { temperature }\left({ }^{\circ} \mathrm{C}\right)\end{array}$ & $\begin{array}{l}\text { Average } \\
\text { temperature }\left({ }^{\circ} \mathrm{C}\right)\end{array}$ & $\begin{array}{l}\text { Standard } \\
\text { deviation }\left({ }^{\circ} \mathrm{C}\right)\end{array}$ \\
\hline 1 & 153 & 148 & 151 & 1.3 \\
\hline 2 & 158 & 151 & 154 & 1.9 \\
\hline 3 & 159 & 154 & 157 & 1.2 \\
\hline 4 & 159.5 & 151 & 155 & 1.2 \\
\hline 5 & 152 & 61 & 65 & 8.9 \\
\hline
\end{tabular}


Figure 36 shows yet another period of temperature data, which is representative of one of a very few extended significant temperature perturbations in the temperature of Probes \#1-\#4. As in previous graphs of this type, the temperature variation of Probe \#4, while not precisely the same as Probes \#1 - \#3, fairly represents the behavior of all four of these probes. Although the digester continued to operate in this period, a process upset apparently contributed to the roughly 24-h period of unusual temperature behavior. As before, relevant statistical data for the same period appears in Table 5.

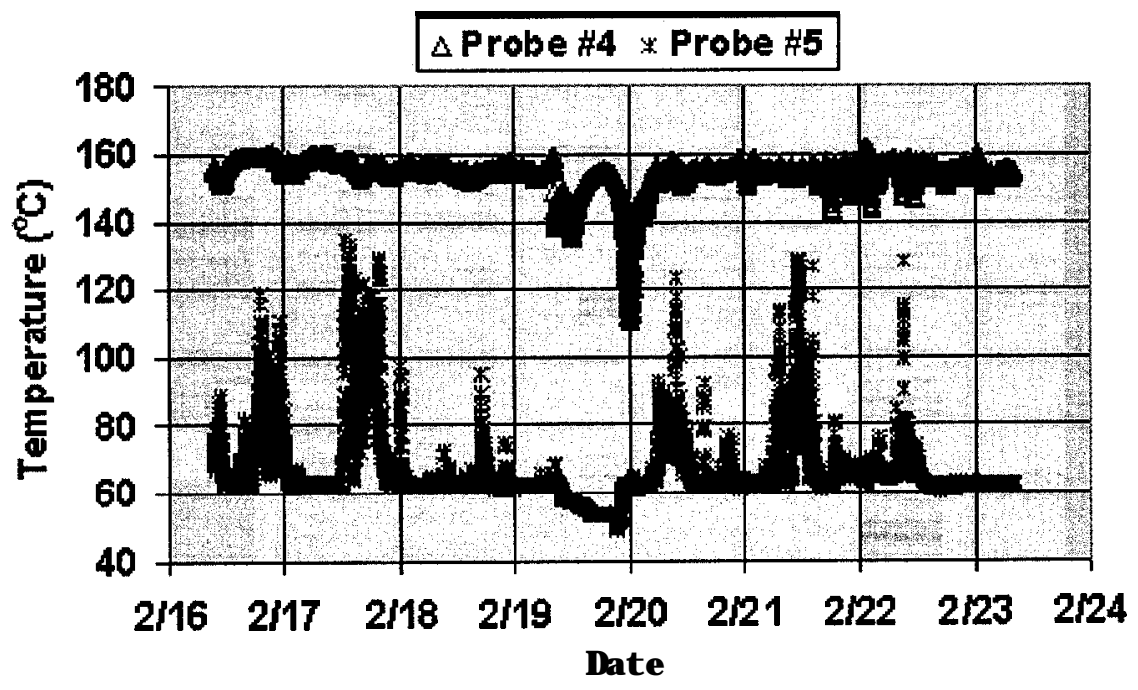

Fig. 36. Temperature profile for Probes \#4 and \#5 during a period with an extended temperature perturbation.

Table 5. Temperature statistics for the time interval depicted in Fig. 36.

\begin{tabular}{|c|c|c|c|c|}
\hline Probe \# & $\begin{array}{l}\text { Maximum } \\
\text { temperature }\left({ }^{\circ} \mathrm{C}\right)\end{array}$ & $\begin{array}{l}\text { Minimum } \\
\text { temperature }\left({ }^{\circ} \mathrm{C}\right)\end{array}$ & $\begin{array}{l}\text { Average } \\
\text { temperature }(\text { “ } \mathrm{C})\end{array}$ & $\begin{array}{l}\text { Standard } \\
\text { deviation }\left({ }^{\circ} \mathrm{C}\right)\end{array}$ \\
\hline \hline 1 & 160 & 131 & 151 & 2.6 \\
\hline \hline 2 & 163 & 146 & 155 & 2.8 \\
\hline \hline 3 & 160 & 138 & 156 & 3.1 \\
\hline 4 & 162 & 111 & 155 & 5.2 \\
\hline 5 & 135 & 49 & 67 & 11.5 \\
\hline
\end{tabular}


Due primarily to installation delays and problems with insulation, the external rings of thermocouples did not begin functioning properly until almost the end of March 2000. While only a relatively small amount of data is therefore available, the data collected by these rings do not suggest a significant temperature gradient around the circumference of the digester at a particular'elevation. For example, eleven of the sixteen thermocouples in the bottom ring (located just below the modified cooking screens, near the position of Probe \#4) faithfully tracked each other within about $5-8^{\circ} \mathrm{C}$ and within $2-3^{\circ} \mathrm{C}$ of the temperature measured internally at Probe \#4, including simultaneous response to minor temperature variations. Among the others at this position, two of the thermocouples registered temperatures excessive for the process possibilities (one at approximately $25^{\circ} \mathrm{C}$ higher than the average value at Probe $\# 4$, and the other was routinely more that $60^{\circ} \mathrm{C}$ higher than the expected value). No sources of external heat sufficient to account for these extremes could be located, and because it is not possible for the process temperature to be that much higher than the temperature of the input liquor, these two thermocouples were regarded as non-functional. However, it is noteworthy that these two thermocouples did tend to simultaneously respond to the same temperature variations/magnitudes as the group of 11 thermocouples generating the expected values.

Three of the thermocouples in the bottom ring, which were located together in a particular quadrant of the digester, all registered temperatures of $30-45^{\circ} \mathrm{C}$ less than the nominal value indicated by the group of 11 thermocouples with similar readings. The intent of the external thermocouples was to evaluate possible temperature gradients at a particular elevation, but there is no process data or history available to suggest the trend indicated by these three thermocouples (temperature variation of $>40^{\circ} \mathrm{C}$ ) is real. For example, the depth and distribution of the "oceans and islands" pitting pattern is uniform around the digester at this elevation (as it is at other elevations as well). However, no ultrasonic wall thickness data is available to assess possible uniform thinning that is over-and-above the pitting depth indicated. In discussion with Weyerhaeuser personnel, it was determined that these three thermocouples most likely were in poor thermal contact with the digester shell and that, while a small temperature gradient might be indicated, it was probably much smaller than $40^{\circ} \mathrm{C}$.

The upper ring of external thermocouples, located just below the extraction screens near the position of Probe \#3, also yielded somewhat erratic results. Ten of the sixteen thermocouples 
tracked each other and Probe $\# 3$ within about $5-8^{\circ} \mathrm{C}$, while two thermocouples (from opposite sides of the vessel) registered values $35-75^{\circ} \mathrm{C}$ lower. Four of the thermocouples (grouped in a quadrant) tracked something slightly above ambient temperature, and it is suspected that the external insulation was not replaced over these thermocouples following installation.

In sum the data presented in this section suggest that temperature (and temperature variation) is not a particularly significant factor in analysis of the ECN data for each probe and among probes. The trend is that Probes \#1-4 each exhibit relatively similar temperatures to each other and that the frequency of small temperature variations for each probe is much higher than the frequency of significant potential changes for each probe. Further, data for Probe \#5 indicates that temperature increases of at least $40-50^{\circ} \mathrm{C}$ are required to generate a $10 \mathrm{mV}$ shift in steel potential at that position. While a different potential dependence on temperature at other positions in the digester (exposed to more aggressive pulp/liquor) is expected, it seems clear that the temperature swings at each probe during digester operation are modest compared to the magnitude required to cause significant potential changes or otherwise significantly influence corrosion.

\subsubsection{Furnish Composition}

The furnish to a digester is the wood chip mass that is introduced for pulping. The furnish composition is typically described by the fraction of each type of wood in the charge, which is usually set by a combination of desired pulp/paper properties, local types of available wood, and wood pile management at the particular mill. At the Kamloops digester, the nominal furnish is approximately $40 \%$ spruce, $40 \%$ pine, and $20 \%$ Douglas fir. To influence pulp/paper properties for specific products, two other furnish compositions are occasionally utilized at Kamloops. One is referred to as "whitewood," which is simply a mixture of roughly $50 \%$ spruce and $50 \%$ pine and the other is termed "Douglas fir," with a typical composition of $>70 \%$ Douglas fir with the remainder approximately equal amounts of spruce and pine.

Analysis of the ECN data at Kamloops over the year-long experiment indicated that, among parameters for which data was collected, furnish composition was the most significant operational variable influencing corrosion activity. Figure 37 is representative of the potential data associated with Probe \#2 for all three furnish compositions. Note that the potential is fairly constant while pulping whitewood, slightly higher and somewhat more noisy (more spikes) while

pulping the normal furnish, and increases about $60 \mathrm{mV}$ in step-function fashion when the furnish 


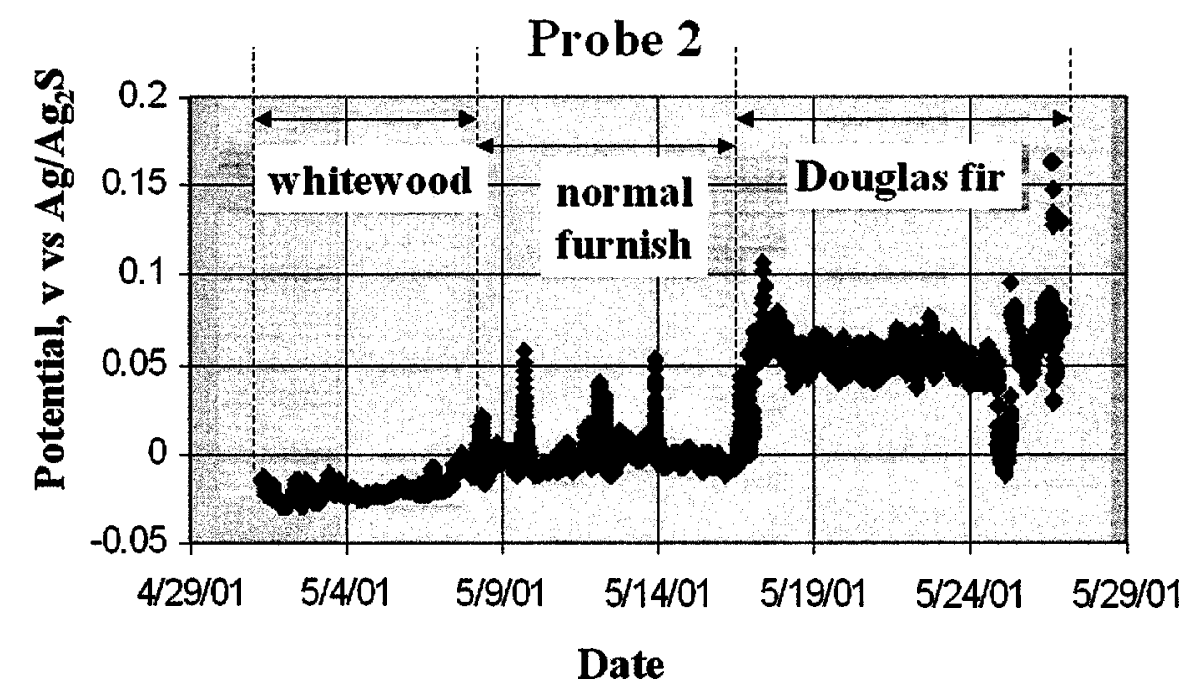

Fig. 37. Representative ECN potential data for Probe \#2 showing variation as a function of furnish composition.

composition changes to Douglas fir. The potential for each corrosion probe changes in a qualitatively similar fashion to that depicted in Fig. 37 for Probe \#2, but this one was selected for graphical representation because the white noise in the potential data was so slight that the change in potential as a function of furnish composition is easy to display graphically.

The corresponding current data for Probe \#2 appear in Fig. 38. Consistent with the potential data, it shows that current activity is very low during whitewood pulping, only modestly higher pulping the normal furnish, but significantly higher during the Douglas fir run. Probe \#2 revealed changes in current and potential associated with furnish changes at times corresponding precisely to those indicated in the operator's log for the digester (no time delay between furnish change and response at Probe \#2). Although there is more general scatter in the data for the other probes further down the digester, it is nevertheless clear that all probes indicate generally similar responses to furnish composition within a very brief time of changes introduced into the vessel. 


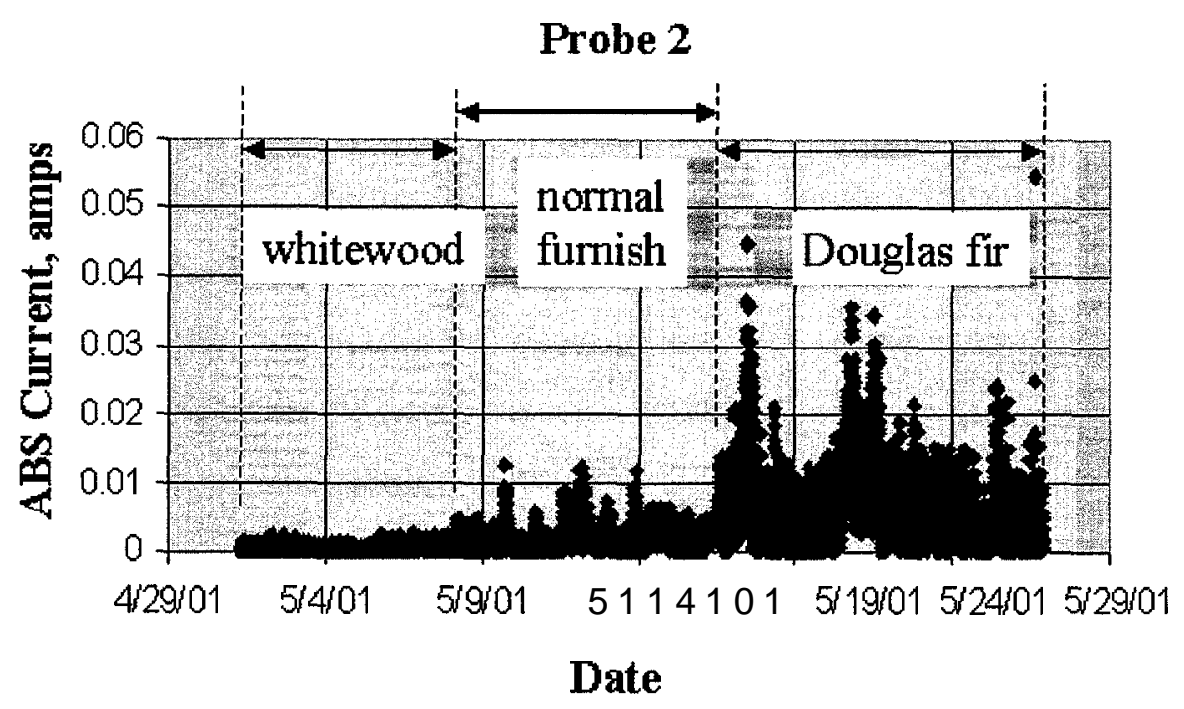

Fig. 38. Representative ECN current data for Probe \#2 as a function of furnish composition.

The precise onset of a change in current/potential activity for each probe associated with furnish compositions high in Douglas fir is difficult to determine, but it is clear from the data that the change is relatively rapid (minutes to about an hour) rather than the several hours that might be required for the slug of wood chip mass to move from the top of the vessel to sequentially lower probe positions in the digester. This result suggests that transport of corrosive constituents within the digester is more rapid than previously thought and occurs via communication in the liquor as opposed to the wood chip mass.

As a general trend observed in this experiment, the increased corrosion activity associated with a high fraction of Douglas fir in the furnish tends to have a larger impact on corrosion at the onset of the change to Douglas fir than after several days of the more aggressive furnish. The reason(s) for this behavior are not clear from the data collected here, but perhaps the steel is able to respond to the more aggressive furnish by corroding to an extent that passivation becomes possible.

The current-summing technique - despite the obvious shortcomings discussed previously - was used to quantify the relative difference in corrosion activity as a function of furnish composition. Over the year-long experiment, the digester experienced six periods of pulping 
Douglas fir (a total of about 51 days). For each probe, the current sum (absolute values used so direction of current between electrodes is eliminated as a factor) over each Douglas fir period was compared to the current sum for an equivalent duration of pulping nonnal furnish immediately prior to (or following, or equally split prior/following, depending on the furnish schedule) the change to Douglas fir. The ratio defined by

¿current (Douglas fir pulping) / $\sum$ current (normal furnish pulping)

was used to assess the relative corrosivity of Douglas fir during each period. In this fashion, ratios of " 1 " indicate that there is no increase in relative corrosion activity upon changing from normal furnish to Douglas fir, while ratios greater than one indicate the relative factor by which Douglas fir is more corrosive. In a few instances, the ratio calculated in this manner was less than one, indicating normal furnish was slightly more corrosive during a particular period of comparison. Table 6 shows summary results of this calculation for the six periods of Douglas fir pulping.

Table 6. Summary data representing the relative change in the ECN corrosion current associated with high concentrations of Douglas fir in the furnish. Over the experiment, there were six periods with furnish composition $>70 \%$ Douglas fir, and the current ratio given in Equation (1) was calculated for each probe in each period. Note the pulping period in which the highest (or lowest) current ratio occurs is not necessarily the same for each probe.

\begin{tabular}{|l|c|c|c|c|c|}
\hline & Probe \#1 & Probe \#2 & Probe \#3 & Probe \#4 & Probe \#5 \\
\hline Douglas fir \#1 & 2.3 & 4.7 & 3.1 & 1.1 & 3.6 \\
\hline Douglas fir \#2 & 0.5 & 2.6 & 1.0 & 1.6 & 1.2 \\
\hline Douglas fir \#3 & 0.7 & 2.4 & 0.9 & 2.0 & 1.1 \\
\hline Douglas fir \#4 & 1.0 & 5.7 & 1.0 & 1.1 & 1.0 \\
\hline Douglas fir \#5 & 3.1 & 5.0 & 2.6 & 3.2 & 0.8 \\
\hline Douglas fir \#6 & 5.0 & 3.5 & 1.1 & 0.7 & 1.3 \\
\hline AVERAGE ratio & 2.1 & 4.0 & 1.6 & 1.6 & 1.5 \\
\hline
\end{tabular}


The data of Table 6 show that, on average, pulping Douglas fir is 1.5 - 4.0 times more corrosive than pulping the normal furnish. Clearly, this is not an absolute number, because the manner of calculation assumes that increased corrosion activity detected by the ZRA corresponds in some regular fashion to corrosion of the steel (as opposed to current associated with redox reactions, for example) and that this comparison is valid under different pulping conditions. However, because the "white noise" of the process seems to remain constant and the corrosion activity on each probe was determined to be only general corrosion (using complementary polarization curves and post-test evaluation), the correlation of corrosivities has at least semiquantitative merit.

Although not substantiated by analytical work, it is suspected that taxifolin is responsible for the observed increase in steel corrosion activity during Douglas fir pulping. Taxifolin (a heartwood component of Douglas fir) is a catechol derivative that is known to be a complexing agent for steel. As early as 1953, increased corrosion of steel as a result of taxifolin and similar constituents was suspected [9], and more recent efforts at the Institute of Paper Science and Technology [10] seem to confirm the aggressive nature of taxifolin in liquors toward steel. As a complexing agent, the taxifolin tends to decrease local activity (remove iron ions from solution) and inhibit iron ions from participation in corrosion passivating product/film formation.

Generally speaking, the largest effect of Douglas fir (taxifolin) was observed at the position of Probe \#2, and the effect decreased with distance down the digester. This observation is potentially consistent with a complexing mechanism for increased corrosion. As the Douglas fir is admitted to the top of the vessel along with the liquor charge, the pulping reaction is initiated. After a short amount of time (less than the time required for the chip mass to move from the top of the vessel to near the trim screens), the chemical reaction generating the catechols (complexing agent) is at a maximum because the reaction between fresh chips and strong liquor produces the most taxifolin/catechols at this location. As the liquor/chip mass moves through the digester, the generation rate of catechols is exceeded by the rate at which they are consumed, so that the effect of the catechols becomes relatively less lower in the vessel. This is not to imply that the total corrosion activity becomes smaller as the chip mass moves through/down the vessel, just that the relative influence of the Douglas fir becomes less with position down the vessel. Furthermore, there is generally upflow of liquor in the bottom half of the vessel (below the EX screens, set by the specific liquor recirculation pattern), and this may have the effect of diluting 
the aggressive chemicals in the lower half of the vessel. This would make the contribution of Douglas fir constituents to corrosion less at lower levels in the digester.

In a manner similar to Equation (1), the relative corrosion activity of the probes during periods in which whitewood was pulped was compared to corrosion activity during normal furnish pulping as

$$
\text { ¿current (whitewood pulping) / ¿current (normal furnish pulping) }
$$

where the current sums are again performed using absolute values. There were three periods of pulping whitewood with a cumulative time of about 24 days. Results of the calculation for relative corrosivity of whitewood appear in Table 7.

Table 7. Summary data representing the relative change in the ECN corrosion current associated with pulping whitewood (near $0 \%$ Douglas fir). Over the experiment, there were three whitewood pulping periods, and the current ratio given in Equation (2) was calculated for each probe in each period. The pulping period in which the highest (or lowest) current ratio occurs is not necessarily the same for each probe.

\begin{tabular}{|l|c|c|c|c|c|}
\hline & Probe \#1 & Probe \#2 & Probe \#3 & Probe \#4 & Probe \#5 \\
\hline Whitewood \#1 & 0.5 & 0.6 & 0.5 & 0.6 & 0.6 \\
\hline Whitewood \#2 & 0.7 & 1.0 & 1.3 & 1.4 & 0.6 \\
\hline Whitewood \#3 & 0.8 & 0.5 & 0.5 & 0.6 & 1.6 \\
\hline AVERAGE ratio & 0.7 & 0.7 & 0.8 & 0.8 & 0.9 \\
\hline
\end{tabular}

This sumrnary suggests that whitewood, containing no Douglas fir, is the least aggressive of the furnish compositions. Although it is likely to be far more complicated that the simple observation suggests, note that the data from Tables 6 and 7 indicate that the relative aggressiveness of the furnish composition generally increases from whitewood ( $0 \%$ Douglas fir) to normal furnish (20\% Douglas fir) to the furnish termed Douglas fir (70-80\% Douglas fir). This correlation is true for all probes, but is most sensitive at Probe \#2, somewhat less so at Probes \#1, $\# 3$, and \#4, and the least so at Probe \#5, which is consistent with the complexing mechanism 
suggested above. Generally speaking, the corrosive conditions near Probes \#3 and \#4 are sufficiently active that the contribution made by Douglas fir components is relatively smaller.

\subsubsection{Other Process Parameters}

The Weyerhaeuser staff permitted ORNL access to a suite of digester process parameter data - such as flow rates, temperatures, pressures, liquor chemistry, etc - for potential correlation with the ECN data and probe corrosion activity. [Appendix B gives the list of process parameters examined and some representative data.] Most of the analysis work attempting to correlate changes in process parameters with corrosion activity was performed via visual examination of graphical representations of ECN data and process parameters plotted on the same time scale. However, a correlation coefficient analysis was also performed in an attempt to find trends that might not be graphically apparent.

The emphasis for these plots was, of course, to identify particular values (or ranges) for specific process parameters that correlate significantly with increased corrosion behavior of at least one of the probes, but this exercise included all combinations and permutations of process parameters. In addition to "instantaneous" correlations, delay times of up to two hours were included in the analysis. The rationale behind the delay times was to recognize that there is potentially a time lag between a change in any particular process parameter (set a valve, turn a knob, etc.) and a response of any kind in the vessel. Since it takes approximately 4-5 hours for a chip mass to move the length of the digester at Kamloops (from chips to pulp) and there are five roughly equi-spaced probes along its processing length, that suggests the amount of time between an input at any probe position and a response at the downstream probe is about 1 hour. In consideration of this concept, delay times up to 2 hours in 15 -minute intervals were included in the analysis. [For example, for a delay time of 30 minutes, data for variable " $x$ " were plotted against data for potentially dependent variable " $y$ " collected precisely 30 minutes from the corresponding time-tag value for "x."]

For the correlation coefficient analysis, each process variable was paired against every other available process parameter and delay interval for each 24-h period of data collection over the course of the experiment. From each data pairing, a linear $\mathrm{R}^{2}$ correlation coefficient for each day/delay combination was calculated. 
In practical terms, no significant correlation was found between any other measured/tracked process parameters and corrosion activity. [Expressed mathematically, no average values of $\mathrm{R}^{2}$ greater than 0.7 were observed.] This indicates that corrosion activity based on ECN data - is not directly related to any process parameter that is presently monitored at Kamloops. Further, it is interesting that this result also suggests the process data is not related to itself via relationships that might be expected due to process control/logic. [That is to say, none of the process variables correlated with any other process variable or measurements, which suggests that these factors are independent of each other rather than related by process logic and control schemes.]

There are several potential explanations for the apparent absence of correlations. In a general sense, this result may indicate that possible correlations are non-linear or multi-variable rather than simple linear relationships. Such complex relationships, at best, are difficult to detect in a large array of variables, particularly when there are no known "outcomes" on which to model non-linear relationships. Related to possible non-linearity, there may be so little variation in the process parameters with time (tight process control aimed at a precise kappa number or other process goal) that the establishment of any strong correlation among process parameters and corrosion is impractical. Ultimately, the absence of even a strong correlation for furnish composition in the mathematical treatment probably relates to the fact that there is not much spread in Douglas fir composition (essentially only three different values), and the corrosion activity associated with two of these values are very similar.

A few operational variables, such as production rate, dilution factor, inner counter-wash rate, alkali charge, and residual alkali were found to exhibit slight variations from the normal values coincident with changes in furnish composition and corrosion activity. While each of these may contribute a small portion to the entire observed effect of Douglas fir pulping, each of these parameters are changed slightly - but intentionally - to facilitate Douglas fir pulping. As a result, these are not independent parameters in the strictest sense. As an example, Fig. 39 shows a slight change in residual alkali content (measured at the bottom circulation loop) as a function of a brief change from normal furnish to Douglas fir. While it could be argued, in a general sense, that decreased alkalinity (weak liquor) could contribute to marginal passivation of the steel and thus increase corrosion activity, the change observed in Fig. 39 is a process adjustment made to account for Douglas fir content in the furnish. Further, brief excursions to reduced alkali content at this and other locations in the vessel do not seem to correlate with increased corrosion 
activity unless there is a coincident change to a more aggressive furnish. As a result, the aggressive furnish is considered to be the independent variable and the parameter of greatest significance for vessel corrosion.

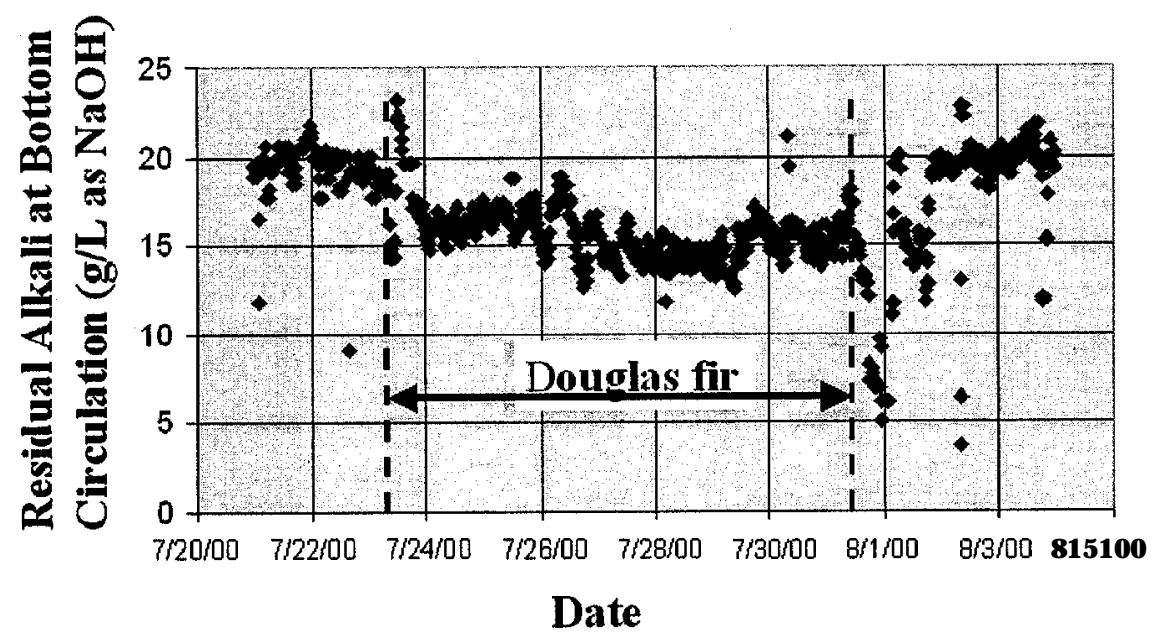

Fig. 39. Residual alkali measured on the bottom circulation loop decreases coincident with a Douglas fir pulping campaign.

\subsubsection{Shutdown and Startup Transients}

In addition to the startup at the beginning of the data collection period in June 2000 and the shutdown at the end of May 200 1, there were two outages during the experiment - one from November 9-29, and one from March 14-28. The digester was drained during both outages, but it was not washed/cleaned. ECN data were collected for portions of the vessel downtime in each case, but various power disruptions and maintenance work caused the data collection routine to be stopped for a significant portion of each outage.

Compared to the nominal potential/current noise during operation, the ECN data indicated that the shutdown and startup transients are quite aggressive in terms of corrosion activity. Figure 29 (also Fig. 33) shows a portion of the November 2000 shutdown data compared to normal operation for Probe \#5, at which corrosion is nominally quite limited. Note in particular that the current value increases, at least during brief periods of the shutdown, to a level 10 or 100 times larger than the nominal current activity. Figure 31 shows a portion of the 
November 2000 shutdown data for Probe \#3, for which general corrosion activity is nominally relatively high. The current spike associated with the November 2000 shutdown at Probe \#3 is of approximately the same magnitude as current spikes associated with more aggressive furnish. In both cases, it is clear that significant potential/current transients are associated with the outage transient.

As in the case for calculating the relative corrosivity of different furnish compositions (see Equations 1 and 2 along with related descriptions), the relative corrosivity of shutdowns can be similarly estimated. In this case, the absolute value of current activity for each probe was summed for about three days of outage and the same amount of time after normal operation was re-established. There was sufficient data available to calculate the ratio

$$
\text { Ecurrent (shutdown) / } \text { current (normal furnish pulping) }
$$

for at least one end of all three shutdowns. (These would be the two outages in November and March as well as the major maintenance shutdown at the end of May 2001; there were 45 cumulative days of outage but only about two weeks of cumulative ECN data collected during the outages.) Table 8 summarizes the results, which indicate that the transients are somewhat irregular in magnitude (possibly a function of the manner of calculation) but are significant corrosion events. In particular, a large fraction of the total apparent corrosion (based on current sums) occurring at the position of Probes \#1, \#2, and \#5 occurs during shutdown transients.

Table 8. Summary data representing the relative change in the ECN corrosion current associated with shutdown transients. Over the experiment, there were three shutdowns, and the current ratio given in Equation (3) was calculated for each probe in each period.

\begin{tabular}{|l|c|c|c|c|c|}
\hline & Probe \#1 & Probe \#2 & Probe \#3 & Probe \#4 & Probe \#5 \\
\hline Nov 2000 shutdown & 34 & 11 & 1.1 & 3.5 & 4.0 \\
\hline Mar 200 1 shutdown & 5.3 & 25 & 3.9 & 4.5 & 23 \\
\hline May 200 1 shutdown & 6.5 & 13 & 1.8 & 2.7 & 3.4 \\
\hline AVERAGE value & 15 & 16 & 2.3 & 3.6 & 10 \\
\hline
\end{tabular}


The reasons for increased corrosion during shutdowns are not immediately obvious, but it seems likely that at least one significant factor has to do with draining the vessel without subsequent washing. When this occurs, residual black liquor adhering to the digester walls slowly reacts with air to generate thiosulfate components in the remaining liquid. [Residual black liquor - meaning liquor that has been at least partially "spent" in the pulping process - is very thick and viscous, and a thin layer of high conductivity material could be expected to persist essentially indefinitely inside a digester at ambient temperature.] The addition of the thiosulfate components to the relatively weak liquor creates a very aggressive solution - even at ambient temperature - toward steel. If this hypothesis is correct, corrosion in digesters potentially could be minimized by washing the vessel following draining so that only very dilute solutions remain in/on the vessel walls over the duration of the outage. Forced-air drying could further minimize the time-of-wetness and the modest steel corrosion associated with damp conditions.

\subsubsection{Assessment of ECN Calculated Parameters}

A number of parameters calculated from the values of current and potential are typically used in the analysis of ECN data. For example, the standard deviation of the current and/or potential and the root mean square value of the current are sometimes sensitive indicators of changes within the process, but in the present experiment these values largely duplicated information drawn directly from the current and potential measurements. Each of these values indeed readily detected furnish composition as a significant variable as monitored by corrosion activity of the probes, but in general the information was no more (and was sometimes less) sensitive than direct current and potential changes.

The noise resistance (denoted $R_{n}$ ) is calculated as

$$
R_{\mathrm{n}}=\sigma_{\phi} / \sigma_{\mathrm{I}}
$$

where $\sigma_{\phi}$ is the standard deviation of the potential signal (in volts) and $\sigma_{\mathrm{I}}$ is the standard deviation of the current signal (in amps). Calculated this way, $\mathrm{R}_{\mathrm{n}}$ has the units of ohms and is inversely related to the corrosion rate through a multiplier called the Stern-Geary constant (which, in practice, is rarely known precisely but there are methods to estimate this value). The ECN data 
collected in this experiment routinely yield very low values of noise resistance, which indicates a high rate of reaction at the electrode surfaces. As a general trend, the lowest values of $R_{n}$ (highest corrosion rate) belong to Probe \#5, with Probes \#3 and \#4 a small increment higher, and Probes \#1 and \#2 with a slightly higher increment yet. Since this agrees so poorly with current sums, historical corrosion rates/observations, and the post-test analysis of the probes (next section), the utility of the $R_{n}$ value seems somewhat dubious for the digester system. Further, the $R_{n}$ values did not seem sensitive to furnish composition - for example, the $R_{n}$ value for Probe $\# 2$ is approximately constant at a value less than $1 \Omega$ during most of the changes from normal furnish to a furnish rich in Douglas fir. As a result, no further analysis of $R_{n}$ values was attempted in this experiment.

Although outside the scope of the present investigation, it seems possible that further laboratory experiments using impedance spectroscopy (to examine the frequency domain) might be capable of separating instantaneous redox reaction rates (potentially very high and what is dominating the present calculation of $\mathbf{R}_{\mathbf{n}}$ ) from corrosion reactions (different time constant from redox reactions, likely a relatively lower rate). While this analysis could be performed with the instantaneous raw data, that data was not permanently stored.

Attempts were also made to calculate/estimate the extent to which the corrosion activity indicated by the probes was localized toward pitting rather than general corrosion. One method utilized the formula

$$
\mathrm{LI}=\sigma_{\mathrm{I}} / \mathrm{I}_{\mathrm{RMS}}
$$

where LI is the localization index, $\sigma_{\mathrm{I}}$ is the standard deviation of the current signal (in amps), and $\mathrm{I}_{\mathrm{RMS}}$ is the root mean square value of the current signal (also in amps). Calculated this way, $\mathrm{LI}$ is a dimensionless number between 0 and 1 expressing tendency toward localized corrosion, with this tendency greater as the number increases. Interpreted this way, values of LI for the digester probes routinely indicate general corrosion with perhaps some slight, periodic tendency toward pitting on Probes \#1 and \#5. As the previous inspections have shown, (and the post-test inspection in the following section), very little corrosion at all occurs at the positions of Probe \#1 and \#5. The very low amount of corrosion may contribute to sporadically high values of LI, but generally it is difficult to interpret/evaluate LI in light of the physical observations in the digester. 
A possible explanation of the failure of $R_{n}$ to predict corrosion while $L I$ is relatively consistent with the observed corrosion lies in the competing sulfide redox reactions. If, as assumed, the sulfide redox reactions are rapid it is likely that they dominate the mixed potential developed on the steel surface. It is also likely that they act to dampen any potential excursions that would otherwise arise from the corrosion reactions. So the measured potential excursions and particularly $\sigma_{\phi}$ - would under-represent the corrosion process. This is consistent with the very low values of $R_{n}$ calculated.

Alternatively, the current flowing between electrodes does seem to represent the actual corrosion process. Integration of the absolute value of the coupling current correlates to weight loss corrosion rate. Therefore, it is to be expected that LI, which depends only on the measured coupling current, should also represent the corrosion process.

\subsection{FINAL VESSEL INSPECTION}

Following the shutdown for the major maintenance work in early June 2001, the digester vessel was again inspected. The purpose of the follow-up inspection was two-fold: (1) to examine the vessel for changes since the inspection in June 2000, and (2) to assess the condition of the probes and remove them for analysis and comparison with the ECN data generated.

\subsubsection{Probe \#1}

The electrodes in the probe were originally flush-mounted in a teflon header and positioned such that the exposed end of the probe was flush with the process on the shell ID. However, at the time of this inspection, the probe port was filled with what appeared to be a mixture of decomposed chips and residual black liquor, and the electrode materials appeared to be protruding from their original mounting in teflon (Fig. 40). The "crud" was removed by careful digging with a nail to expose the electrodes and the teflon header (Fig. 41). With most of the crud removed, it was apparent that the entire length $(1.2 \mathrm{~cm})$ of the metal electrodes (steel cylinders at the bottom of Probe \#1) rather than just the round surface at the end of the electrode was exposed. Light prodding/poking of the header face with the nail indicated that the teflon was not soft/degraded and that the face of the head was still flat, smooth, firm, and unstained. These observations suggest that the teflon was not unduly affected by the nearly year-long exposure to the pulping process, but it was nevertheless displaced from its intended position prior to this inspection. [This will be discussed more fully in a subsequent paragraph, but it is likely that the displacement of the teflon header occurred during pressure washing at the end of the experiment.] 


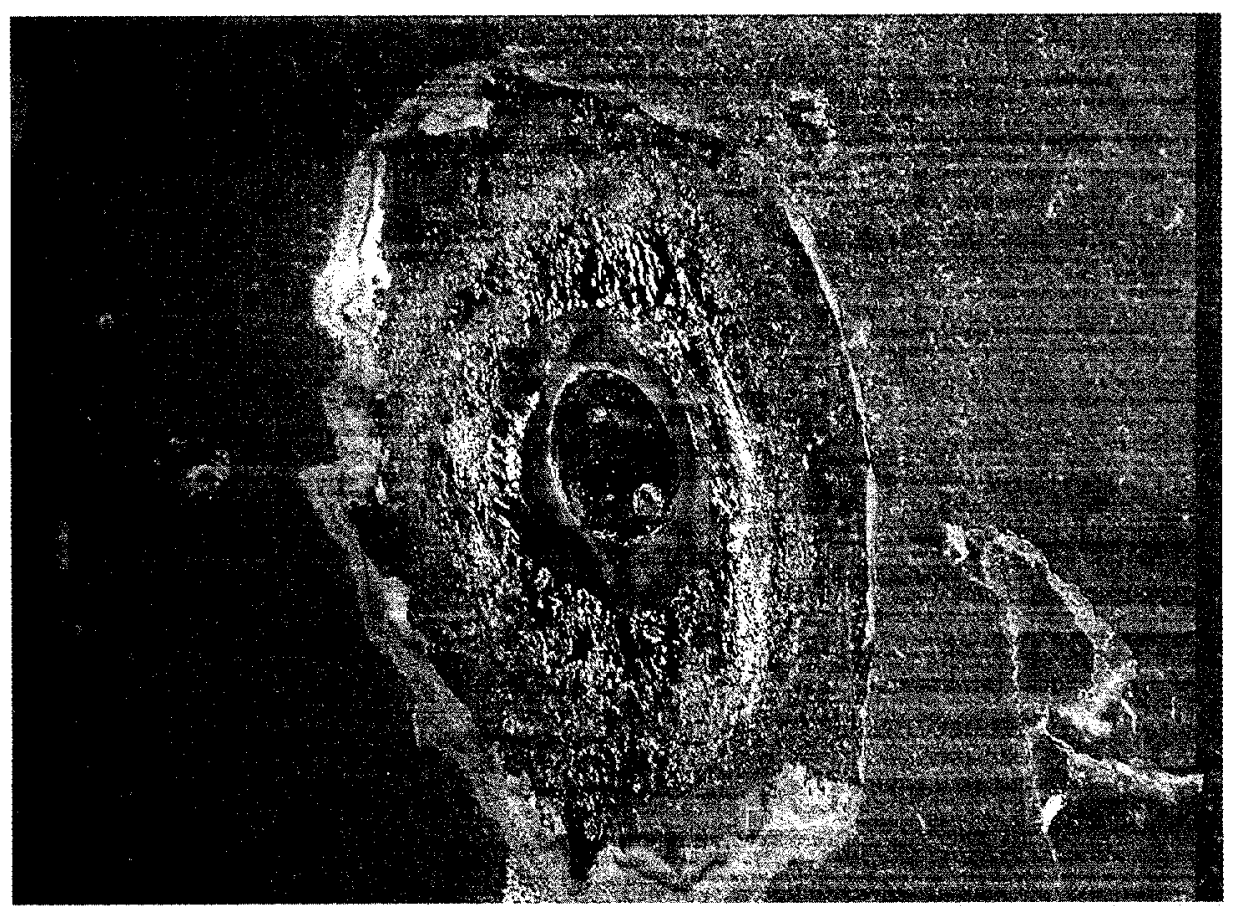

Fig. 40. Post-test view of Probe \#1. The area $10-12 \mathrm{~cm}$ around the probe position has been cleaned of carbonate scale. Red/orange regions are rust stains associated with low spots in the surface relief and shallow pitting.

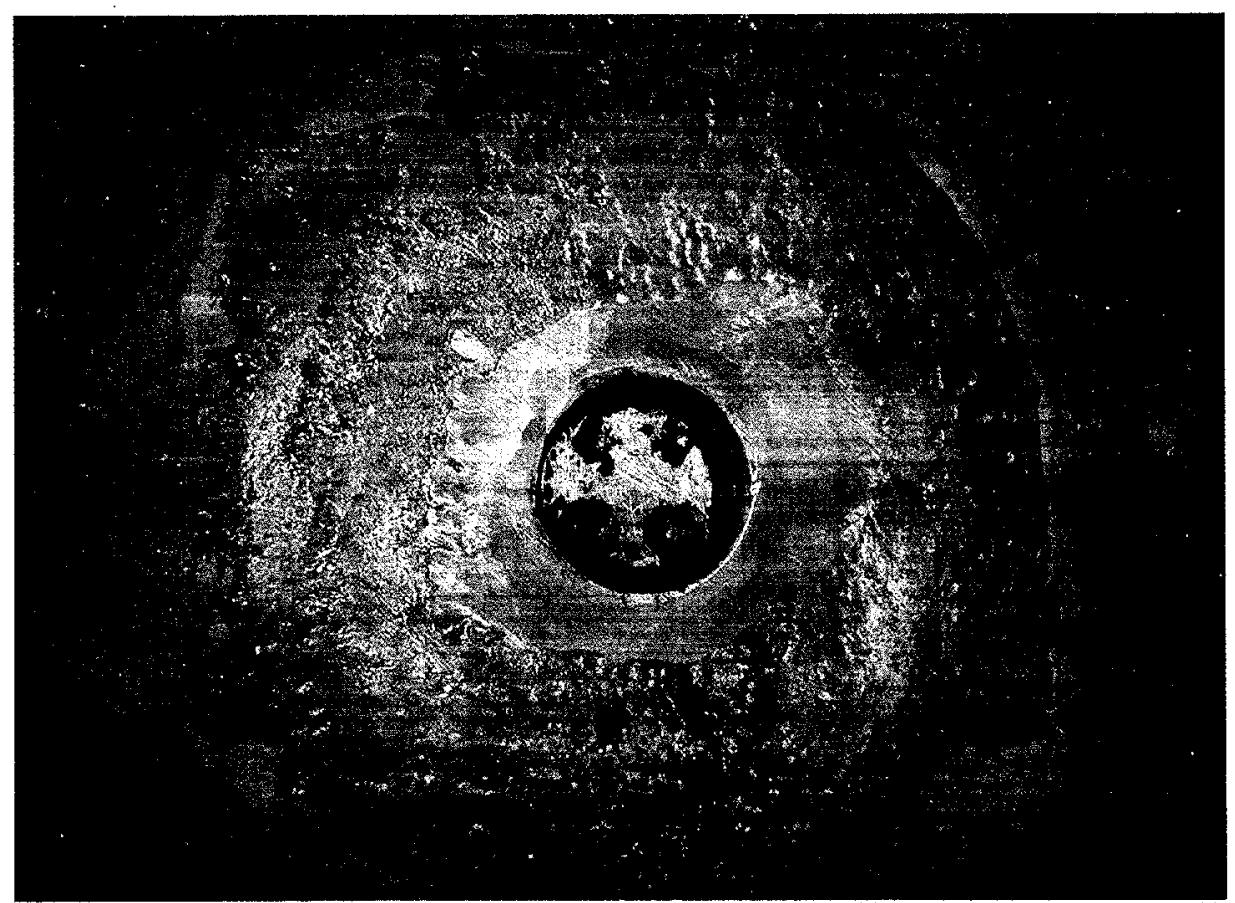

Fig. 41. Post-test view of Probe \#1 following removal of accumulated "crud" in the port opening. 
At the position of Probe \#1, most of the digester shell was covered with a relatively thick carbonate scale. [This digester was not acid-cleaned.] It is not clear whether the scale was specifically removed from around Probe \#1 by the water wash or by other mechanical action, or if the carbonate scale simply doesn't adhere in this location very well. In any case, there was minor shell corrosion evident in the area around Probe \#1, most of which is immediately adjacent to the boss for the port. The "pitting" and other surface relief in this area is $<0.25 \mathrm{~mm}(<10$ mils $)$ deep. Chipping at the scale exposed other small sections of digester shell surface, which were largely smooth but not entirely free of shallow, random pits on the order of $0.25 \mathrm{~mm}$ (10 mils) deep. Comparison of these observations with those from the previous inspection (e.g., Fig. 5) indicates the digester shell in the vicinity of Probe \#1 has experienced some mild corrosion during the experiment. Specifically, it seems that the scattered shallow corrosion/pitting observed in June 2000 at a position several meters below that of Probe \#1 has advanced upward to the top of the vessel.

Figure 42 shows the port flange for Probe \#1 from outside the vessel. It appears that a small leak of black liquor has occurred here. On the day it was examined, the fluid was still slightly moist/tacky and no accumulation other than what is evident in the picture was observed on the vessel or nearby floor/grating. Taken together, these observations suggest a small/recent leak, perhaps encouraged by the pressure washing to clean the vessel internals. None of the other probes revealed any evidence of a leak of this type.

Much of the area at the top of the vessel (between RS22 and the trim screens) retained a variable thickness of carbonate scale. In areas cleared of scale for examination by other inspectors, it was obvious that shallow light pitting, particularly on/near welds, was present. Figure 43 is representative of this observation at RS2 1. Note the " $\mathrm{T}$ " stamps in the base metalused to help locate ultrasonic thickness measurement positions - appear sharp and distinct, indicating little general corrosion in this region over the seven year operational history of the vessel. 


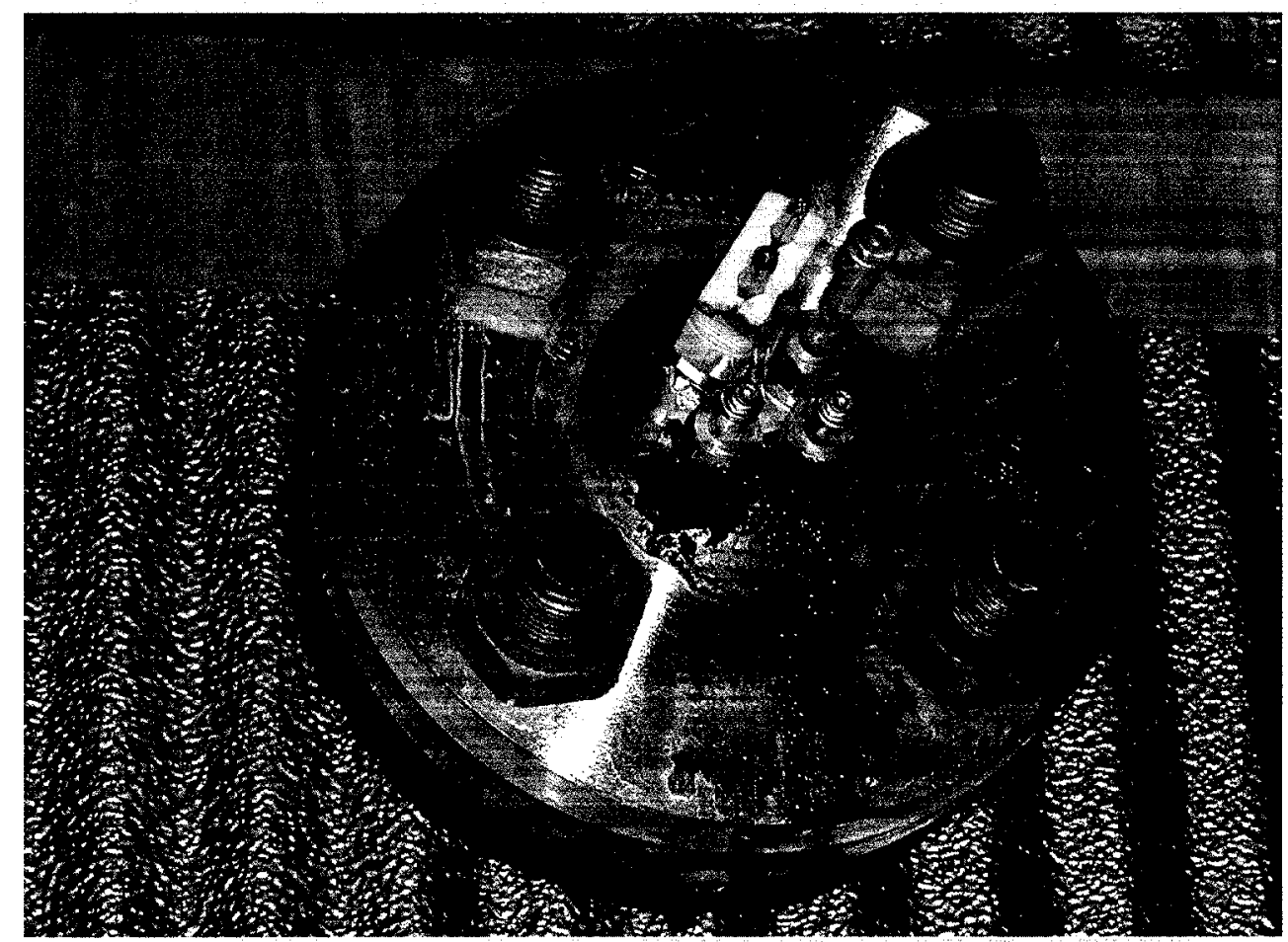

Fig. 42. View of the external flange associated with Probe \#1. None of the other flanges showed any sign of leakage.

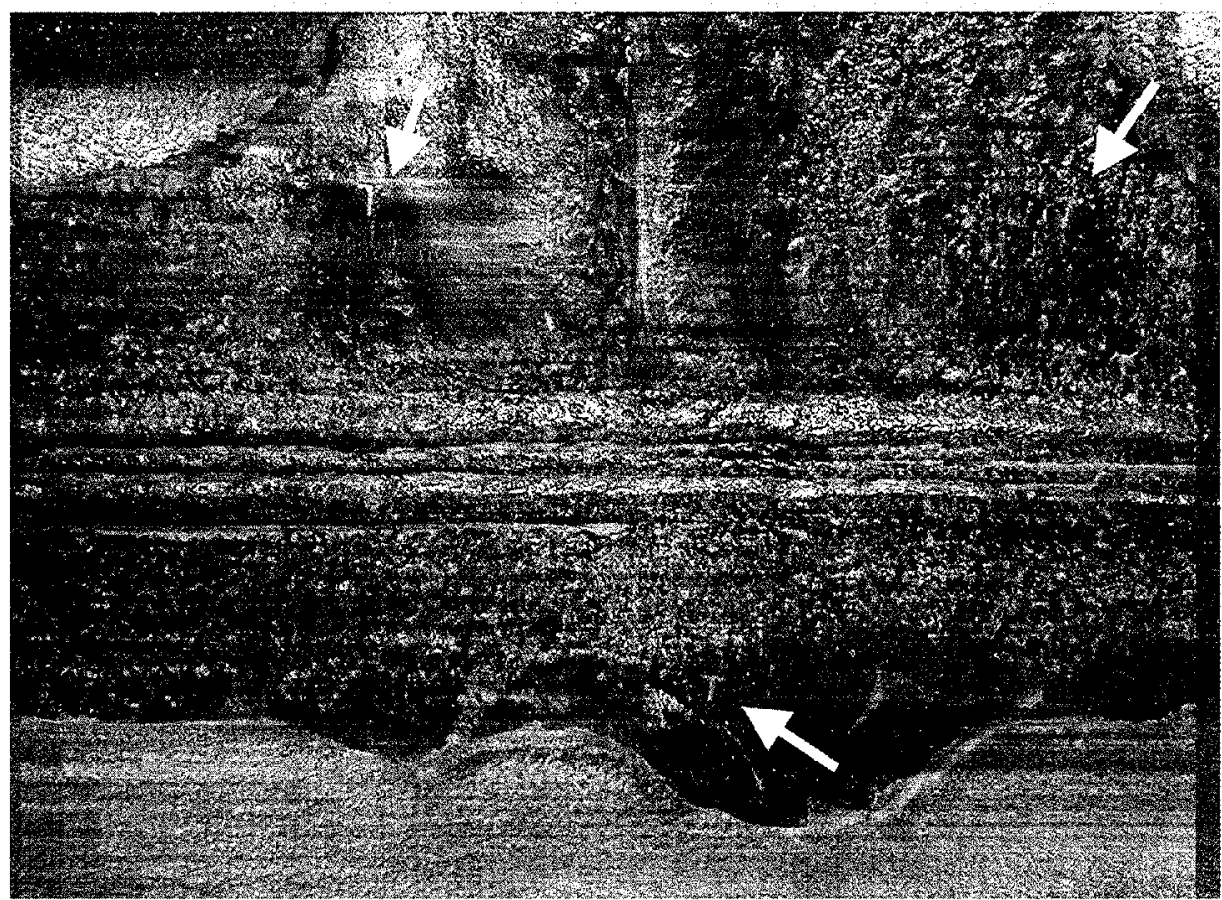

Fig. 43. Intersection of RS21 with LS33 or LS34. Gray material - particularly evident at the bottom of the photo - is carbonate scale. 


\subsubsection{Probe \#2}

The teflon header in Probe \#2 was similarly "pushed back" to reveal the full length of the metal electrodes (see Fig. 44). Immediately adjacent to the port boss, the steel shell exhibited significant pitting in the "oceans and islands" pattern previously discussed, but it was unchanged (depth or extent, see Fig. 7) since the prior inspection. The majority of the shell at this elevation shows only the modest beginnings of the "oceans and islands" pitting pattern. Figure 45 shows a representative area of shell at/near a trim screen. The shell generally has a thin carbonate scale through which surface relief is readily detected, but the only significant surface relief is adjacent to the boss of the trim screen port. Similar photos from the previous inspection (see Figs. 8 and 9) as well as pit depth measurements indicating approximately $1.0 \mathrm{~mm}$ (40 mils) in this location suggests little or no change in the extent or depth of pitting adjacent to the trim screen since the previous inspection.

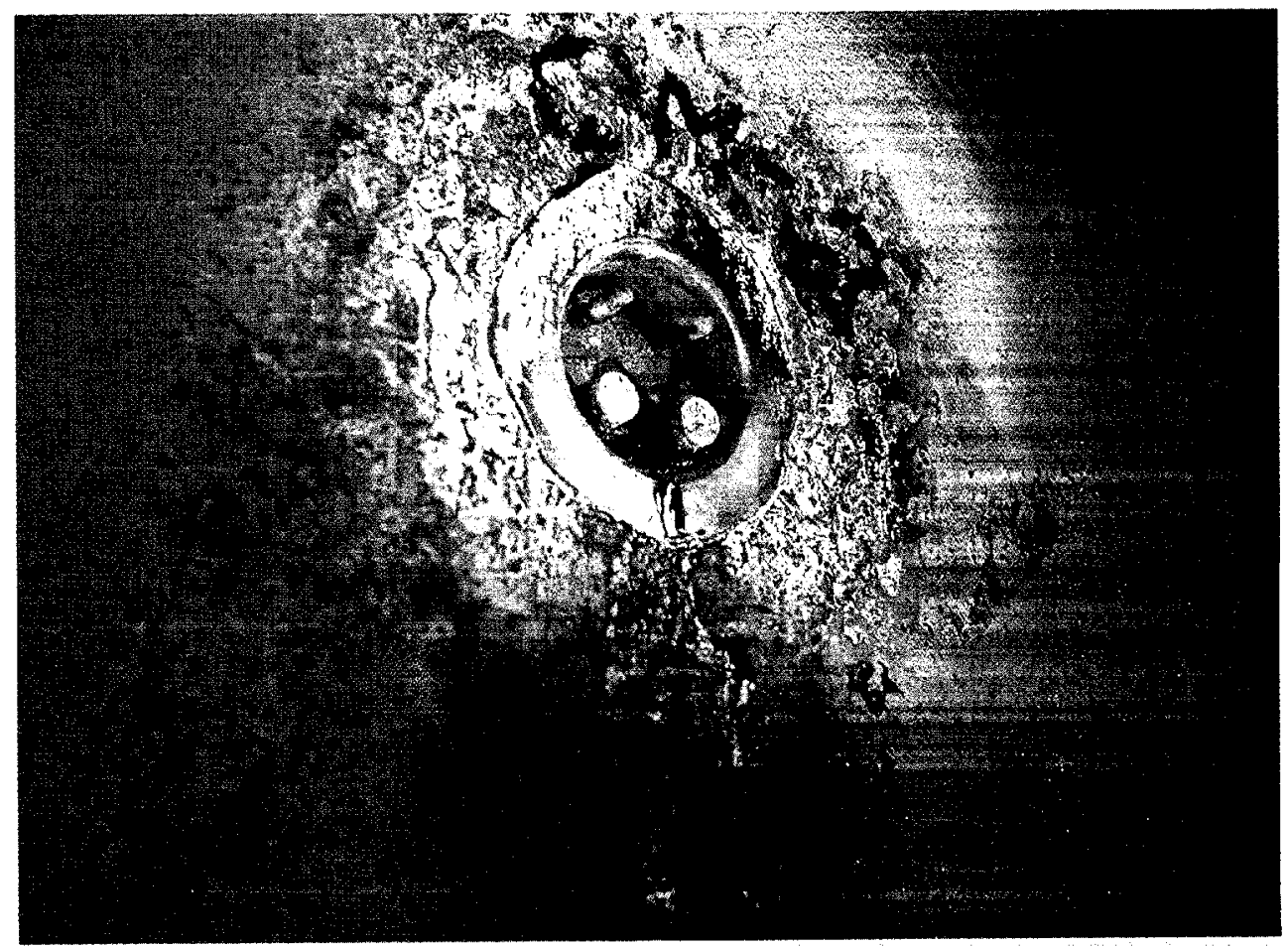

Fig. 44. Post-test view of Probe \#2. Significant corrosion and surface relief is confined to the area adjacent to the port boss. Residual carbonate scale covers most of the shell at this position, but it is sufficiently thin to reveal surface relief contours. 


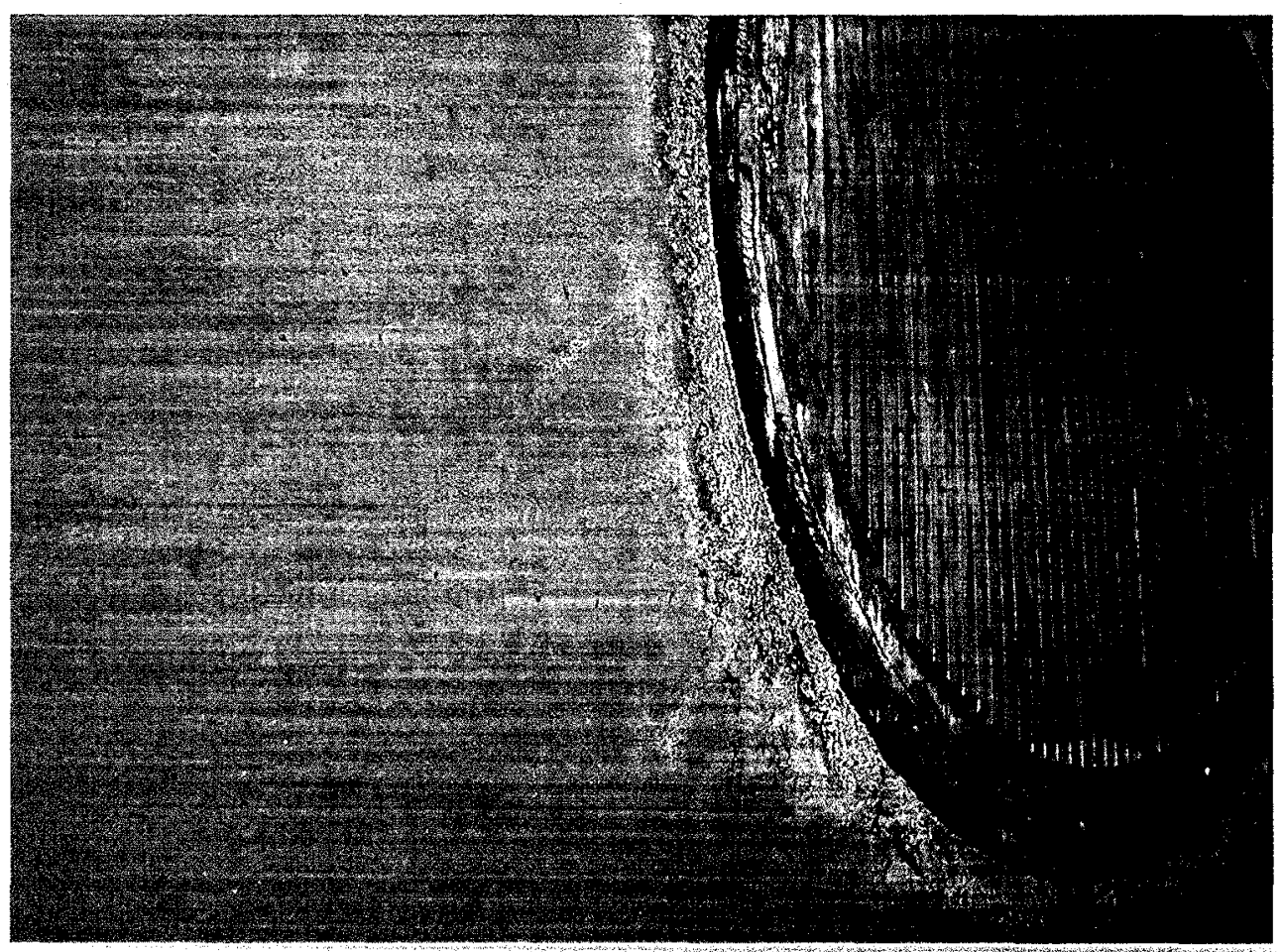

Fig. 45. Shell and trim screen near the position of Probe \#2. The most significant corrosion is adjacent to the port boss.

\subsubsection{Probe \#3}

Probe \#3 is shown in a general view in Fig. 46 and in a closer view in Fig. 47. A general pitting pattern on the shell around the port is evident and was insignificantly changed in depth/extent from the previous year's inspection. In particular, compare Figure 11 (June 2000) with Fig. 46 (June 2001). Some minor pit agglomeration may have occurred, particularly adjacent to the port boss (absence of flash rust and similar lighting in the recent photo obscures the comparison), but otherwise there was so little change over the past year that individual pits/patterns can be identified in both photographs. Like the other probes, the teflon header was displaced from the steel electrodes into the port cavity, but it was not apparent that the teflon had been degraded in any fashion. 


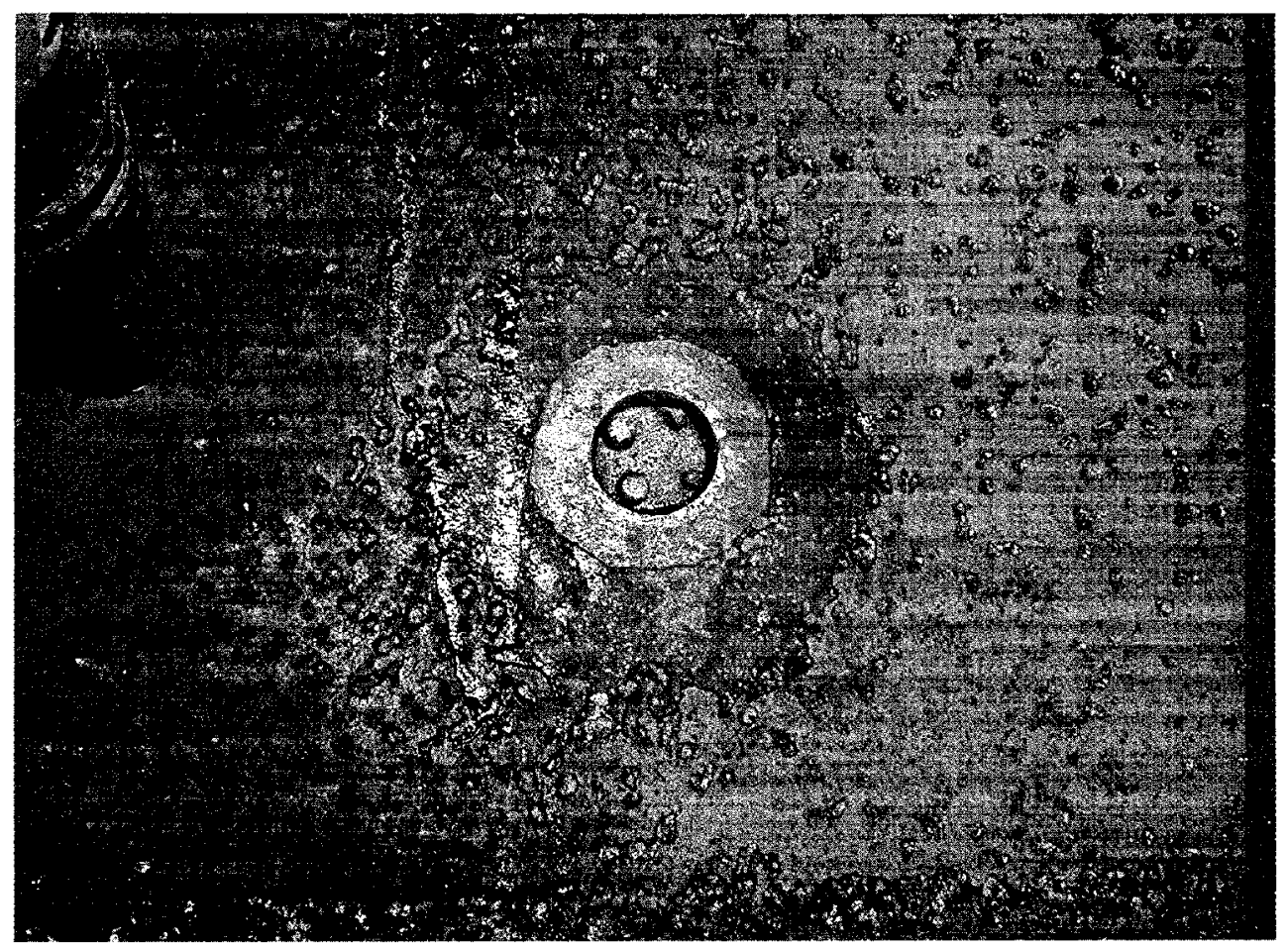

Fig. 46. Post-test view of Probe \#3 and the surrounding digester shell.

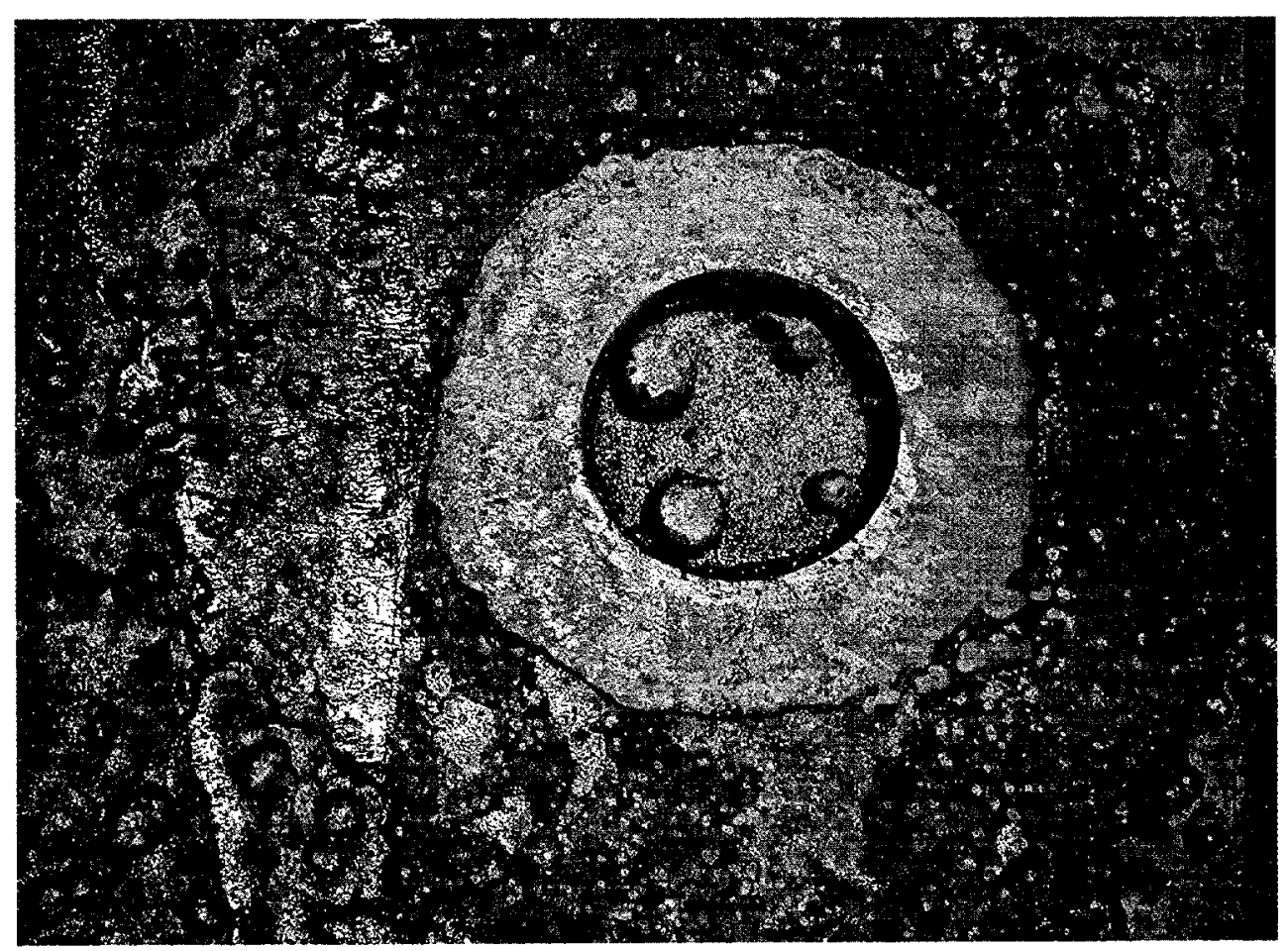

Fig. 47. Closer view of Probe \#3. The teflon has recessed from its original position flush with the process at the mouth of the port by about $1 \mathrm{~cm}$. 
In the area between the EX screens and the MC screens (RS 10-12), the weld areas seemed to have a somewhat greater density of pitting than the general shell areas, but all of the pits were on the order of 1.5-1.7 mm (60-70) mils deep. The pits in this area, like other "ocean and island" pitting patterns, were characterized by smooth, flat bottoms and sharp edges at which the pit periphery meets the shell wall. Figure 48 is a photograph of the area around RS 11, showing corrosion at/along the weld as well as on the shell in general. Pits here are $1.5-1.7 \mathrm{~mm}$ (60-70 mils) deep and relatively uniform. Figure 49 shows a large "ocean" region (large recessed area from agglomerated pitting) that appears to have a relationship to surface grinding associated with a weld bracket. Both areas were observed in the prior inspection and were not detectably changed in general appearance or depth of pitting.

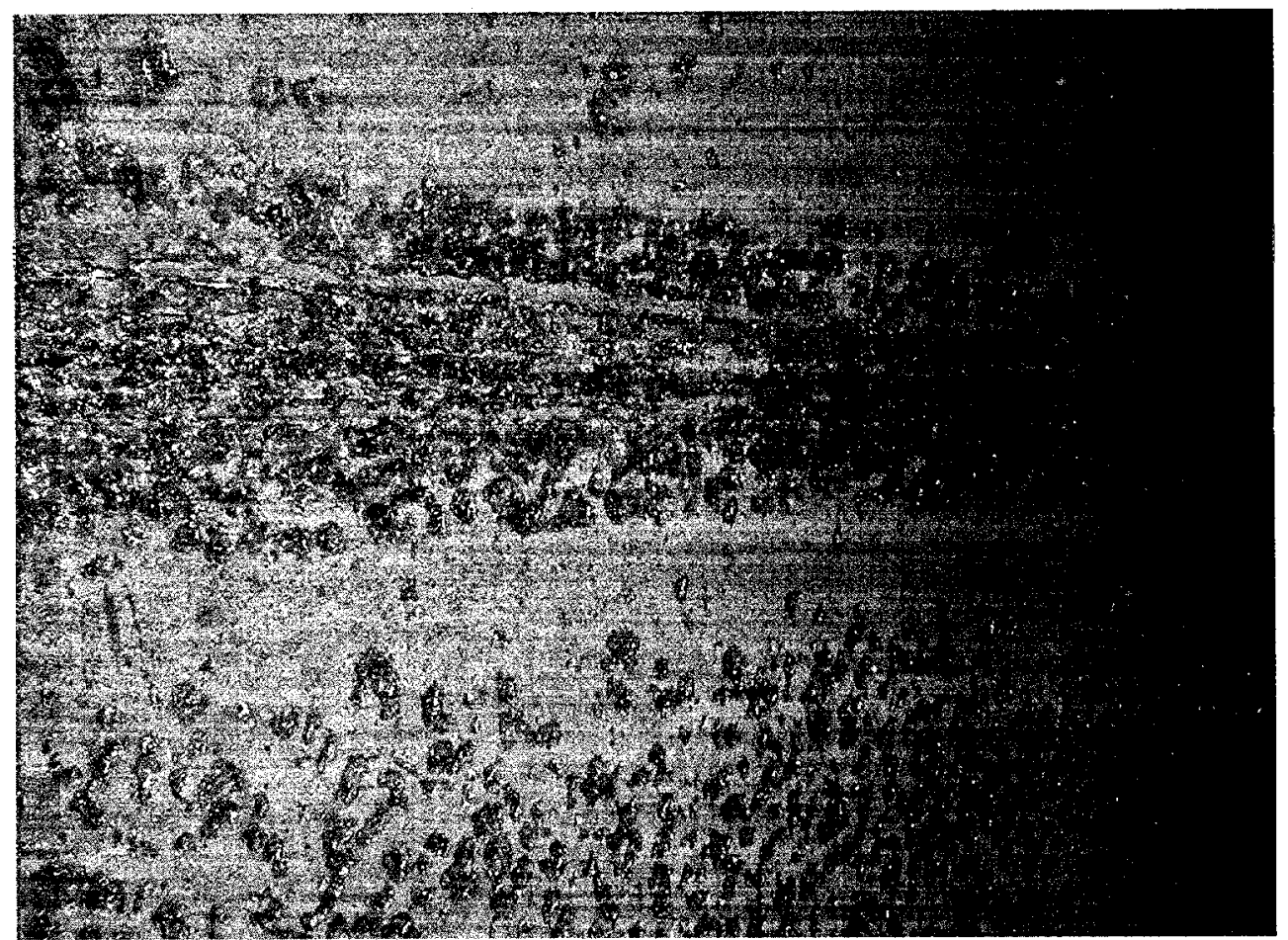

Fig. 48. Representative view of RS11 and the adjacent shell. 


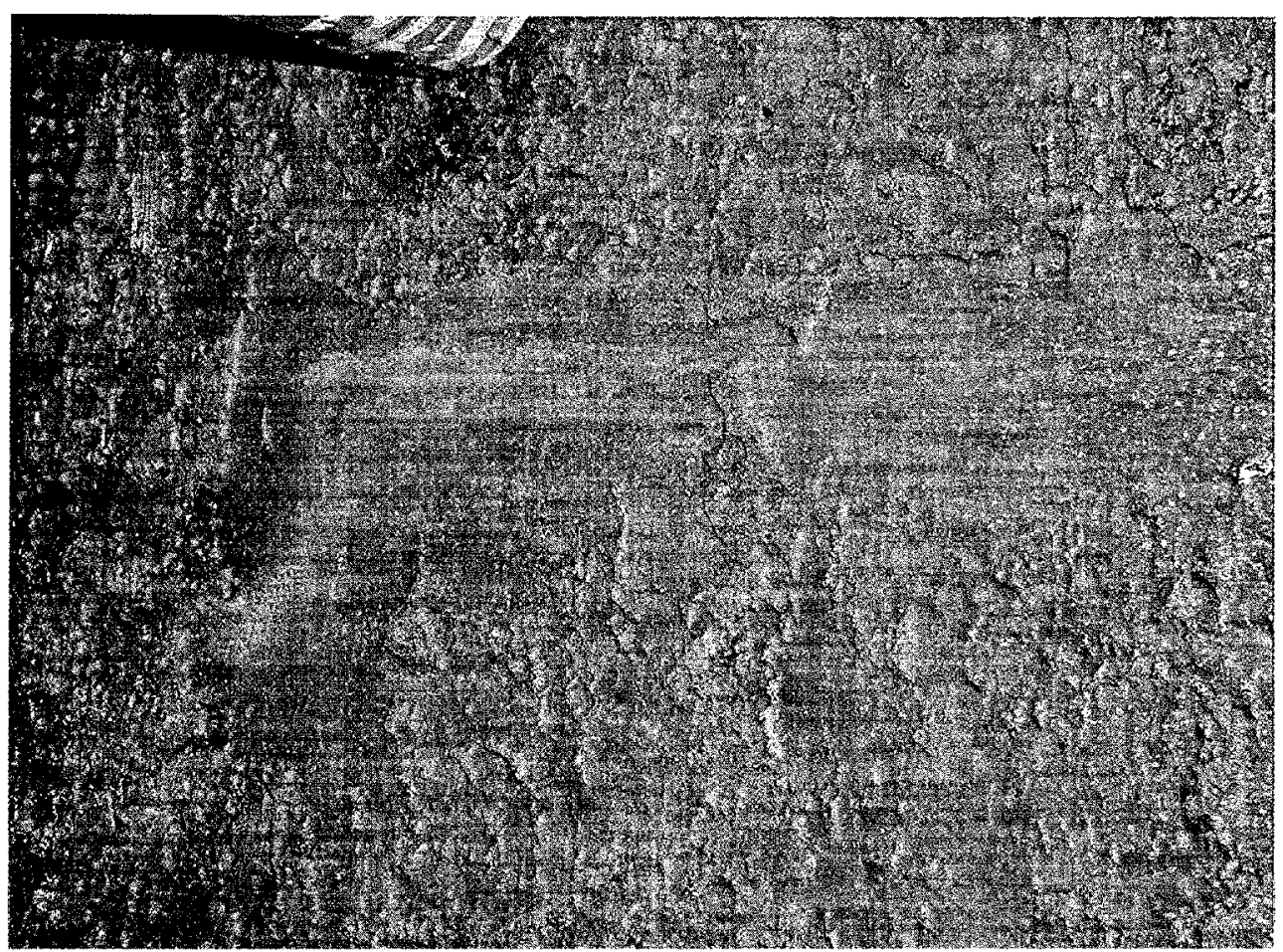

Fig. 49. A recessed area associated with grinding the shell surface to remove an attachment.

\subsubsection{Probe \#4}

The teflon header of Probe \#4 was displaced completely from the probe face and was lodged several centimeters inside the port. Although no significant inspection could be made of the teflon from that position, it appeared that the teflon from the header face remained flat, smooth, and unstained. Figures \#50 (general) and 51 (close-up) are representative of Probe \#4 and the condition of the shell in the vicinity. Comparing to similar pictures from the previous inspection, very little if any change occurred in the density and depth of pits in this area. Photos fi-om June 2000 are not at the same angle/view as photos from 200 1, and it was also somewhat cleaner in 2001 compared to 2000, so the photos are more difficult to compare. Individual pits at this location are difficult to identify in consecutive-year pictures, but the general pattern of pits is very similar for each year.

On either side of RS6 - located slightly below Probe \#4 - a weld track was clearly evident. This feature was also noted in the prior inspection (see Fig. 19), and it had not changed in a perceptible fashion. 


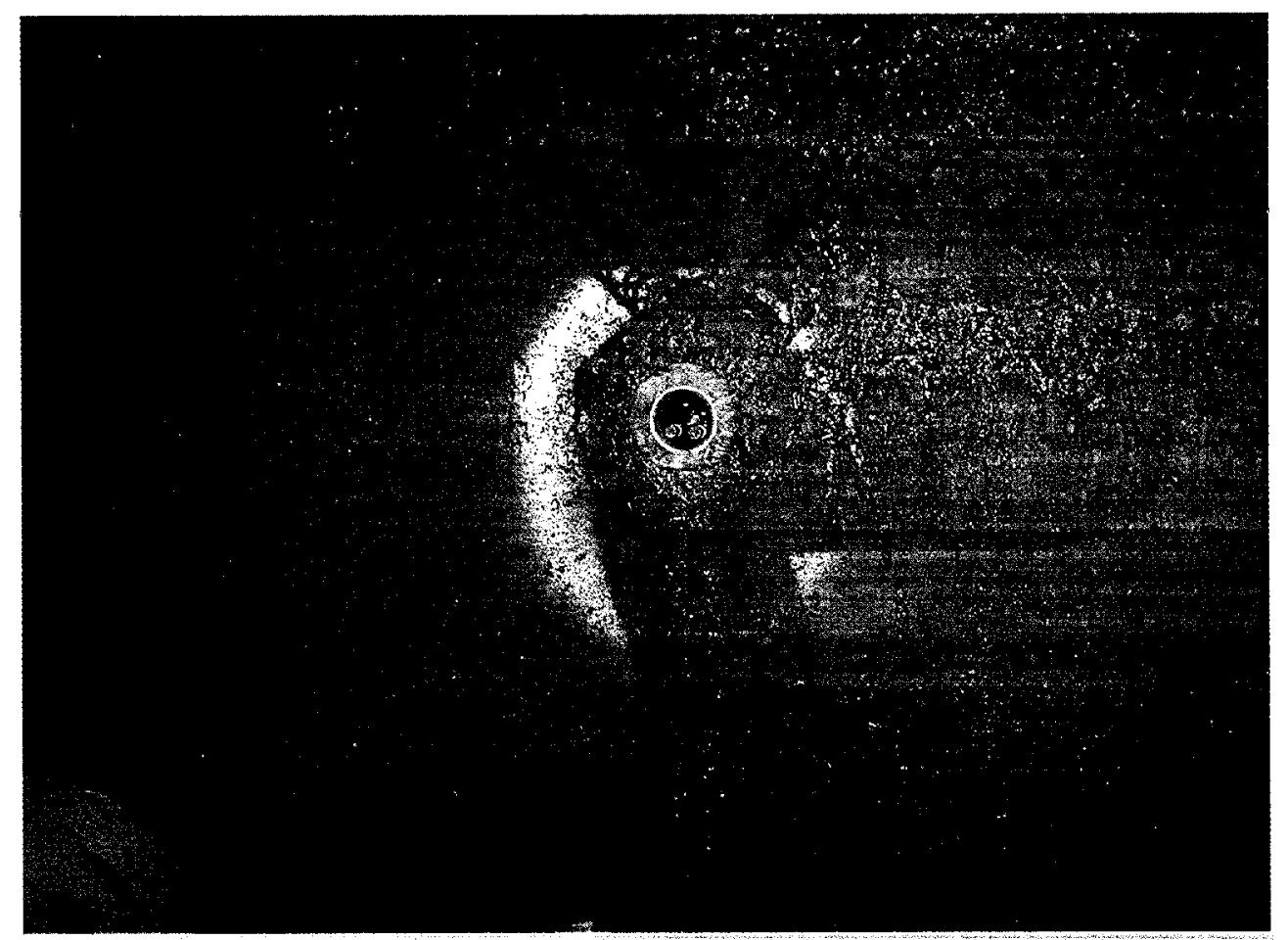

Fig. 50. Post-test view of Probe \#4.

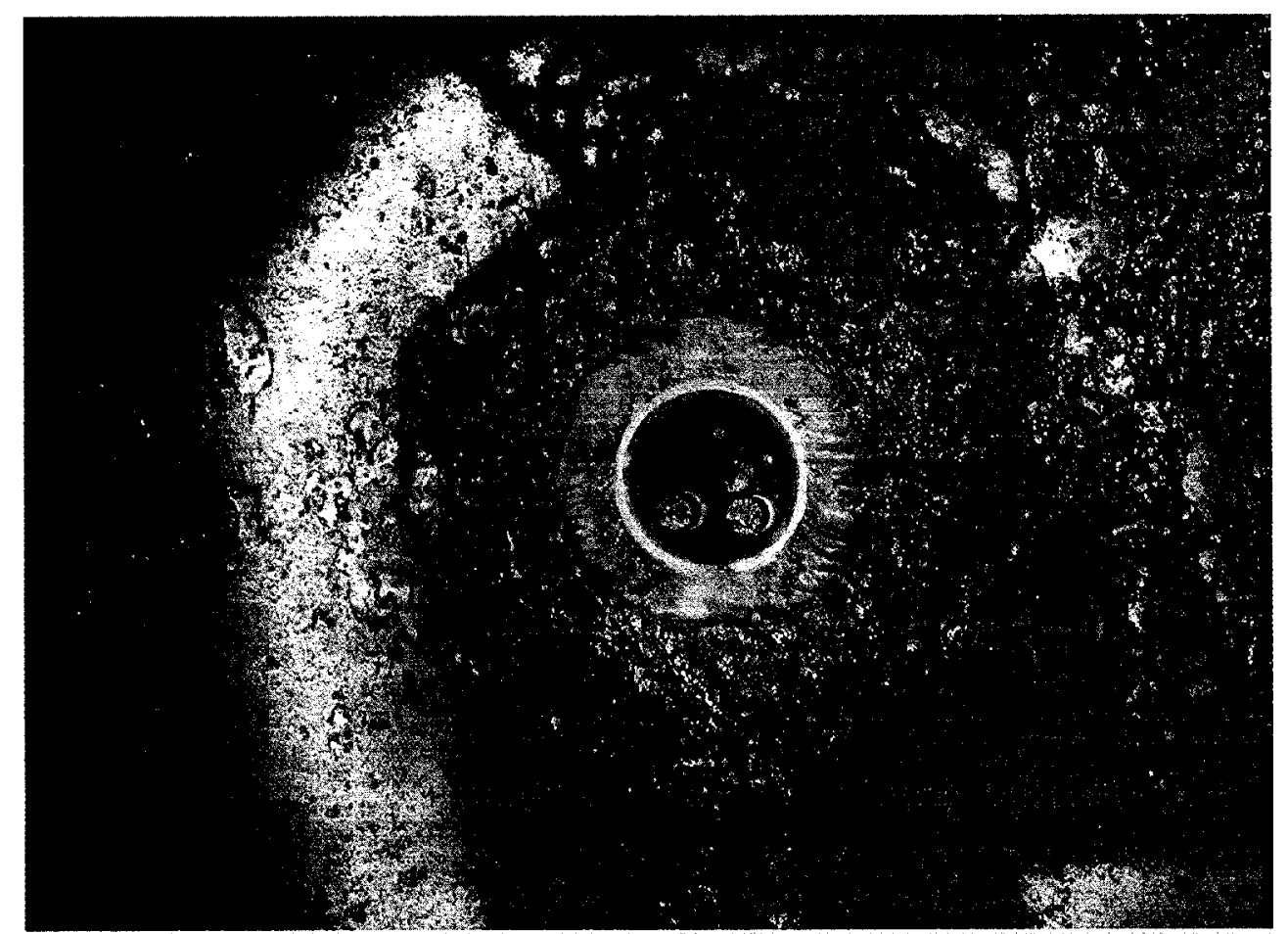

Fig. 51. Closer view of Probe \#4. The teflon is displaced completely from the electrodes. Note the ID of the port appears relatively uncorroded. Also note that the end of the piece of steel formerly attached to the silver is rusted - the silver has been broken off at the braze joint. 


\subsubsection{Probe \#5}

Figure 52 shows a general view of Probe \#5 (below the wash screens) and Fig. 53 shows a close-up photograph of the same region. Like Probe \#4, the teflon header is significantly displaced but physically unchanged. The shell around the probe was relatively smooth, and exhibited only shallow surface relief and pit precursors. Comparison of Fig. 18 (June 2000) and Fig. 53 (June 2001) suggest little or no change in the vicinity of Probe \#5.

\subsubsection{Summary of Follow-Up Inspection}

Compared to the inspection in June 2000, only very modest changes in location/extent of corrosion were observed in June 200 1. Perhaps the least subtle change was that shallow light pitting, previously not observed above RS20 or 21 , was observed on the digester shell immediately adjacent to the port for Probe \#1. In and around the other probe positions, any changes in corrosion pattern were much less apparent. By comparing photographs from each inspection of the same region, some individual pits and certainly general pit patterns were found to be essentially unchanged. Pit depth at each location seemed essentially unchanged over the year, with the depth of the "oceans-and-islands" pattern being about 1.5-1.6 mm (65 mils deep, \pm a few mils) at the June 2000 inspection, and $1.5-1.7 \mathrm{~mm}$ (60-70 mils and occasionally $70+$ mils) in most cases during the June 2001 inspection. Any difference in pit depths between inspections was no doubt influenced by the scatter of the measurement technique (pit depth gauge). The teflon header was displaced on each probe such that the entire length of the steel electrodes was exposed, but this is believed to be related to the conditions of the pressure wash after the termination of the experiment (more on this in a subsequent paragraph). 


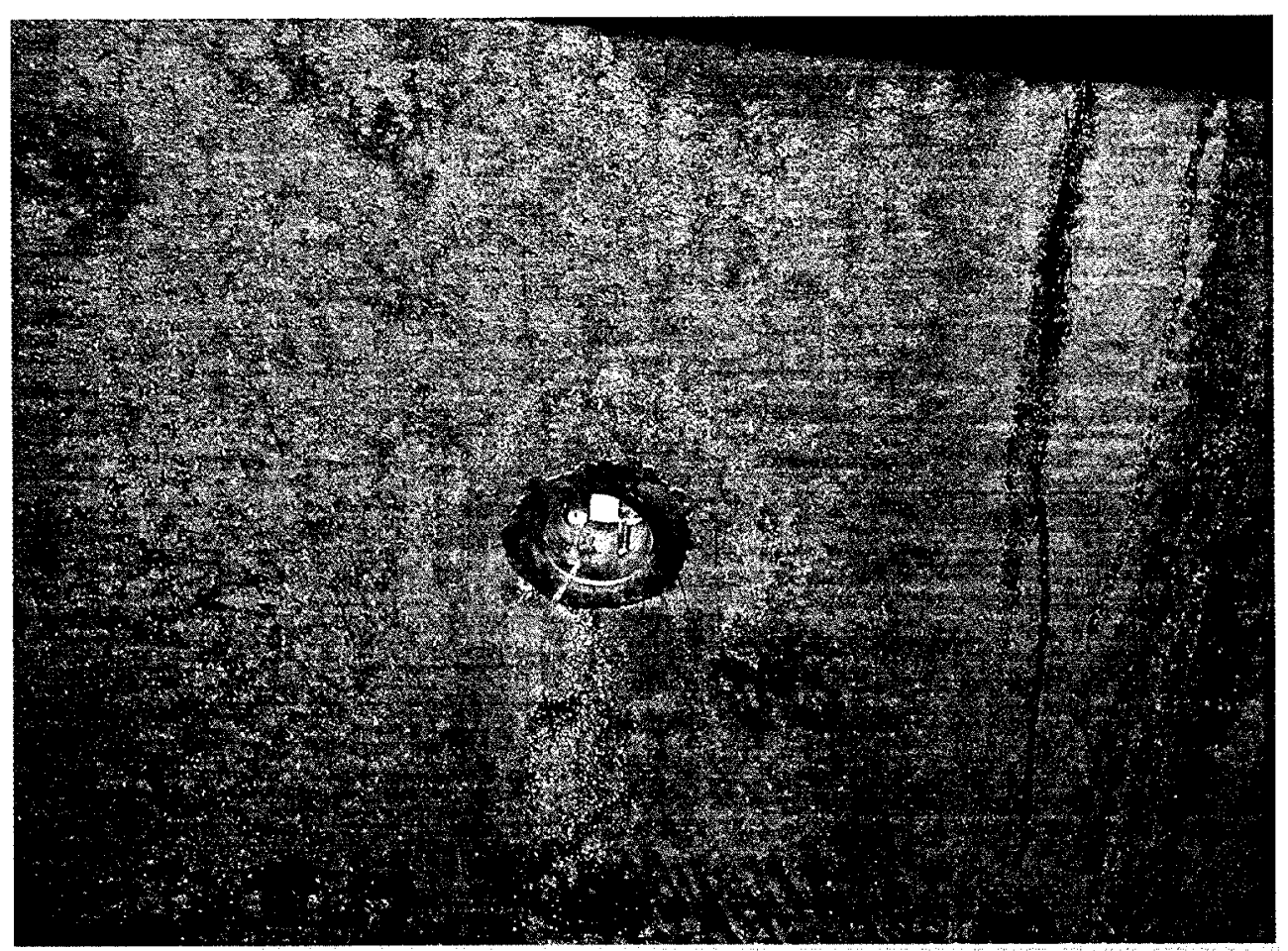

Fig. 52. Post-test view of Probe \#5.

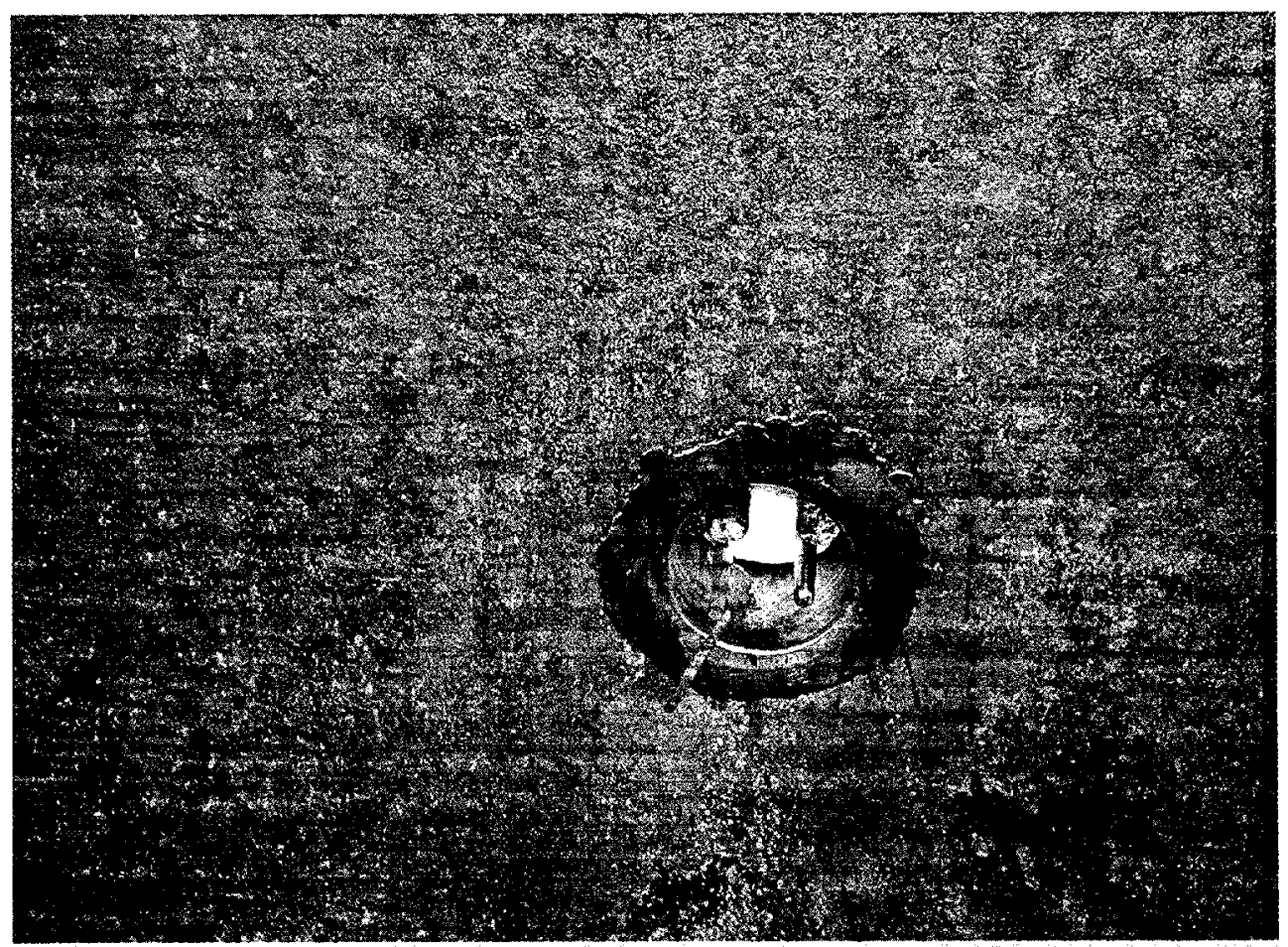

Fig. 53. Closer view of Probe \#5. 


\subsubsection{Examination of Electrodes from Each Probe}

Following the initial inspection inside the digester during the June 2001 outage, the probes were removed and returned to ORNL for evaluation. After photographic documentation of the probes, each was carefully disassembled to examine the components for signs of corrosion in locations other than the exposed (intended) surface area.

After cleaning, the teflon shroud for each probe was found to be smooth and firm with no indication of discoloration or degradation. As nearly as can be determined (precise pre-test measurements were not recorded), the dimensions of the teflon shrouds were unchanged from the initial values.

The individual electrodes were removed from each probe assembly and, in each case, found to exhibit clean, smooth threads on the rear of the specimen. Further, the steel rod to which each electrode was attached was found to be smooth and free of all except superficial corrosion. The shrink wrap material covering the steel rods appeared tough and largely unaffected by the exposure. However, the shrink wrap covering the joint between the teflon cone and the steel rod on one of the electrodes of Probe \#1 appeared to have "let go" sometime during service, which permitted the small leak observed in Fig. 42. For all four of the other probes, the heat shrink joint at this location was reinforced by a second, overlapping piece of heat shrink, but the second piece of heat shrink material was missing for both electrodes on Probe \#1 (fabrication error). Despite the fact that some amount of process fluid clearly got between the heat shrink and steel rod on Probe \#1, the rod itself suffered only very minor corrosion, which was isolated to the immediate vicinity of the failed joint.

It appears that the displacement of the teflon shroud observed during the post-test inspection was a direct result of the pressure washing that occurred after shutdown of the digester, but prior to any inspection. The probe shrouds were subjected to brief blasts of water from a 100- $140 \mathrm{MPa}(15-20 \mathrm{ksi})$ pressure washing unit. The probes were designed to withstand considerably less pressure, and it seems likely the blast displaced the teflon after the experiment had concluded. This conclusion is consistent with several important observations: 
- the only leak observed was for Probe \#1; which was very small (no accumulation) and fresh (still moist) at the time of the June 2001 inspection,

- the ECN data does not detect a sudden change in corrosion activity during the operation that would be consistent with suddenly exposing 6-8 times the expected electrode surface area,

- the slightly conical shapes of the corroded electrodes from Probes \#2, \#3, and \#4, which only progressive corrosion from the limited exposure area at the end of the shroud would generate, suggests that the entire electrode was not exposed for an entire year, and

- the end-of-life inspection in the digester indicated the piece of silver (used for a reference electrode) on Probe \#4 had been broken off; if this had happen prior to the final shutdown of the digester, the ECN data collection routine would have readily detected the loss of the reference.

The electrodes from each probe were examined in the as-corroded condition following the test and found to have relatively uniform corrosion product accumulation and coloration patterns common to general corrosion. No pits or signs of crevice corrosion (for example, on the electrode surfaces nominally against the teflon shroud) were apparent on any of the electrodes. Figure 54 is representative of the post-test appearance (prior to any cleaning) of the electrode specimens.

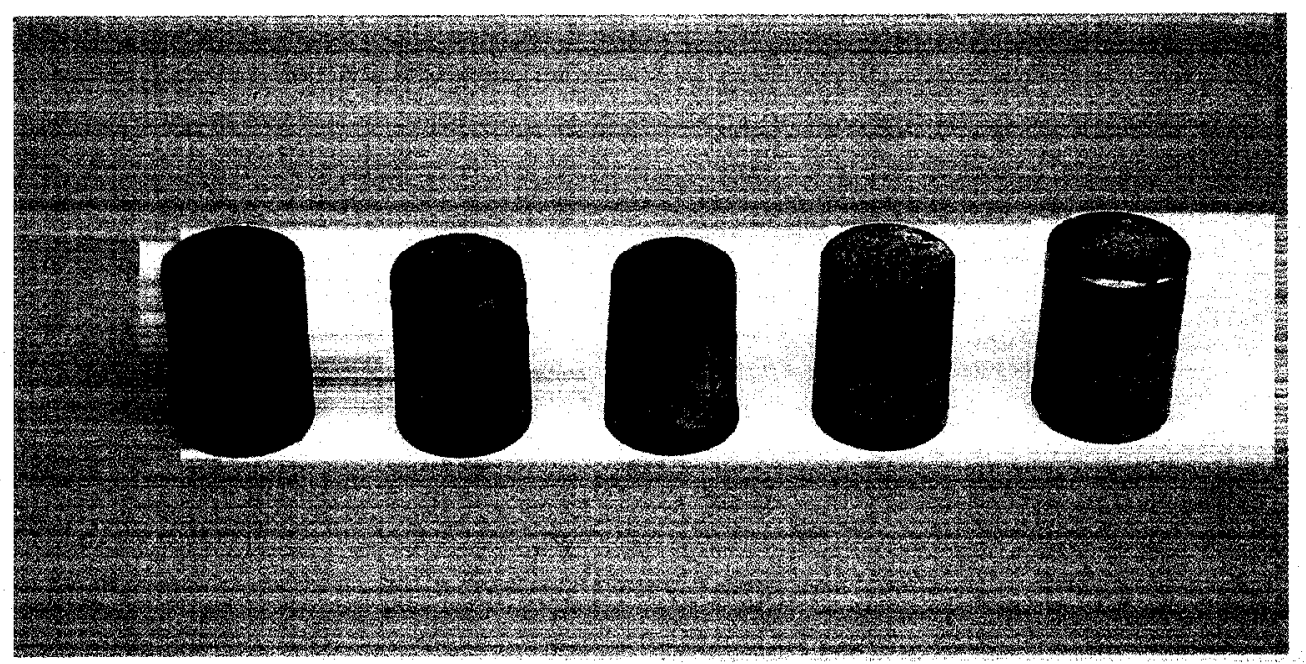

Fig. 54. Post-test appearance of an electrode from each probe in the digester. Probes \#1-5 are represented left-to-right, respectively, in the photograph. 
After the initial examination, the electrode specimens were cleaned in inhibited hydrochloric acid per the standard practice of ASTM G-1 (Procedure C.3.5) to remove the corrosion products without incurring further corrosion on the specimens. Figure 55 is representative of the post-cleaning appearance of the specimens, and it reveals that the specimens also appear very similar following cleaning. The cleaning procedure also did not reveal any signs of significant localized corrosion on any of the electrodes, simply a slightly mottled appearance common to general corrosion processes. The exposed circular faces of Probe \#3 appeared almost polished, indicating a rather high general corrosion rate, as did some portion of the cylindrical sides that became exposed as the specimens corroded during the test.

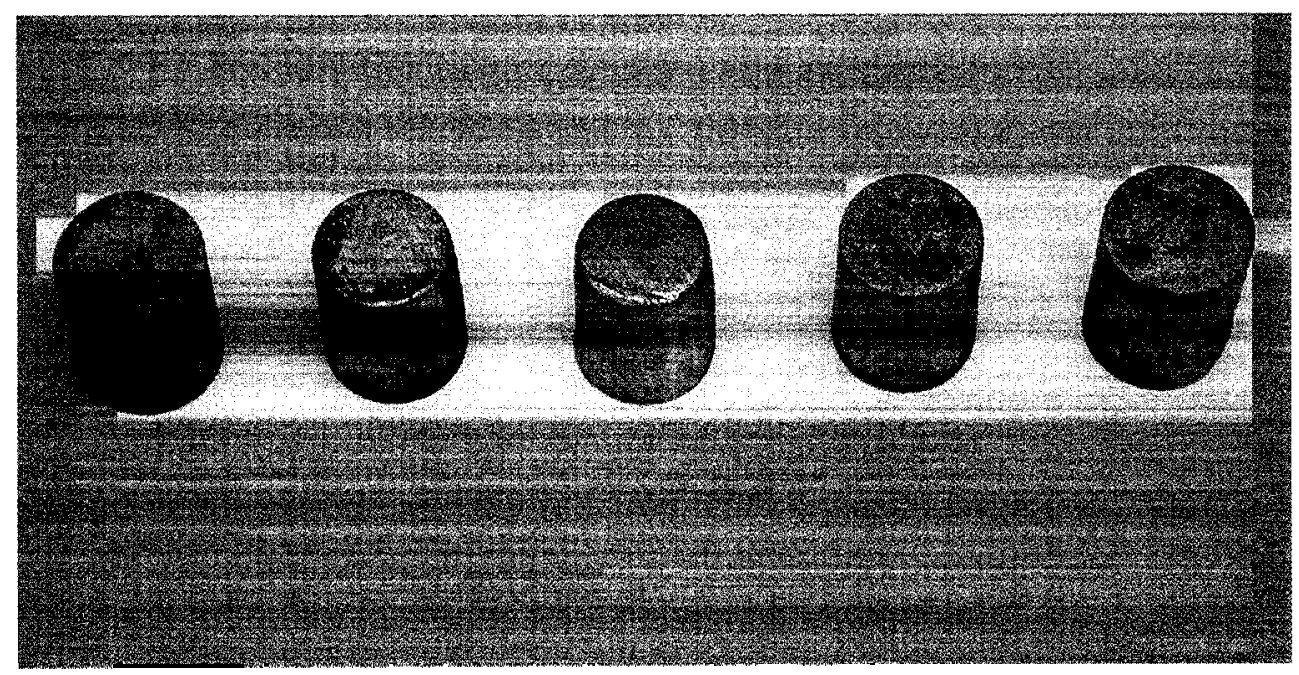

Fig. 55. Post-cleaning appearance of an electrode from each probe in the digester. Probes \#1-5 are represented left-to-right, respectively, in the photograph.

In the cleaned condition, the post-test dimensions of the electrodes were recorded for comparison with initial dimensions. Table 9 gives a summary of the results. Due to the post-test appearance indicating no surface roughening and $\mathrm{ECN}$ data revealing no significant corrosion on Probe \#5, the dimensions of electrodes from Probe \#5 were considered to be representative of the precise initial dimensions of the electrodes. Probes \#1 and \#5 have dimensions essentially 
unaffected by exposure for one year in the digester. However, Probes \#2, \#3, and \#4 each suffered a readily detectable change in dimensions over the course of the experiment. Using a total exposure time of approximately one year and the fact that corrosion on the diameter happens from two directions while corrosion on the specimen length happens in only one, the average annual corrosion rate for each probe position, shown in Table 9, was calculated.

Table 9. Post-test dimensions on electrodes from each probe. Dimensions are given in nonstandard units (mils, rather than $\mathrm{mm}$ ) because the measurements were collected in this fashion, which facilitates ready comparison and mitigates round-off errors. [To convert to $\mathrm{mm}$, multiply the numbers in the table by 0.025 .] Designation "top" means the exposed end of the electrode.

\begin{tabular}{|c|c|c|c|c|}
\hline & Diameter & Length & $\begin{array}{l}\text { Change from } \\
\text { unexposed }\end{array}$ & $\begin{array}{l}\text { average annual } \\
\text { corrosion rate }\end{array}$ \\
\hline Probe \#1 & $374-375$ & 514 & $\Delta \mathrm{d}=1-2 ; \Delta \mathrm{l}=0$ & $1 \mathrm{mil} / \mathrm{y}$ \\
\hline Probe \#2 & $\begin{array}{l}\text { 351-353@top } \\
360-364 @ \text { middle } \\
370-372 @ \text { bottom }\end{array}$ & $503-505$ & $\begin{array}{l}\Delta d @ \text { top }=24 \\
\Delta 1=9-11\end{array}$ & $10-12$ mils $/ y$ \\
\hline Probe \#3 & $\begin{array}{l}\text { 339-343@ @op } \\
352-355 @ \text { middle } \\
360-362 @ \text { bottom }\end{array}$ & $497-498$ & $\begin{array}{l}\Delta \mathrm{d} @ \text { top }=35 \\
\Delta 1=16-17\end{array}$ & $16-17 \mathrm{mils} / \mathrm{y}$ \\
\hline Probe \#4 & $\begin{array}{l}\text { 359-363@top } \\
\text { 364-366@middle } \\
\text { 372-374@bottom }\end{array}$ & $506-508$ & $\begin{array}{l}\text { Ad @ top }=15 \\
\text { A } 1=7-8\end{array}$ & $7-8 \mathrm{mils} / \mathrm{y}$ \\
\hline Probe $\# 5$ & 376 & 514 & $\mathrm{Ad}=\mathrm{O} ; \mathrm{Al}=\mathrm{O}$ & Nil \\
\hline
\end{tabular}

Ultrasonic wall thickness measurements collected by mill personnel were also used in an attempt to compare corrosion rates indicated by the probes with current and historical corrosion rates in the digester. As previously indicated, wall thickness data of two different types is collected in the vessel. In one type, referred to as line surveys, a series of measurements typically eight in a vertical row with about $30-40 \mathrm{~cm}$ between spots - are made at approximately the same locations on opposite sides of the digester ( 0 and 180" positions) in most of the round seam sections each year. The line surveys are typically remote to any welds in the vessel. The other type of measurement, referred to as "weld T" surveys, collects wall thickness data from three positions around a number of the RS/LS intersections throughout the vessel. From the measurement positions nearest to each probe position, the wall thickness data were used to estimate the historical corrosion rate for each location. To generate the estimate, the change in 
wall thickness (line survey and/or weld-T survey data) over the inspection interval 1996-2001 (4.75 calendar years of service time) was used to calculate the historical corrosion rate at each location. [Data prior to 1996 is suspect, as the initial wall thickness of the vessel at the measurement points was not recorded properly.] In almost all cases, the values derived from the line surveys are somewhat different from the values at the weld-T locations, but the range of these numbers is given in Table 10 as the historical average corrosion rate. The current corrosion rate number that appears in Table 10 is the change in wall thickness at the same locations between the inspection in June 2000 and the one in June 2001 (approximately 1 year of service time). In this instance, there is a large difference between the results of the line surveys (the lower value for all except Probe \#1) and the weld-T surveys, and the reasons are not clear.

Table 10. Average corrosion rates calculated for the digester shell compared with corrosion rate information available from the ECN probes. Corrosion rates are given in the nonstandard units of mils/y (rather than $\mathrm{mm} / \mathrm{y}$ ) because mill personnel routinely use the mils/y designation. To convert to $\mathrm{mm} / \mathrm{y}$, multiply the numbers in the table by 0.025 .

\begin{tabular}{|l|l|l|l|l|l|}
\hline & Probe \#1 & Probe \#2 & Probe \#3 & Probe \#4 & Probe \#5 \\
\hline Historical Average (UT) & $5-8$ & $7-10$ & $10-12$ & $7-10$ & $1-2$ \\
\hline Current rate (UT) & $1-2$ & $1.5-24$ & $3-15$ & $1.5-12$ & $0.5-2$ \\
\hline Probe assessment (examination) & $1-2$ & $10-12$ & $16-17$ & $7-8$ & $<1$ \\
\hline Integrated current (1 ${ }^{\text {st }}$ six mos.) & 5 & 5 & 12 & 7 & 2 \\
\hline Integrated current (full 12 mos.) & 3 & 4 & 7 & 5 & 1 \\
\hline
\end{tabular}

To compare to the digester corrosion rates determined from locations near the probes, the corrosion rates indicated by the probes were also calculated in two ways. The maximum change in dimensions of the electrodes was used to calculate the average corrosion rate at each location, and this number appears in Table 9 (final column) and the third row of Table 10. [Both electrodes from each probe exhibited remarkably consistent measurements.] In addition, the corrosion rate of the probes was also estimated from the integrated current sums (methods of calculation have been described in a previous section as well as mathematically developed in Appendix A) over the initial six months of exposure and over the entire year (actually 0.852 year, over which time probes were generating data). 
The data of Table 10 suggest several important trends. First, the corrosion rate of the probes determined from the dimensional change during the experiment is consistent qualitatively (ranking of corrosion rates among locations) and quantitatively (specific corrosion rate at each location) with the historical corrosion rates in the vessel., More importantly, because operational conditions vary with time, the probe corrosion rates calculated from dimensional changes are also consistent with the vessel corrosion rates calculated from the most recent changes in wall thickness values.

Within some predictable limitations, the integrated current sums also predict corrosion rates consistent with wall thickness measurements., The corrosion rates so calculated are initially relatively high, but the corrosion rate for freshly exposed steel (no mill scale or corrosion product accumulation) should be expected to be somewhat higher in the initial stages of exposure compared to later stages. It is significant to note that the digester shell also experienced higher rates of corrosion in the initial periods of operation (first few months after start-up) than those currently experienced, as much of the "pitting" and "oceans-and-islands" patterns of corrosion developed between the initial start-up of the vessel and the first visual inspection.

As corrosion products accumulate on the electrodes with extended exposure time, the corrosion rates calculated from the integrated current sums for each probe tend to decrease. These values are consistent with both the current corrosion rate estimates from UT measurements for the vessel and the historical ranking of corrosion rates from UT measurements at these locations. Recall that, generally speaking, the integrated current sums should underestimate the total corrosion from each probe because the current sums account for only the current that passes through the ZRA between electrodes, and that any contributions of self-terminating current (anodes and cathodes near each other on the same electrode rather than on different electrodes) are not counted toward the total. Further, as corrosion products tend to accumulate and increase the resistance between electrodes, the statistical likelihood of anodes and cathodes near to each other on the same electrode surface increases, so the integrated current sums might be expected to decrease with extended exposure.

The primary conclusion to be drawn from Table 10 is that the ECN probes generate corrosion rates that are consistent with wall thickness changes at nearby locations of the digester shell. That they do not agree precisely with wall thickness measurements is of no practical 
concern, particularly given that the scatter in wall thickness measurements - or perhaps significant irregularities regarding corrosion patterns or lack thereof within the digester - seem extreme. For example, some trends observed among the wall thickness data surveys include:

- more than half of the line surveys at $0^{\circ}$ and 180 " for a given elevation do not exhibit the greatest change in the same year,

. more than half the round seam comparisons (between 0 and 180" positions) have corrosion rates that vary by more than $25 \%$ in any given year and that vary by more than $25 \%$ total thinning since inspections were initiated,

- the largest single reduction in wall thickness for a particular year is more than twice the next largest decrease for about half the line surveys, and the year in which the maximum decrease occurs seems random among the line surveys,

. in $75 \%$ of the line survey cases for which a value can be determined, the maximum change in wall thickness for any specific year/location line survey combination is followed by the least change, and in $80 \%$ of all the cases for which a value can be determined, the maximum amount of thinning in a single year accounts for more than half the total thinning observed at that location,

- consistent with trends indicated in Table $10,85 \%$ of the line survey data reveals corrosion rates in the last two years significantly lower than the historical average for that location; however, more than $90 \%$ of the weld-T survey data indicates corrosion rates significantly higher than the historical average over the last two years,

- in almost two thirds of the wall thickness data, the 2001 result indicates less than 0.25 mm (10 mils) total change from the nominal value recorded in 1994, and

- the total spread among thickness measurements in any line survey or weld-T group for an inspection year is often about $0.75 \mathrm{~mm}$ (30 mils); using averages over specific areas tends to minimize the impact of such a large scatter, but that sort of thickness variation among points so close together in physical location (and, presumably, similar in environment to which they are exposed) indicates significant uncertainty in values.

These comments on the wall thickness data simply suggest that perhaps the information is useful for identification of trends, but that there is often far too much scatter and uncertainty in the specific data sets to specify a particular corrosion rate for a period as small as a year. The ECN probe data seems sensitive to changing conditions on much shorter intervals and remains consistent with confirmed trends. 


\subsection{CONCLUSIONS}

To the knowledge of the authors, the ECN probe installation at Kamloops was a first-ofa-kind effort to bring corrosion monitoring technology of this type into an operating digester. The equipment and probes functioned successfully throughout the year-long experiment with no failures or disruptions to mill operations.

The corrosion data derived from the ECN probes was found to be consistent with the type and extent of digester shell corrosion accumulated during the period of probe deployment. Posttest examination of the electrodes revealed only modest general corrosion (and no pitting) in a magnitude consistent with both historical wall thinning near the respective probe position and with wall thinning accumulated at the same positions during the period of probe deployment. Further, integrated current sums from each probe also were found to be qualitatively consistent with corrosion rates in the digester at each probe position.

Using the integrated current sum technique, operation, with furnish compositions high in Douglas fir $(>70 \%)$ and shutdown periods were identified as particularly aggressive corrosion events. Corrosion activity at each probe location increased sharply with changes from whitewood or normal furnish to Douglas fir furnish, although the effect was largest/strongest relatively high in the digester (near the trim screens). All probes in the digester tend to respond to changes in furnish composition within minutes to an hour or so, suggesting relatively rapid chemical communication through the liquor. The current sum technique also indicated that start-up/shutdown transients were significant corrosion events, with a large fraction of the total apparent corrosion at the positions of Probes \#1, \#2, and \#5 occurring during these transients.

Corrosion activity monitored by the probes does not correlate linearly with any of the other approximately sixty digester operational variables that are routinely tracked at the mill. This result implies that the relationships between operating variables and corrosion are complex (e.g., non-linear or multivariate) or that the data most relevant to digester corrosion is not being collected.

The digester shell reveals a consistent pattern of somewhat localized corrosion - similar to pitting in many respects - that is often referred to as an "oceans-and-islands" pattern. 
However, during the period of probe deployment, pitting corrosion was not observed in the ECN data, on the post-test electrode surfaces, or on the digester shell near/around the probe positions. This result suggests that the environmental conditions causing the observed "pitting" pattern were not present during the probe deployment. In fact, a series of observations associated with the vessel inspections suggests that the bulk of the localized corrosion occurred very early in the service life of the digester:

- the series of photos from RS/LS intersections indicating the present localized corrosion pattern was fully established prior to 1997 ,

- the absence of significant increase in depth of the existing pits between June 2000 and June 2001 (although a small amount of lateral spread may have occurred),

- the very modest corrosion rate indicated by all the probes, and

- the nearly pristine condition of the new dummy plate (put in service in late 1996), which replaced a heavily pitted plate.

The observed localized corrosion patterns - particularly the positions at which corrosion seems to have advanced significantly compared to surrounding areas in the oceans-and-islands pattern - suggest a critical role of surface condition for initiation of the corrosion process. In particular, areas subjected to grinding or other disruptions of the mill scale (for surface preparation in/around weld areas, for removal of construction-related fixtures, where automatic welder tracks rubbed/eroded the shell $\mathrm{ID}$, etc.) suffer the greatest extent of corrosion, which then spreads laterally at a generally slow pace. This pattern implies that the individual "pits" on large portions of the digester shell are associated with small inhomogeneities in the steel surface, but it is not clear whether these conditions developed during vessel construction or at some early stage in the operation of the digester due to aggressive pulping conditions. That the "pits" tend to spread laterally and sometimes agglomerate without exceeding a particular critical depth generally observed to be about $1.75 \mathrm{~mm}$ (70 mils), largely independent of the location in the digester - is curious but unexplained by data collected in this experiment, 


\subsection{ACKNOWLEDGEMENTS}

This research was funded by the United States Department of Energy Office of Industrial Technologies for the Agenda 2020 Forest Products Program. The Oak Ridge National Laboratory Program Manager for this effort was P. Angelini. The industrial advisory board consisted of M. E. Gorog (Weyerhaeuser), W. B. A. Sharp and S. J. Lukezich (MeadWestvaco), and D. C. Crowe (International Paper). M. Gregson (Weyerhaeuser) was instrumental in arranging field support services at the pulp mill to facilitate probe installation and data gathering. J. McKee (Corrosion and Condition Control, Ltd) was helpful in data collection and transfer efforts from the data collection system, and J. Gancas (Weyerhaeuser) provided convenient summaries of operational data from the mill. D. A. Singbeil and N. J. Stead (Paprican) provided probe design support and fabrication, and generated the polarization curves reported herein. E. T. Manneschmidt and K. A. Choudhury (ORNL) provided computer graphics/image file support and H. F. Longmire (ORNL) provided metallography support. J. R. Keiser (ORNL) provided technical support and reviewed this manuscript. 
. 


\subsection{REFERENCES}

1. "Electrochemical Noise in Assessing MIC in Offshore Injection Systems," M. Amaya, et. al., CORROSION200 1 paper no. 0 1269, NACE, Houston, TX, March 2001.

2. "Application of Electrochemical Noise Monitoring to Inhibitor Evaluation and Optimization in the Field: Results from the Kaybob South Sour Gas Field," E. E. Barr, A. H. Greenfield, and L. Pierrard, CORROSION 2001 paper no. 01288, NACE, Houston, TX, March 2001.

3. "Electrochemical Noise Based Corrosion Monitoring at the Hanford Site: Third Generation System Development, Design, and Data," G. L. Edgemon, CORROSION 2001 paper no. 01282, NACE, Houston, TX, March 2001.

4. "Instrumentation Considerations for Electrochemical Noise Corrosion Monitoring in the Field," D. Townley and S. J. Duranceau, CORROSION 2001 paper no. 01287, NACE, Houston, TX, March 2001.

5. Secondary Side SCC of Alloy 600 in Occluded TSP Crevices - Development of an Electrochemical Noise Probe for Plant Installation," G. P. Quirk, D. A. Eden, and R. J. Jacko, CORROSION 2001 paper no. 0 1123, NACE, Houston, TX, March 2001.

6. "Electrochemical Noise Analysis and its Application to Corrosion," U. Bertocci, CORROSION 1989 paper no. 24, NACE, New Orleans, LA, April 1989.

7. “Corrosion Monitoring Using Electrochemical Noise Measurements," J. L. Dawson, et. al., CORROSION 1989 paper no. 31, NACE, New Orleans, LA, April 1989.

8. "The Encyclopedia of Chemical Electrode Potentials," M. S. Antelman and F. J. Harris, Plenum Press, New York, 1982.

9. "Heartwood Extractives in Digester Corrosion," H. MacLean and J. A. F. Gardner, Pulp and Paper Magazine of Canada, p.125, November 1953.

10. Corrosivity of Black Liquors - Role of Wood Species Pulped," P. M. Singh, et. al., $10^{\text {th }}$ International Symposium on Corrosion in the Pulp and Paper Industry, EFC Event \#249, Helsinki, Finland, August 2001. 



\section{APPENDIX A - Corrosion Rate Calculation from Current Sums}

The fundamental relationship of interest is Faraday's Law, expressed as the definition of current, is:

$$
\mathrm{I}=[\mathrm{W} / \mathrm{M} \cdot \mathrm{t}] \mathrm{N}_{\mathrm{o}} \cdot \mathrm{m} \cdot \mathrm{e}^{+}
$$

where I is current (coulombs/sec, or amps),

$\mathrm{W}$ is mass in grams (of $\mathrm{Fe}$, in this case) dissolving as a result of corrosion in time $\mathrm{t}$, $\mathrm{M}$ is the atomic weight of' the corroding material $(\mathrm{g} / \mathrm{mol})$,

$t$ is the amount of time of corrosion (seconds),

$\mathrm{N}_{\mathrm{o}}$ is Avagadro's number $\left(6.023 \times 10^{23} / \mathrm{mol}\right)$,

$\mathrm{m}$ is the oxidation state on the corroding ion, and

$\mathrm{e}^{+}$is the unit charge of electricity $\left(1.60 \times 10^{-19}\right.$ coul $)$.

Equation (1) can be manipulated to a more useful form as:

$$
\mathrm{W}(\text { in measurement time } \mathrm{t})=[\mathrm{I} \cdot \mathrm{t}] \cdot \mathrm{M} /\left[\mathrm{N}_{\mathrm{o}} \cdot \mathrm{m} \cdot \mathrm{e}^{+}\right]
$$

Expressed this way, the quantity [ I . t ] is the number of coulombs Q that is the integrated area under the amps vs. time curve that the ECN data produces.

Since it can be assumed that the primary corrosion reaction of steel in the digester liquor is

$$
\mathrm{Fe} \rightarrow \mathrm{Fe}^{2+}+2 \mathrm{e}^{-}
$$

" $m$ " in Equation (2) is 2. Of course, further oxidation to the $\mathrm{Fe}^{3+}$ can also occur, but this is not typically the initial reaction and the one detectedby the probes.

Therefore, substituting appropriate numbers in to Equation (2):

$\mathrm{W}($ in measurement time $\mathrm{t})=\mathrm{Q} \cdot(55.85 \mathrm{~g} / \mathrm{m}) /\left(6.023 \times 10^{23} / \mathrm{m}\right) \cdot(2) \cdot\left(1.60 \times 10^{-19}\right.$ coul $)$

which reduces to

$$
\mathrm{W}(\mathrm{g} \text {, in measurement time } \mathrm{t})=\mathrm{Q} \cdot\left(2.90 \times 10^{-4}\right) .
$$


Next, to convert the mass loss (W) to a penetration (P), it is necessary to assume that the mass loss is uniform over the exposed electrode area (which was confirmed by post-test inspection of the electrodes for all probes). If the corrosion is uniform, the mass loss can be converted to a penetration by dividing by the density of the material $\left(\mathrm{Fe}=7.86 \mathrm{~g} / \mathrm{cm}^{3}\right)$ and the exposed electrode area (sum is $1.42 \mathrm{~cm}^{2}$ for the pair of electrodes in each probe). Substituting into Equation (3):

$\mathrm{P}(\mathrm{cm}$, in measurement time $\mathrm{t})=\mathrm{Q} \cdot\left(2.90 \times 10^{-4}\right) /\left[\left(7.86 \mathrm{~g} / \mathrm{cm}^{\prime}\right) \cdot(1.42 \mathrm{~cm} ")\right]$ and

$$
\mathrm{P}(\mathrm{cm}, \text { in measurement time } \mathrm{t})=\mathrm{Q} \cdot\left(2.60 \times 10^{-5}\right)
$$

To modify Equation (4) to the more useful units of mm or mils, the conversions are

$$
\mathrm{P}(\mathrm{mm}, \text { in measurement time } \mathrm{t})=\mathrm{Q} \cdot\left(2.60 \times 10^{-4}\right)
$$

or

$$
\mathrm{P}(\text { mils, in measurement time } \mathrm{t})=\mathrm{Q} \cdot\left(1.02 \times 10^{-2}\right)
$$

Therefore, for any total measurement time t, the current sum Q over that period may be used to calculate the penetration rate consistent with the previous assumptions. As an example, consider a 100-day period ( 0.274 years) over which Probe \#3 passed a total of 254.1 coulombs. The corresponding penetration rate is then

$$
\text { Penetration rate }(\text { in mils } / y)=(254.1) .\left(1.02 \times 10^{-2}\right) /(0.274 \mathrm{y})=9.5 \mathrm{mils} / \mathrm{y}
$$

Of course, the rate so calculated is only an estimation, because the current detected by the ZRA is only net current and because some of the corrosion current self-terminates on each electrode (does not pass through the ZRA). In addition, redox reactions on the electrode surfaces possibly contribute to current detected by the ZRA, although in the general sense this contribution should approximate white noise for each electrode in a probe and cancel out as zero net contribution. 


\section{APPENDIX B - Process Data Collected at Kamloops}

The information in Table B 1 represents the operational and process data information provided to the project from Weyerhaeuser. The function/purpose of each of these process parameters is beyond the scope of this documentation, but these are the parameters tracked by the mill operators to control the process. These data, recorded on 15 minute intervals, were used in an attempt to find correlations between one or more of these and corrosion activity as defmed by the ECN probes. The group of parameters near the end of the table (final 8 points) were only periodically gathered and/or may have not functioned throughout the experiment period.

Table B 1. Process data points provided by Weyerhaeuser.

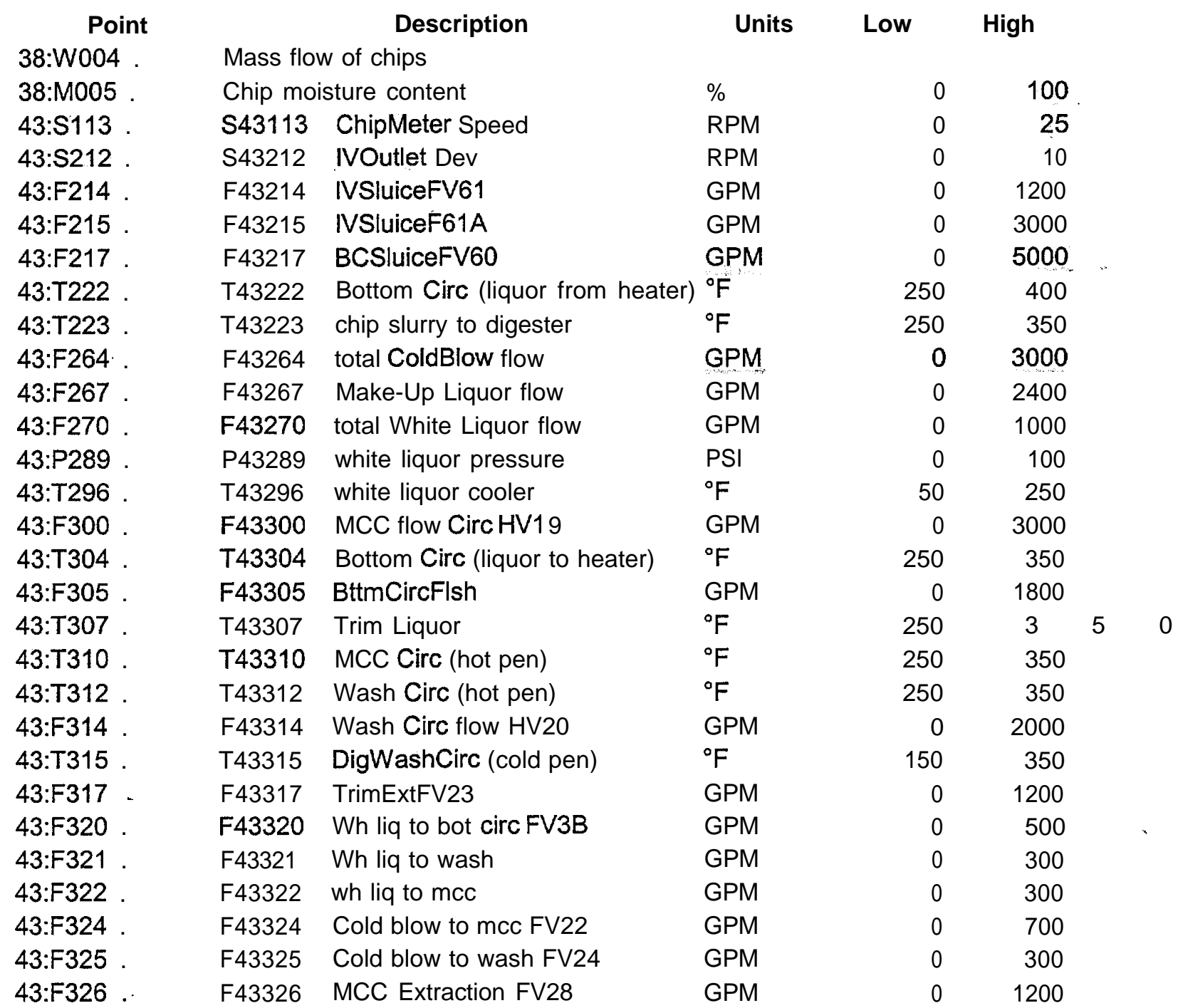




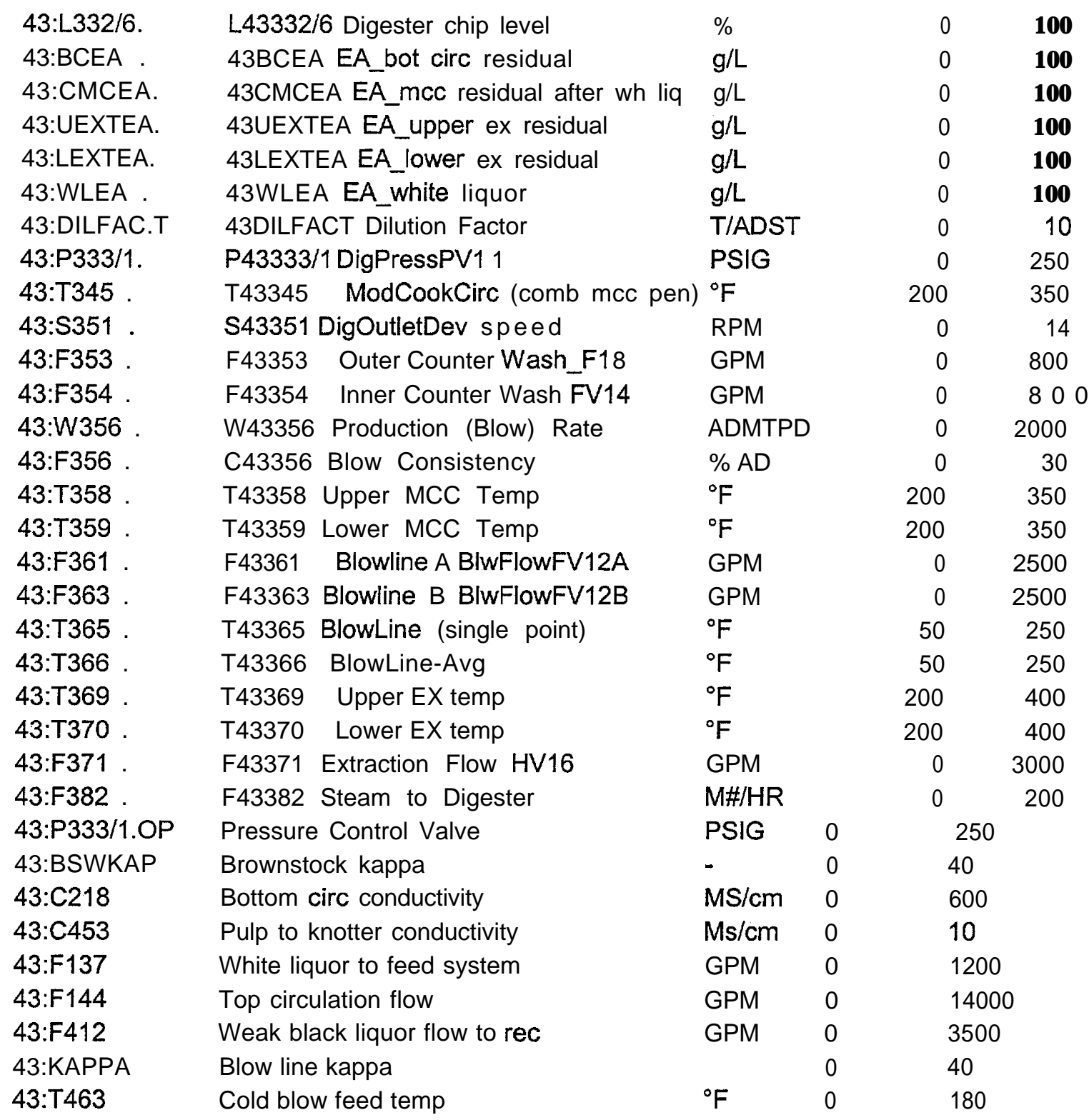




\section{INTERNALDISTRIBUTION}

1. P. Angelini

2. E. E. Bloom

3. G. E. Giles

4. L. L. Horton

5. J. R. Keiser

6-17. S. J. Pawel(12)

18. P. F. Tortorelli

19-23. D. F. Wilson (5)

24-25. Central Research Library (2)

26. Document Reference Section

27. ORNL Laboratory Records - RC

28. Office of Scientific \& Technical Information

\section{EXTERNALDISTRIBUTION}

29. E. Bibeau - Process Simulations Ltd, \#204, 2386 East Mall, Vancouver, BC V6T 123; Canada

30. D. C. Crowe - International Paper, Mfg Tech. Center, 6285 Tri-Ridge Blvd, P.O. Box 7910, Loveland, OH 45140

3 1-32. M. E. Gorog - Weyerhaeuser Technical Center, Weyerhaeuser Way South, Federal Way, WA 98063 (2)

33-34. M. D. Gregson - Weyerhaeuser Canada Limited, Kamloops Pulp Mill, P. 0. Box 800, Kamloops, BC V2C 5M7, Canada (2)

35. S. J. Lukezich - MeadWestvaco Research Laboratory, 232 Eighth St., P.O. Box 1700, Chillicothe, $\mathrm{OH} 45601-5700$

36. V. Robinson - DOE, Office of Industrial Technologies, EE-22, Washington, DC 205850121

37. D. E. Roy - P.H. Glatfelter Company, 228 South Main St., Spring Grove, PA 17362

38. W. B. A. Sharp - MeadWestvaco, Laurel Technical Center, 11101 Johns Hopkins Rd, Laurel, MD 20723-6006

39. D. A. Singbeil - Paprican, Vancouver Laboratory, 3800 Wesbrook Mall, Vancouver, BC V6S 2L9, Canada

40. P. M. Singh - Institute of Paper Science and Technology, $50010^{\text {th }}$ Street, Atlanta, GA 303 18-5794

41. N. J. Stead - Paprican, Vancouver Laboratory, 3800 Wesbrook Mall, Vancouver, BC V6S 2L9, Canada

42-43. D. W. Townley - M. J. Schiff and Assoc, 1308 Monte Vista Ave, Suite 6, Upland, CA 91786-1361

44. D. A. Wensley - D. A. Wensley Consulting Engineering Services, 15397 Columbia Ave, White Rock, BC V4B1K1, Canada 


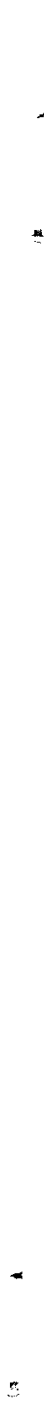

